\title{
Finite-Element barotropic model for the Indian and Western Pacific Oceans: Tidal model-data comparisons and sensitivities
}

\author{
Pringle William J. ${ }^{1,}{ }^{*}$, Wirasaet Damrongsak ${ }^{1}$, Suhardjo Andika ${ }^{1}$, Meixner Jessica ${ }^{2}$, \\ Westerink Joannes J. ${ }^{1}$, Kennedy Andrew B. ${ }^{1}$, Nong Shangyao ${ }^{3}$
}

\author{
${ }^{1}$ Univ Notre Dame, Dept Civil \& Environm Engn \& Earth Sci, Environm Fluid Dynam Grp, Notre Dame, \\ IN 46556 USA. \\ 2 NOAA, IMSG, NCEP, EMC,Ctr Weather \& Climate Predict, College Pk, MD USA. \\ 3 FM Global, Res Div, Norwood, MA USA. \\ * Corresponding author : William J. Pringle, email address : wpringle@nd.edu
}

\begin{abstract}
:
In this study, a 9.6 million node large-scale unstructured grid finite-element forward barotropic model is developed and applied to understand the tidal dynamics and dissipation mechanisms of the Indian and western Pacific Oceans down to sub-kilometer scale at the coast. Tidal model-data comparisons are presented to assess the capabilities and limitations of our large-scale barotropic model. The average rootmean-square (RMS) discrepancies of tidal elevations at coastal tide gauges is $14 \mathrm{~cm}$, which is similar to $3 \mathrm{~cm}$ smaller than those of a state-of-the- art global data assimilated barotropic tidal model. Sensitivities to lateral boundary conditions, bathymetry, and dissipative processes are explored to guide future endeavors related to large-scale barotropic modeling in the region and other regions throughout the world. Lateral boundary conditions are found to induce adverse resonant effects on the lunar semi-diurnal modes when poorly placed elevation specified boundary conditions are used. This problem is largely resolved by using an absorption-generation layer at the boundary. Parameterization of internal tide energy conversion is identified as the most important aspect to control deep water solutions, and help reduce the RMS discrepancies of the entire system. Two forms of this parameterization are presented and their spatial distributions of dissipation are compared. Bathymetry has a negligible effect on the tidal solutions in deep water, but local high resolution bathymetry results in significant reductions to the average RMS discrepancies on the continental shelf $(26 \%)$ and at the coast $(30 \%)$. Implementing a spatially varying bottom friction coefficient based on sediment types decreases the average RMS discrepancy at the coast by $9 \%$ predominantly due to its positive effects in the Yellow Sea. The model is shown to capture a large amount of the tidal physics and has the potential for application to a range of barotropic problems such as wind-driven surge and tidal processes.
\end{abstract}

\section{Highlights}


- Mean RMS tidal elevation errors at coastal gauges are smaller than a data assimilated model. $>$ An absorption-generation sponge layer at lateral boundaries is necessary to help reduce resonant effects in the domain. Dissipative effects of two internal tide energy conversion parameterizations are compared. - Bathymetry reduces mean continental shelf $(26 \%)$ and coastal $(30 \%)$ RMS tidal elevation errors. Spatially varying bottom friction coefficients reduce mean coastal RMS tidal elevation errors $(9 \%)$.

Keywords: Finite-element, Unstructured grid, Barotropic tides, Bathymetry, Internal tide energy conversion, Bottom friction 
The Indian and western Pacific Oceans represent approximately $30 \%$ of the surface area of the world oceans. They are interconnected by marginal seas such as the Java, Timor, Banda, 4 Andaman and Arafura Seas, and are separated by the intricate island chains of Indonesia and the 5 Philippines. Major ports and cities are located in the northern parts of both the Indian Ocean 6 (Dubai, Karachi, Mumbai, Colombo) and the western Pacific Ocean (Hong Kong, Shanghai, Tokyo, 7 Singapore), representing a significant portion of the world's economy and human population. Thus, \& within this region (which we call IndWPac hereafter), there is great interest in being able to better understand coastal hazards and hydrodynamics for e.g., coastal protection and management, risk evaluation, and navigational purposes.

For such purposes, our long-term objective is to develop a large domain depth-integrated forward model of the IndWPac region which couples tides, atmospheric driven currents, density driven circulation, and wind waves. The focus is to advance the modeling of these individual processes and systematically understand the interactivity of dissipation mechanisms, bathymetric sensitivities, and lateral boundary forcing mechanisms on the response functions throughout this domain. In particular, our interests lie on inner shelf and estuarine processes, and how these mechanisms impact coastal and inland water levels and currents. This is notwithstanding the challenge of the IndWPac region in terms of its complex geometry, topography (such as the many interconnected shallow seas and island chains), and associated hydrodynamics in comparison with e.g., the western North Atlantic region that has received significant attention (Hope et al., 2013; Kerr et al., 2013; Bunya et al., 2010).

To model the dynamics at coastal and inland locations within the IndWPac region, all processes and exchanges from ocean scale to harbor inlet scale, must be appropriately represented. Coarse resolution global models (e.g. Egbert et al., 2004; Green and Nycander, 2013; Buijsman et al., 2015; Green et al., 2017) have been developed to simulate the large-scale global ocean dynamics, but as a result of grid resolution they may inadequately capture geometric features and nonlinearities of the hydrodynamics in the inner shelf and nearshore region. Conversely, higher resolution shelf scale 
regional domain models are often developed to accurately capture local effects (e.g. Green and David, 2013; Cai et al., 2006; Zu et al., 2008, in South China Sea). However, accurate lateral boundary conditions are required to propagate in all of the required information from offshore. The closer one gets to the coast, the more boundary conditions become complicated and difficult to match with the interior domain physics in order to correctly exchange mass, momentum and energy across the boundary. Furthermore, regional model parameters are calibrated to generate accurate results in the specific region that may not be generally applicable in other regions.

Thus, this study presents the development of an ocean basin scale model which minimizes lateral boundary interaction, yet sufficiently resolves energetic processes from the deep water to the coast using a single unstructured computational grid in a physically consistent manner without ad-hoc parameterization. The scale of this model fits somewhere in between the global scale and shelf scale regional models that are more commonly developed. The ocean basin scale model utilizes varying resolutions to produce high fidelity coastal bathymetry of critical geographic and topographic features such as island chains, reef systems, and floodplain systems; provides connectivity to estuarine and harbor systems where dense coastal populations live; and captures key dynamics of a large regional domain in which the effects of changing dynamics in a certain region can propagate into other regions. At the same time, lateral boundaries are placed further offshore than shelf scale regional models, thus more focus is placed on the inner model dynamics allowing the governing physics to equilibrate without constraining the system. Hence, a more accurate understanding of the controls and the extent of impact throughout the domain may be obtained. Note that in future work as computational resources allow, we would like to extend this ocean basin scale model to the global scale while maintaining high resolution in the coastal areas.

The aim is to systematically build complexity into the external forcing terms and the underlying physics. In the process, sensitivity of the dynamical system and sub-grid scale parameterizations will be explored to assess the capabilities and limitations of the model in the IndWPac region. In this study, we begin this process through model-data comparisons of tidal elevations (predominantly) and tidal currents due to astronomical forcing. Since tides can be reduced to a series of harmonic constituents of well-defined frequencies, model-data comparisons can be robustly made. Comparisons are conducted against point observations at tide gauges and regionally against global data-assimilative model atlases. Examples of the latter include TPXO8 (Egbert and Erofeeva, 2002) (http://volkov.oce.orst.edu/tides/tpxo8_atlas.html), FES2014 (Lyard et al., 2006) (https: //www.aviso.altimetry.fr/en/data/products/auxiliary-products/global-tide-fes/description-fes2014. 
html), and NAO.99b (Matsumoto et al., 2000). These models assimilate elevation data from satellite altimetry and selected coastal tide gauges to accurately obtain estimates of the tidal elevation fields in terms of individual harmonic constituents. $\mathrm{M}_{2}$ tidal wave root-mean-square errors (RMSE) of modern data assimilated models are typically 0.5-0.7 cm versus deep-ocean bottom pressure recorder stations (Stammer et al., 2014). In contrast, $\mathrm{M}_{2}$ RMSE ranges within 5.6-12.7 cm for purely hydrodynamic global models without data-assimilation (Stammer et al., 2014). However, non-assimilative forward models on large domains can be applied to a wide variety of problems including wind, pressure, ice and wave coupling effects, and may be used to conduct past (Egbert et al., 2004; Green, 2010; Wilmes and Green, 2014; Green et al., 2017) or future forecasting and perturbation response analysis (Green and David, 2013), e.g., due to changing sea level, large-scale ice sheet collapse (Wilmes et al., 2017), dredging operations, and land reclamation (Suh et al., 2014).

Importantly, this study explores the sensitivities of various controls on the barotropic tidal dynamics. At first, the effects of lateral boundary placement, and the addition of an absorptiongeneration sponge layer at the lateral boundary, are discussed. Secondly, the responses to two different global bathymetric databases are directly compared. Thirdly, high resolution local bathymetric data are included, where available, to assess its potential to facilitate improvements in the solution. Lastly, internal tide and bed stress (bottom friction) driven dissipative effects are explored: After it was discovered that around $25-30 \%$ of the total global tidal dissipation is in the deep ocean (Egbert and Ray, 2000), the conversion of barotropic energy into baroclinic energy through the generation of internal tides over rough submarine topography was determined to be an important process to include in ocean tide models (for a review see Garrett and Kunze, 2007). Parameterizations of internal tide energy conversion (in which it is incorporated as a sink term) through this process is critical to reduce tidal elevation discrepancies in barotropic ocean models (Jayne and St. Laurent, 2001; Egbert et al., 2004; Zaron and Egbert, 2006; Green and Nycander, 2013; Buijsman et al., 2015). The effects of the energy conversion parameterization in the IndWPac region, including comparisons between two different forms of parameterization, are discussed. In addition, spatially varying bottom friction coefficients in the parameterization of bed stress are rarely considered in large-scale models. Instead, a canonical spatially constant coefficient is commonly applied (Lyard et al., 2006; Egbert and Erofeeva, 2002). However, changing the bottom friction coefficient has been shown to have positive effects regionally (Kerr et al., 2013; Lefevre et al., 2000). We briefly discuss the impacts of estimating spatially varying coefficients based on local sediment types and the local hydrodynamics. The requirements for improved estimations of local bottom friction coefficients for 
future research are considered.

To summarize, this paper describes the development of the IndWPac unstructured grid and hydrodynamic modeling system ( $\S 2-3)$. It is built with state-of-the-art bathymetric datasets $(\S 2)$, absorption-generation boundary conditions (§3.5), and data-informed parameterizations of internal tide energy conversion (§3.3) and bottom friction dissipation (§3.4). We analyze the sensitivity of the model to these four factors $(\S 5)$, and conduct model-data comparisons of tidal elevations and tidal currents against both tide gauge records and a data assimilated tidal model (§4). The capabilities and limitations of the model are identified and discussed (§4-5). Suggested areas of focus to advance barotropic coastal ocean models are highlighted.

\section{Domain Definition, Bathymetry, and Unstructured Grid Development}

Our ocean basin scale model includes the entire Indian Ocean, the western half of the Pacific Ocean, and the Southern Ocean between these extents. Specifically, the domain (Fig. 1) lies between $17.9^{\circ} \mathrm{E}-175.8^{\circ} \mathrm{E}$ longitude and $73.3^{\circ} \mathrm{S}-62.7^{\circ} \mathrm{N}$ latitude covering an area of roughly $150 \mathrm{million}^{\mathrm{km}}{ }^{2}$ There are two open ocean boundaries: a longitudinal parallel boundary running from nearby the Cape of Good Hope, South Africa to Antarctica; and a concave shaped boundary between the Bering Sea coast of Kamchatka Krai, Russia and Antarctica. The boundaries were chosen so that tidal amphidromic points and complications with the Aleutian, Hawaiian and New Zealand islands in the Pacific Ocean were avoided (an illustration on the effects of boundary placement is shown in $\S 5.1)$.

The mesh is a triangular unstructured grid with resolution ranging from as large as $25 \mathrm{~km}$ in parts of the deep ocean down to $1 \mathrm{~km}$ along most coastlines (Fig. 1(b)). Additionally, resolution is as fine as $100 \mathrm{~m}$ in the ports and harbors of Hong Kong, Tokyo Bay and Osaka Bay. The mesh contains a total of 9.6 million nodes and 18.8 million elements.

Development of the unstructured mesh is achieved predominantly through an automated algorithm developed in-house based on the MATLAB DistMesh code (Persson and Strang, 2004). Resolution is varied through an edgelength (local grid resolution) function $\lambda_{E}$, defined as the minimum of three criteria:

$$
\lambda_{E}=\min \left(\lambda_{m}+\alpha_{d} d, \quad \frac{T}{\alpha_{w}} \sqrt{g h}, \quad \frac{2 \pi}{\alpha_{s}} \frac{h}{|\nabla h|}\right)
$$

where $\lambda_{m}$ is the nominal minimum edgelength, $d$ is the distance from a node to the closest coastline boundary, $T$ is the period of the $\mathrm{M}_{2}$ tidal wave, $h$ is the bathymetric depth, and $\alpha_{i}$ are the dimensionless user-defined coefficients for each criterion: distance from the coastline $\left(\alpha_{d}=0.075\right)$, 


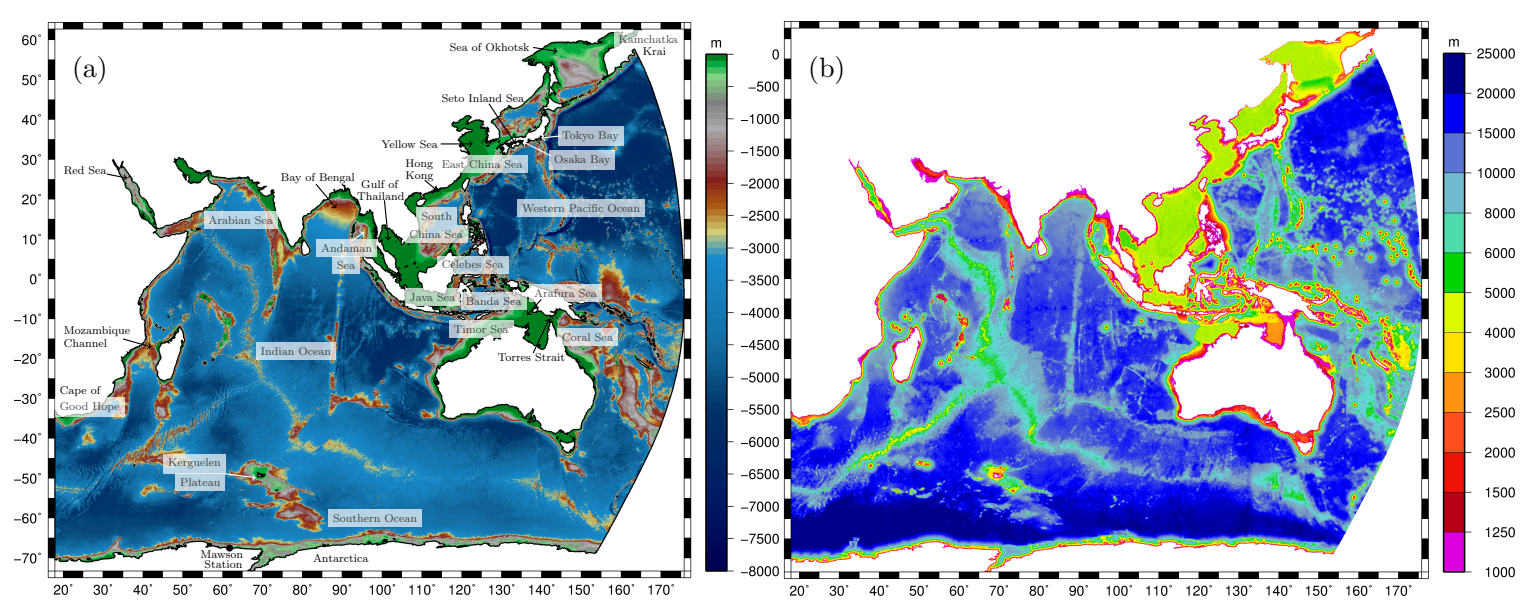

Figure 1: (a) Bathymetric depths of the grid as interpolated from various sources (Table 1) using a cellaveraged approach; pertinent place names are annotated. (b) Resolution of the unstructured mesh, which varies based on topographic gradients, depths and proximity to the coastline; mesh resolution at the coastline is $\sim 1 \mathrm{~km}$ in most regions, and up to $\sim 25 \mathrm{~km}$ in the deep and flat regions of the ocean.

wavelength $\left(\alpha_{w}=600\right)$, and topographic length scale $\left(\alpha_{s}=30\right.$, Lyard et al., 2006). In addition to obtaining higher resolution nearshore to support local bathymetric data and capture complex geometries of the coastline, these edgelength criteria ensure that important bathymetric features are adequately represented throughout the ocean.

Model bathymetry (Fig. 1(a)) is interpolated onto the mesh from a number of sources in a specified order using an automated cell-averaging technique (Bilskie and Hagen, 2013) as summarized in Table 1 (references are included here). The adopted background bathymetry is the $1 / 120^{\circ}$ SRTM30_PLUS global database (Becker et al., 2009) combined with a synthetic realization of seafloor roughness along the abyssal hills (Goff and Arbic, 2010; Timko et al., 2017). The synthetic abyssal hill roughness is used because the effective resolution of the global altimetric based bathymetry is limited to $>10 \mathrm{~km}$ in the deep ocean while $\sim 1 \mathrm{~km}$ resolution is necessary to describe the required topographic roughness that generates internal tides converting barotropic energy into baroclinic energy (Goff and Arbic, 2010; Melet et al., 2013; Timko et al., 2017). In addition, to include depths under ice shelves in Antarctica we interpolate from the TPXO8 model bathymetry containing the Padman et al. (2002) dataset.

For shallower regions (in depths $<500 \mathrm{~m}$ ) where the abyssal hill roughness is not important, we start by interpolating from the global $1 / 240^{\circ}$ SRTM15_PLUS database which improves 
on SRTM30_PLUS with newer measured nearshore bathymetry and topography sources thereby reducing the number of erroneous holes in the data. On top of this, $100 \mathrm{~m}$ Deepreef Explorer Great Barrier Reef and Coral Seas (GBR), and Kerguelen Plateau (KP) datasets are applied. It was discovered that Deepreef Explorer GBR in the Torres Strait/New Guinea Region matches substantially better with GEBCO_2014 than SRTM15_PLUS, thus GEBCO_2014 is applied locally here (differences between the two databases are discussed further in §5.2). Also, $90 \mathrm{~m}$ East Asia nearshore bathymetry datasets in the Philippines, Japan, Gulf of Thailand, South China Sea, and East China Sea regions; and local high-resolution bathymetry and grids privately obtained for Tokyo Bay and South Korea are applied. However, even in the high-resolution datasets, erroneous depth in harbor complexes and channels persist. These are corrected where possible using data from FUGAWI navigational charts (https://www.fugawi.com/). However, the errors in the final bathymetry that is applied to IndWPac are still largely uncertain. Furthermore, the bathymetric data sources included in this study are not exhaustive and there may be others available, possibly more accurate than the sources currently used, that we have not yet included (e.g. Choi et al., 2002; Krien et al., 2016).

Table 1: Bathymetric data sources, location applied, resolution and availability. Interpolation onto our grid is conducted in the order shown in this table

\begin{tabular}{|c|c|c|c|c|}
\hline Name & Source(s) & Location & Resolution & Availability \\
\hline SRTM30_PLUS & Becker et al. (2009) & globally $>500 \mathrm{~m}$ depth & $1 / 120^{\circ}$ & free at website ${ }^{1}$ \\
\hline Abysall Hills & Goff and Arbic (2010); Melet et al. (2013) & globally $>500 \mathrm{~m}$ depth & $1 / 120^{\circ}$ & prvt. comm. \\
\hline SRTM15_PLUS & Sandwell et al. (2014) & globally $<500 \mathrm{~m}$ depth & $1 / 240^{\circ}$ & free at website ${ }^{2}$ \\
\hline TPXO8 & Padman et al. (2002) & $<65^{\circ} \mathrm{S}$ & $1 / 30^{\circ}$ & free at website ${ }^{3}$ \\
\hline GEBCO_2014 & Weatherall et al. (2015) & Torres Strait/New Guinea & $1 / 120^{\circ}$ & free at website ${ }^{4}$ \\
\hline Deepreef Explorer GBR & Beaman (2010) & Great Barrier Reef \& Coral Sea & $1 / 1000^{\circ}$ & free at website ${ }^{5}$ \\
\hline Deepreef Explorer KP & Beaman and O'Brien (2011) & Kerguelen Plateau & $1 / 1000^{\circ}$ & free at website ${ }^{6}$ \\
\hline TCarta Marine & TCarta Marine (2012) & East Asia nearshore & $1 / 1200^{\circ}$ & proprietary $^{7}$ \\
\hline Tokyo Bay HR & Shintaro Bunya (prvt. comm., 2015) & Tokyo Bay & FE grid & prvt. comm. \\
\hline South Korea HR & SeungWon Suh (prvt. comm., 2017) & South Korea & FE grid & prvt. comm. \\
\hline Harbor hand-edits & FUGAWI Navigational Charts & various harbors and channels & FE grid & - \\
\hline
\end{tabular}

FE grid: indicates data was received on a finite-element grid

1: ftp://topex.ucsd.edu/pub/srtm30_plus/

2: ftp://topex.ucsd.edu/pub/srtm15_plus/

3: http://volkov.oce.orst.edu/tides/tpxo8_atlas.html

4: http://www.gebco.net/data_and_products/gridded_bathymetry_data/

5: https ://www . deepreef .org/bathymetry/65-3dgbr-bathy.html

6. https://www.deepreef .org/bathymetry/98-kergdem-bathy.html

7: provided by Factory Mutual Insurance Company (FM Global), Norwood, MA 


\section{ADCIRC Hydrodynamic Model}

\subsection{Governing Equations}

The horizontal two-dimensional implementation of the Advanced Circulation coastal ocean model (ADCIRC-2DH) is used to calculate the hydrodynamics (Westerink et al., 2008, 1992). The governingequations are the shallow water equations (SWE) in primitive, non-conservative, and barotropic form:

$$
\frac{\partial \eta}{\partial t}+\nabla \cdot(\boldsymbol{u} H)+\sigma(\boldsymbol{x})\left(\eta-\eta_{c}\right)=0
$$

$$
\begin{aligned}
\frac{\partial \boldsymbol{u}}{\partial t}+\boldsymbol{u} \cdot \nabla \boldsymbol{u}+f \mathbf{k} \times \boldsymbol{u} & +g \nabla\left(\eta-\eta_{E Q}-\eta_{S A L}\right)+C_{f} \frac{|\boldsymbol{u}| \boldsymbol{u}}{H}+\mathbf{C u} \\
& -\frac{1}{H} \nabla \cdot\left[\nu_{t} H\left(\nabla \boldsymbol{u}+\nabla \boldsymbol{u}^{\mathrm{T}}\right)\right]+\sigma(\boldsymbol{x})\left(\boldsymbol{u}-\boldsymbol{u}_{\boldsymbol{c}}\right)=0
\end{aligned}
$$

where $\eta$ is the surface elevation, $H=h+\eta$ is the total water depth in which $h$ is the still water depth, $\boldsymbol{u}$ is the depth-averaged velocity vector, $g$ is the acceleration due to gravity, $\mathbf{k}$ is the vertical unit vector, and $f=2 \Omega \sin \phi$ is the Coriolis parameter in which $\Omega$ is the angular speed of the earth, and $\phi$ is the latitude. The quantity $\eta_{E Q}$ is the equilibrium tide, and $\eta_{S A L}$ is the ocean self-attraction and loading term $(\mathrm{SAL})$. In the dissipation terms, $C_{f}$ is the coefficient of bottom friction, $\mathbf{C}$ is the dissipation matrix due to the internal tide energy conversion, and $\nu_{t}$ is the horizontal eddy viscosity coefficient that is calculated through the Smagorinsky model (Smagorinsky, 1963; Dresback et al., 2005). Finally, we impose an absorption-generation sponge layer (e.g. Zhang et al., 2014) where, $\sigma(\boldsymbol{x})$ are the spatially varying absorption coefficients applied over the defined sponge boundary, and $\eta_{c}$ and $\boldsymbol{u}_{\boldsymbol{c}}$ are the corresponding reference solutions for surface elevation and velocity respectively (see $§ 3.5$ for details).

\subsection{Ocean Self-attraction and Loading Term}

The ocean self-attracting and loading (SAL) term, $\eta_{S A L}$ is related to the yielding of the solid Earth to tides and to the weight of the ocean and its self-attraction (Hendershott, 1972). For the large-scale IndWPac domain it is essential to include the effect of SAL terms on the tides. However, since the model is regional, the global integrals of the tidal elevations required to be solved iteratively for the SAL terms (Ray, 1998) are not available. Thus, in this study the amplitudes and phases of SAL for each tidal constituent are simply interpolated from those used in the global data-assimilated model FES2014 (Lyard et al., 2006) onto our mesh and forced by reconstructing the time series from the constituents. Given the accuracy of state-of-the-art global data-assimilated models (Stammer et al., 2014), the slowly varying SAL terms obtained from these models are also 
assumed to be sufficiently accurate. However, the calculation of SAL through global integrals to obtain full consistency with the surface elevation (including non-periodic components) is ultimately desired (c.f. Apecechea et al., 2017).

\subsection{Internal Tide Energy Conversion}

Internal tides generated by flow over rough bathymetry are major contributors to barotropic tidal energy dissipation (more precisely, the conversion into baroclinic energy) in the deep ocean, equivalent to around 25-30\% of the global total (Egbert and Ray, 2000, 2001). As a result, parameterization of this energy conversion is necessary in barotropic ocean models that include expanses of ocean where major submarine ridges, island chains and shelf breaks that induce internal waves are present. In this study, parameterization of internal tide energy conversion is particularly important since the Indian Ocean basin contains narrow shelves and vast expanses of open ocean where the dissipation due to internal tides over its well defined abyssal hills is crucial to the accuracy of the tidal solutions.

Parameterizations of internal tide energy conversion are usually based on a linear wave drag type implementation, valid only for subcritical topography $(\gamma<1)$ (Bell, 1975; Jayne and St. Laurent, 2001). Here, $\gamma=\frac{\|\nabla h\|}{\alpha}$, in which $\alpha=\left(\frac{\omega^{2}-f^{2}}{N_{b}^{2}-\omega^{2}}\right)^{1 / 2}$ is the internal wave slope, $\omega$ is the angular frequency of the pertinent tidal wave $\left(\mathrm{M}_{2}\right.$ in this study), and $N_{b}$ is the Brunt-Väisälä frequency at the seabed. In this study, we investigate two subcritical theory parameterizations for the dissipation matrix $\mathbf{C}$ in (3): one based only on local topographic features, and another that includes the nonlocal effects on wave generation.

First, we use a simple and robust parameterization that takes into account the directionality of dissipation (which we denote as the 'Local' method) similar to that presented by Lyard et al. (2006) is:

$$
\mathbf{C}=C_{D i r} \frac{\left[\left(N_{b}^{2}-\omega^{2}\right)\left(\tilde{N}^{2}-\omega^{2}\right)\right]^{1 / 2}}{\omega}\left[\begin{array}{cc}
h_{x}^{2} & h_{x} h_{y} \\
h_{x} h_{y} & h_{y}^{2}
\end{array}\right]
$$

where $C_{D i r}$ is a scale factor, $\tilde{N}$ is the depth-averaged Brunt-Väisälä frequency, and the subscripts ' $x$ ' and ' $y$ ' indicate gradients in the longitudinal and latitudinal directions respectively. Note that we have substituted the typical wavenumber, $\kappa$ in Lyard et al. (2006) for the fundamental internal mode at the pertinent tidal frequency (Zaron and Egbert, 2006). The Local method only dissipates across slopes (rather than along them).

Second, a rigorous formulation for $\mathbf{C}$ that includes the nonlocal effects of the nearby topography on internal tide generation (Melet et al., 2013) was derived by Nycander (2005) (denoted as the 
'Nonlocal' method hereafter). It has the following form in a general coordinate system (Green and Nycander, 2013):

$$
\mathbf{C}=C_{N y c} \frac{N_{b}}{4 \pi h} \sqrt{1-\frac{f^{2}}{\omega^{2}}}\left[\begin{array}{cc}
2 J_{x} h_{x}^{*} & J_{x} h_{y}^{*}+J_{y} h_{x}^{*} \\
J_{x} h_{y}^{*}+J_{y} h_{x}^{*} & 2 J_{y} h_{y}^{*}
\end{array}\right]
$$

where $C_{N y c}$ is a scale factor, and $J$ is a convolution integral of a filtered Green's function of the topographic heights $h^{*}$ (defined positive from seabed) within a specified radius from the point of interest (c.f. Green and Nycander, 2013; Nycander, 2005).

Details of the calculation of the gradients of $J, h^{*}$, and $h$; the correction to (4) and (5) at supercritical topographical slopes $(\gamma>1)$; and the calculation of the buoyancy frequency terms $\left(N_{b}\right.$, $\tilde{N})$ required for the two methods are detailed in Pringle et al., submitted. Buoyancy frequencies are calculated from the World Ocean Atlas 2013 mean annual decadal-averaged (1955-2012) database of salinity (Zweng et al., 2013) and temperature (Locarnini et al., 2013). Note that for $h<100 \mathrm{~m}$ we set $\mathbf{C}=0$, because the topographic gradients on the continental shelf should be small, and bottom friction dissipation starts to dominate here.

The advantage of the Local method is that $\mathbf{C}$ is positive definite, and it does not require the computationally intensive calculation of $J$ allowing it to be quickly implemented into the model. On the other hand, the Nonlocal method accounts for the nonlocal topographic effects on internal tide generation. However, $\mathbf{C}$ in (5) is not guaranteed to be positive definite since the sign of the gradients of $J$ and $h^{*}$ do not necessarily conform. Furthermore, the calculation of the gradients of $J$ is computationally expensive so it is not as readily implemented into a numerical model.

Modifications to get a positive definite $\mathbf{C}$, and Guassian smoothing of $N_{b}$ to incorporate the nonlocal effects of buoyancy frequencies for the Nonlocal method are implemented and briefly evaluated in this study (see Pringle et al., submitted, for details on modifications). We also investigate whether the Nonlocal method provides any meaningful advantageous effect over the Local method by comparing the results between the two methods (see $\S 5.3$ ).

\subsection{Bottom Friction Dissipation}

Dissipation due to bottom friction (bed stress) is known to account for a significant proportion of dissipation of the barotropic tides, particularly in shallow regions $(h \ll 100 \mathrm{~m})$. Values for the coefficient of bottom friction $C_{f}$, in the bed stress term (refer (3)), have shown to be predominantly on the order of $10^{-3}$ based on measurements of the flow velocity at $1 \mathrm{~m}$ above the bed in continental shelf and estuarine regions (e.g. You, 2005; Heathershaw, 1979; Heathershaw and Simpson, 1978; Charnock, 1959). Thus, canonical global values of $C_{f}$ equal to $2.5 \times 10^{-3}$ (Lyard et al., 2006) or 
$3.0 \times 10^{-3}$ (Egbert and Erofeeva, 2002) are usually applied as a spatial constant in large-scale tidal models.

It has been suggested that deviations from the canonical value of $C_{f}$ globally do not significantly change the overall dissipation but that deviations by an order of ten can significantly degrade the tidal solution (Lyard et al., 2006). Nevertheless, if other dissipation mechanisms are reliable (internal tide energy conversion), there is evidence that local variations in $C_{f}$ over the range of physically plausible values $\left(10^{-4}\right.$ to $\left.10^{-2}\right)$ can improve local tidal solutions (e.g. Lefevre et al., 2000). In this study, we present a semidata-informed method of calculating spatially varying $C_{f}$. We aim to show that it is possible to calculate a spatially varying $C_{f}$ map that locally improves tidal elevations based on some knowledge of the seabed and physical properties of the flow, notwithstanding the assumptions of the method and uncertainties in the data used to inform the method.

We start with the log-law formulation of $C_{f}$ (Schlichting, 1979):

$$
C_{f}=\left[\kappa / \ln \left(0.5 H / z_{0}\right)\right]^{2}
$$

where $\kappa=0.4$ is the von Kármán constant, and $z_{0}$ is the seabed roughness length which can be equated to an effective sediment roughness, $k_{s}\left(=30 z_{0}\right)$. It is important to note that $k_{s}$ is not simply a function of the sediment roughness (grain-size) itself, rather it is mainly determined by the heights of ripples and dunes (bedforms) that form due to the prevailing currents which can be a major source of the resultant bed stress (Heathershaw, 1979). To estimate $k_{s}$ that takes into account the bedform heights, we use empirical equations (van Rijn, 2007) that are a function of median sediment grain diameter $d_{50}$, sediment density relative to water $s$, an effective mean current speed $u_{f}$, and the depth $h$ (see Appendix A). The empirical equations return small values of $k_{s}$ when either the sediments are light and the tidal currents are strong flattening out the bed, or when the sediment grains are too heavy for the currents to create bedforms. In between these extremes, ripples and dunes will form resulting in larger values of $k_{s}$. In addition, due to inadequate data availability of their locations, a large grain-size roughness due to very large rocks or boulders is ignored.

To obtain the sediment grain sizes we make use of a database of the census of the world's seafloor sediment types (Dutkiewicz et al., 2015). We map these sediment types onto physically reasonable values of $d_{50}$ (see Table 2). For pelagic type sediments (oozes and clays) $C_{f}$ is set to $2.5 \times 10^{-3}$ as a default roughness. Relative sediment density $s=1.722$ (dry bulk density by mass of sand, van Rijn, 2007 ) for $d_{50} \geq d_{\text {sand }}, s=1.2$ (natural sediment with organic materials involved, van Rijn, 2007) for $d_{50} \leq d_{\text {silt }}$, and is linearly interpolated in between. Here, $d_{\text {sand }}=6.2 \times 10^{-5} \mathrm{~m}$, and $d_{\text {silt }}=3.2 \times 10^{-5}$ $\mathrm{m}$, where the assumption is made that the finer-sized sediments in the census database contain a 
higher percentage of lighter organic material. The effective mean current speed $u_{f}$ is defined as (Zaron, 2017):

$$
u_{f}=\left(u_{0}^{2}+0.5 \sum_{k}\left|\boldsymbol{U}^{k}\right|^{2}\right)^{0.5}
$$

where $u_{0}$ is a constant non-tidal current (Snyder et al., 1979), that we set equal to $0.25 \mathrm{~m} / \mathrm{s}$ (Zaron, 2017), and $\boldsymbol{U}^{k}$ are the amplitudes of the east and north components of the tidal currents of the $k^{\text {th }}$ constituent. The spatially constant $C_{f}=2.5 \times 10^{-3}$ simulation is used to approximate $u_{f}$ in order to compute the spatially varying $C_{f}$ map (see $\S 5.4$ for details on this $C_{f}$ map and its effectiveness).

\subsection{Lateral Boundary Conditions}

Lateral open ocean boundaries are forced by reconstructing the elevations from the tidal constituents obtained from a global data-assimilative model, TPXO8 (Egbert and Erofeeva, 2002). In this study we force with the major semi-diurnal $\left(\mathrm{M}_{2}, \mathrm{~N}_{2}, \mathrm{~S}_{2}, \mathrm{~K}_{2}\right)$ and diurnal $\left(\mathrm{K}_{1}, \mathrm{O}_{1}, \mathrm{P}_{1}, \mathrm{Q}_{1}\right)$ constituents, which are also used to force the SAL and equilibrium potential terms. Prescribing the elevations at the open boundaries provides a reflecting boundary condition that allows the velocities to freely satisfy the governing equations. In some cases this condition can generate spurious modes that may lead to instabilities. Utilizing an absorption-generation sponge layer can reduce the production of these modes, as demonstrated in $\S 5.1$.

Firstly, the location and width of the sponge layer $l$ must be specified. We take $l$ to be approximately equal to $10 \%$ of the wavelength of the $\mathrm{M}_{2}$ tidal wave, $\lambda_{\mathrm{M}_{2}}$. The overall solution is found to be fairly insensitive to the choice of sponge layer width, but for $l<0.1 \lambda_{\mathrm{M}_{2}}$ the solutions may not match well across the sponge-calculation domain interface. To show the location and width of the sponge layer region, a hatched ' + ' region is included in figures throughout this paper.

Table 2: Median grain sizes $d_{50}$ and relative density $s$ for each sediment type used in the calculation of $C_{f}$

\begin{tabular}{lcc}
\hline Sediment Type & $d_{50}[\mathrm{~m}]$ & $s$ \\
\hline Gravel and coarser & $3.0 \times 10^{-3}$ & 1.722 \\
Sand & $1.0 \times 10^{-4}$ & 1.722 \\
Silt & $5.0 \times 10^{-5}$ & 1.513 \\
Ash and volcanic sand/gravel & $1.0 \times 10^{-3}$ & 1.722 \\
Siliceous mud & $4.0 \times 10^{-5}$ & 1.339 \\
Fine-grained calcareous sediment & $4.5 \times 10^{-5}$ & 1.426 \\
\hline
\end{tabular}


In addition, the sponge layer requires spatially varying absorption coefficients $\sigma(\boldsymbol{x})$, and reference solutions of the free surface $\eta_{c}$ and velocities $\boldsymbol{u}_{c}$. Assuming a polynomial type function for the absorptive coefficients inside the sponge layer, they are derived from the linear shallow water solution:

$$
\begin{aligned}
\sigma & =\sigma_{m}\left(\frac{r}{l}\right)^{\alpha} \\
\sigma_{m} & =-\frac{\sqrt{g h}(\alpha+1) \ln (1 / F)}{l\left(r_{c} / l\right)^{\alpha+1}}
\end{aligned}
$$

where $r$ is the distance from the edge of the sponge layer, $\alpha$ is the order of the polynomial function, $F$ is the reduction factor of the outgoing wave at the position $r_{c}$ from the edge of the sponge. The parameters $\alpha=2, F=20$ and $r_{c} / l=0.5$ are chosen in this study but the solution is not typically sensitive to the choice of these factors. The reference solutions $\eta_{c}$ and $\boldsymbol{u}_{c}$ are obtained by interpolating tidal constituents from the TPXO8 model onto every vertex node in the sponge zone. Note that to get $\boldsymbol{u}_{c}$, the conservative transport variable, $\boldsymbol{u}_{c} h$, is interpolated from TPXO8 before dividing this by our model nodal depths for consistency.

\subsection{Finite-Element Solution}

ADCIRC solves the governing equations in a continuous-Galerkin framework, where the generalized wave continuity equation (GWCE) is utilized to eliminate spurious modes (c.f. Westerink et al., 1992). The two-part symmetrical velocity based method for the lateral stress terms (Dresback et al., 2005), and explicit mass-lumping mode are used to solve the GWCE in this study.

A time step $\Delta t=2 \mathrm{~s}$ can be used with our current grid without generating Courant-FriedrichsLewy (CFL) induced numerical instabilities. Wall-clock times are approximately 11 min day ${ }^{-1}$ of simulation time using 960 computational cores $(\approx 10,000$ finite-element nodes per core) of a highperformance computing machine with Haswell processors and a Mellanox FDR Infiniband network connection. To validate the model with observations, we simulated for 195 days, including a 15 day spin-up from a completely zero state. The final 180 days are used for the harmonic analysis of the tides. The long six-month time period is required to correctly separate all the tidal constituents of interest (e.g $\mathrm{K}_{1}$ and $\mathrm{P}_{1}$ ).

\section{Summary of Tidal Validation from Best Model Setup}

\subsection{Best Model Setup}

To obtain the best model setup we first find the global amplification factor of the internal tide energy conversion parameter so that the model skill (in terms of tidal elevations) versus TPXO8 is 
maximized in the deep ocean $(h>500 \mathrm{~m})$. A positive definite and spatially smoothed $N_{b}$ modified version of the Nonlocal method with $C_{N y c}=2.9$ and local multiplier coefficients over the Luzon Strait (see §5.3) was decided on. Local bathymetry datasets and hand-edits are applied to shallow water regions and responses against coastal tide gauges are checked for reliability in the harmonic analysis. Finally, a map of varying bottom friction dissipation coefficients $C_{f}$ is calculated based on some information of the local sediment types, as described in $\S 3.4$, in an attempt to increase the model skill versus using a spatially constant $C_{f}$. The best model setup is denoted by 'Comp $+I T$ $+S V^{\prime}$, indicating the use of our comprehensive bathymetric data (Table 1), optimal internal tide dissipation, and spatially varying $C_{f}$.

\subsection{Measure of Model Skill}

To measure the skill of the model for the purpose of determining and evaluating the best setup in $\S 4.4$, we compare with the root-mean-square (RMS) discrepancy $D$ of the elevation (either for a single tidal constituent or for the total free surface) at a point. $D$ is the average of the squared differences between measured and observed elevations integrated over a long period of time. It is calculated in this study using the sum of the vector differences of the in-phase $\left(A^{k} \cos \theta^{k}\right)$ and quadrature $\left(A^{k} \sin \theta^{k}\right)$ components of each constituent (Wang et al., 2012):

$$
D=\left(0.5 \sum_{k}\left[\left(A_{0}^{k}\right)^{2}+\left(A_{m}^{k}\right)^{2}-2 A_{0}^{k} A_{m}^{k} \cos \left(\theta_{0}^{k}-\theta_{m}^{k}\right)\right]\right)^{1 / 2}
$$

where $A^{k}$ and $\theta^{k}$ are the amplitudes and phase lags of the $k^{t h}$ constituent respectively, and the subscripts ' $O$ ' and ' $m$ ' refer to the observed and modeled values respectively. In addition, the relative RMS discrepancy is defined as $R D=D / V$, where $V$ is the absolute average value of the variability in the free surface elevation, and is calculated by (Wang et al., 2012):

$$
V=\left[0.5 \sum_{k}\left(A_{0}^{k}\right)^{2}\right]^{1 / 2}
$$

For an overview of the spatial distribution, we include scatter plots of $D$ and $R D$ at the tide gauges (and contour plots versus TPXO8) in order to highlight regions of notably small or large discrepancies. However, to obtain a single global metric of performance the mean of the discrepancy $D$, denoted $\bar{D}$, or the mean of $R D$, denoted $\overline{R D}$, is used. Note that when calculating $\bar{D}$ over a region to compare against TPXO8 (tpx) this is computed as:

$$
\bar{D}_{t p x}=\frac{\iint D d A}{\iint d A}
$$


where $\iint d A$ indicates an area integral that is performed over the elements of the grid. When comparing against tide gauges $\left(\bar{D}_{t g}, \overline{R D}_{t g}\right)$, the arithmetic average is used. In comparison to $\bar{D}$, the RMSE metric commonly used (e.g. Stammer et al., 2014; Buijsman et al., 2015) is:

$$
\mathrm{RMSE}=\sqrt{\frac{\iint D^{2} d A}{\iint d A}}
$$

i.e., it is the square-root of the mean of $D^{2}$ and is always larger than $\bar{D}$. The RMSE may experience abrupt changes with depth and tends to overestimate the overall discrepancy (Wang et al., 2012). In contrast, $\bar{D}$ has been shown to decrease monotonically with depth (Wang et al., 2012), thus we choose to predominantly use $\bar{D}$. However, we also quote values of RMSE for comparison with those reported in other studies.

Finally, in $\S 4.5$ comparisons of the tidal currents at seven tide gauges are shown. To evaluate the comparison here, the RMS discrepancy of the tidal current ellipse $D_{T C}$ (Cummins and Thupaki, 2018) for the $k^{\text {th }}$ constituent is used:

$$
\begin{aligned}
D_{T C}^{k}= & {\left[0.5\left(U_{+_{0}}^{k}{ }^{2}+U_{-_{0}}^{k}{ }^{2}+U_{+_{m}}^{k}{ }^{2}+U_{-_{m}}^{k}{ }^{2}\right)-\cos \left(g_{0}^{k}-g_{m}^{k}\right) \cos \left(\Theta_{0}^{k}-\Theta_{m}^{k}\right)\left(U_{+_{0}}^{k} U_{+_{m}}^{k}+\right.\right.} \\
& \left.\left.U_{-{ }_{0}}^{k} U_{-m}^{k}\right)-\sin \left(g_{0}^{k}-g_{m}^{k}\right) \sin \left(\Theta_{0}^{k}-\Theta_{m}^{k}\right)\left(U_{+_{0}}^{k} U_{-_{m}}^{k}+U_{-_{0}}^{k} U_{+_{m}}^{k}\right)\right]^{1 / 2}
\end{aligned}
$$

where $U_{+}^{k}$ and $U_{-}^{k}$ are the amplitudes of the semi-major and semi-minor tidal current axes respectively, $\Theta^{k}$ is the ellipse inclination angle, and $g^{k}$ is the phase lag of alignment along the semi-major tidal current axis.

\subsection{Tidal Gauge Database}

A database of tidal elevation harmonic constituents (used to evaluate the model in $\S 4.4$ ), consisting of 39 deep-water stations, 62 shallow water/shelf stations, and 659 unique coastal tide gauge locations has been assembled from multiple sources for the computational domain (Table 3, see Pringle (2017) for tide gauge locations, and tidal constituent values). Some of the sources are listed tidal constituent values at websites or in refereed journals (denoted const. in Table 3). Other sources are long-term hourly time series of elevations (denoted elev. in Table 3) where we have used the Utide MATLAB function ut_solv (Codiga, 2011), which uses the iteratively-weighted least-square harmonic analysis technique, to obtain up to 68 tidal constituents. Within the coastal tide gauge set there are a number of data points duplicated between sources so we set up a hierarchy between the different sources to decide what value to use in our model evaluation based on perceived reliability (Table 3 is listed in hierarchical order, and the number of stations listed for each source 
Table 3: Tide gauge data sources, number and availability. Listed in hierarchical order for the coastal

\begin{tabular}{|c|c|c|c|c|}
\hline Name & Source & Number & Type & Availability \\
\hline Truth_Pelagic & Shum et al. (1997) & 31 & deep-water const. & free at website ${ }^{1}$ \\
\hline Truth_Shallow & Stammer et al. (2014) & 52 & shallow-water const. & free at website ${ }^{1}$ \\
\hline TOPEX/POSEIDON Crossovers & Robertson and Ffield (2008) & $8 / 5$ & deep/shallow-water const. & listed in paper \\
\hline Java Sea/SCS & Wei et al. (2016) & 5 & shallow-water const./curr. & listed in paper \\
\hline North SCS & Cai et al. (2006) & 2 & shallow-water/coastal curr. & listed in paper \\
\hline NOAA & NOAA/CO-OPS (2017) & 4 & coastal const. & free at website ${ }^{2}$ \\
\hline JMA & Japanese Meteorological Agency (2017) & 181 & coastal const. & free at website ${ }^{3}$ \\
\hline AusTides & Australian National Tide Tables (2013) & 63 & coastal const. & proprietary \\
\hline KHOA & Korean Hydrographic and Oceanographic Agency (2017) & 35 & coastal elev. & free at website ${ }^{4}$ \\
\hline GESLA-2 & Woodworth et al. (2017) & 107 & coastal elev. & free at website ${ }^{5}$ \\
\hline UHSLC FD & Caldwell et al. (2015) & 19 & coastal elev. & free at website ${ }^{6}$ \\
\hline $\mathrm{NBoB}$ & Krien et al. (2016) & 2 & coastal const. & listed in paper \\
\hline SCS & Fang et al. (1999) & 29 & coastal const. & listed in paper \\
\hline Yellow Sea & Fang et al. (2004) & 6 & coastal const. & listed in paper \\
\hline ST727 & British Hydrographic Institute (c.1848-1970) & 130 & coastal const. & free at website ${ }^{1}$ \\
\hline $\mathrm{IHO}$ & International Hydrographic Office (1990) & 83 & coastal const. & proprietary \\
\hline
\end{tabular}

elev.: indicates original data is hourly elevation time series

curr.: indicates original data is tidal current harmonic constituent values

1: ftp://ftp.legos.obs-mip.fr/pub/FES2012-project/data/gauges/2013-12-16/

2: https://tidesandcurrents.noaa.gov/gmap3/

3. http://www.data.jma.go.jp/kaiyou/db/tide/suisan/station2017.php

4. http://www.khoa.go.kr/koofs/kor/observation/obs_real.do

5: http://www.gesla.org/

6. ftp://ftp.soest.hawaii.edu/uhslc/fast

\subsection{Tidal Elevations}

\subsubsection{Spatial Distribution of Tidal Elevations and Discrepancies}

This study focuses on presenting the $\mathrm{M}_{2}$ and $\mathrm{K}_{1}$ tidal waves and their discrepancies, although $\S 4.4 .2$ presents statistics for a combination of all major eight tidal constituents as well. This choice is justified because out of the 760 tide gauges in the domain (§4.3), the $M_{2}$ constituent is dominant at 

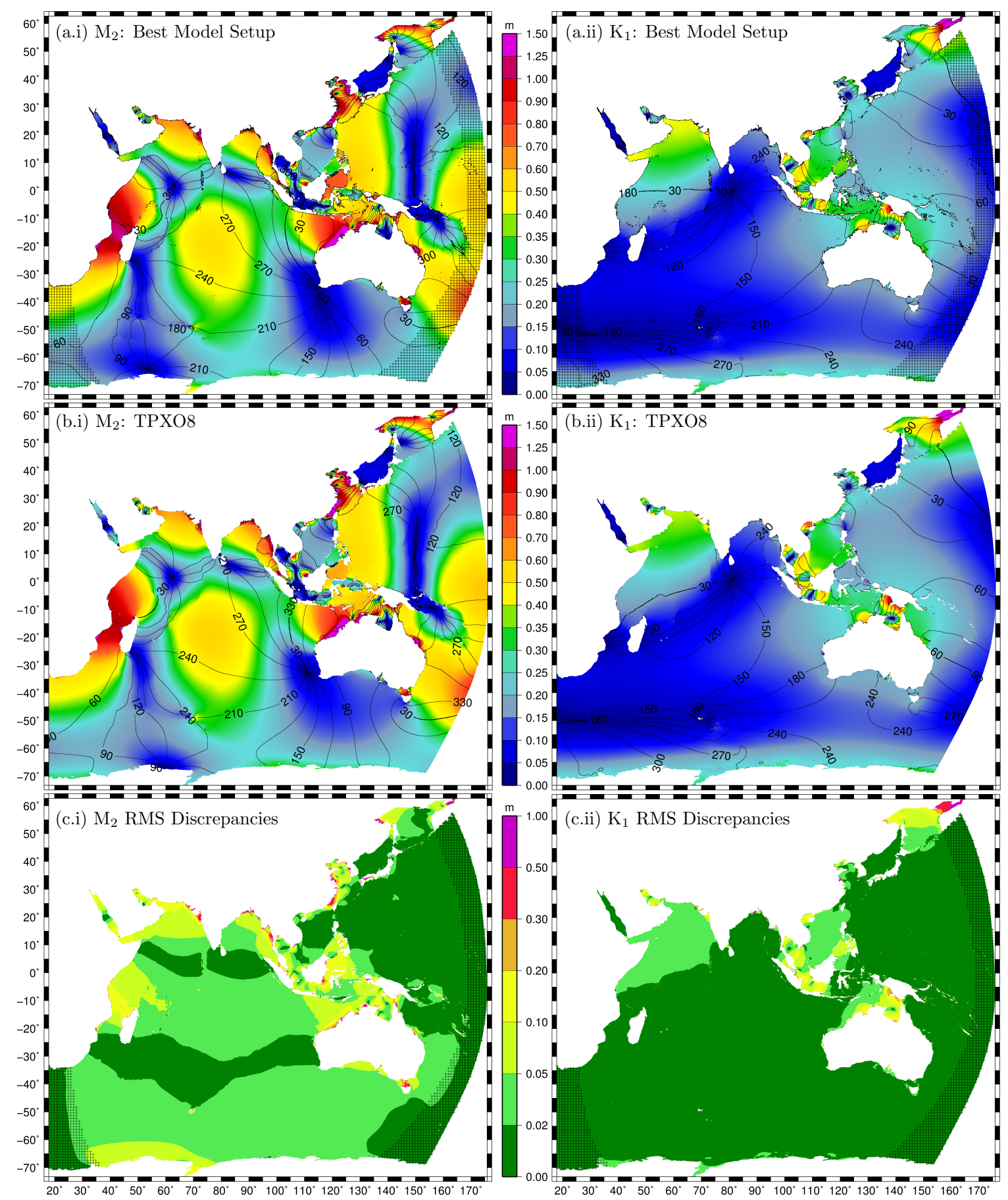

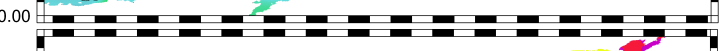

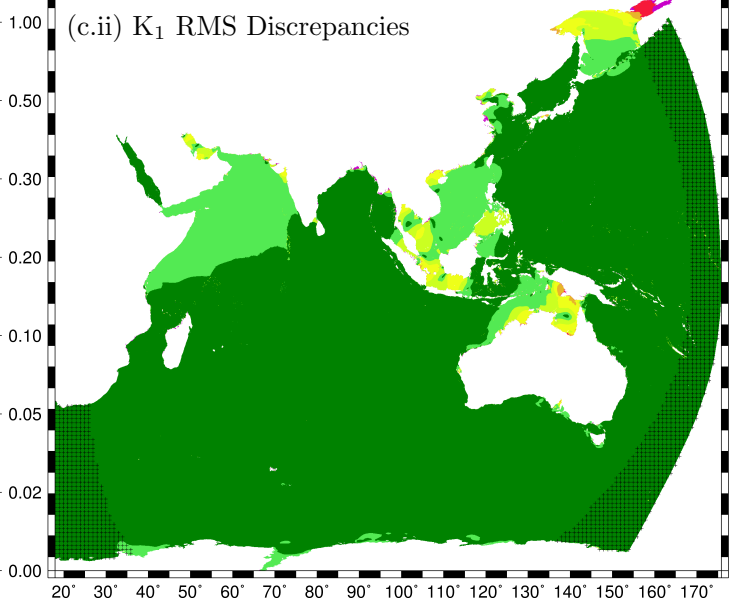

Figure 2: Amplitude (m) and phase responses of the (i) $\mathrm{M}_{2}$ and (ii) $\mathrm{K}_{1}$ tidal waves; (a) Comp $+I T+S V$ model setup, (b) TPXO8 model, (c) RMS discrepancies (m) between Comp $+I T+S V$ model setup and TPXO8, $D_{t p x}$. '+' hatched regions indicate absorption-generation sponge zone. 


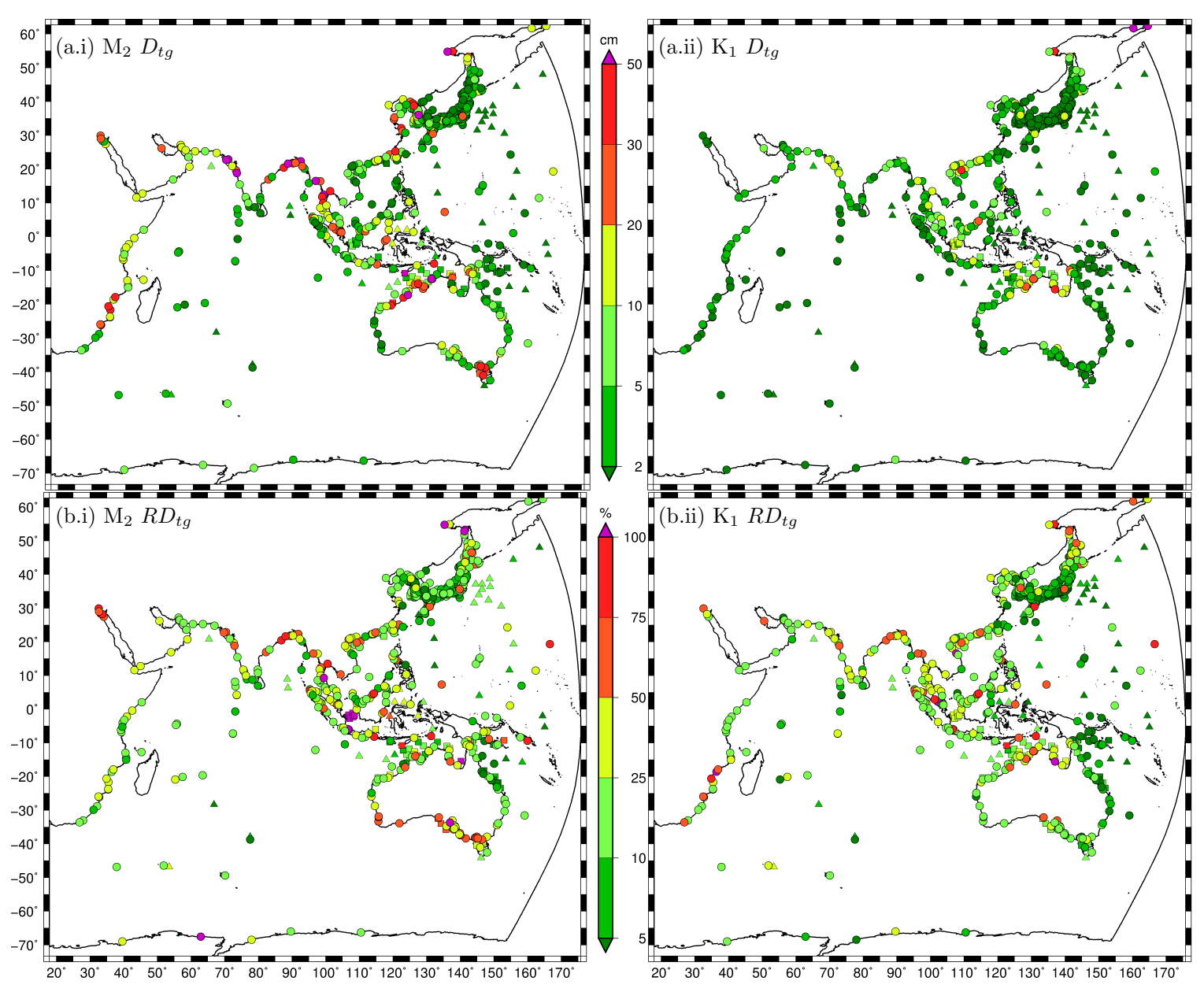

Figure 3: Spatial distribution of discrepancies of the (i) $M_{2}$ and (ii) $K_{1}$ tidal waves versus tide gauges for the Comp $+I T+S V$ model setup; (a) RMS discrepancy $D_{t g}$, (b) relative RMS discrepancy $R D_{t g}$. Triangles: deep water gauges, Squares: continental shelf water gauges, Circles: coastal tide gauges.

625 locations (82\%), $\mathrm{K}_{1}$ is dominant at 106 locations (14\%), thus another constituent is dominant at just 29 locations (4\%). The global responses of the $\mathrm{M}_{2}$ and $\mathrm{K}_{1}$ tidal waves, and their RMS discrepancies against TPXO8 $\left(D_{t p x}\right)$ for the Comp $+I T+S V$ model setup are illustrated in Fig. 2.

The general response for both constituents is well described by our model, including the positions of most amphidromes, except for the two $\mathrm{M}_{2}$ amphidromes in the southern region of the domain; one near the south-west tip of Australia, and another near Mawson Station, Antarctica. The positions of these amphidromes and the solution in the Southern Ocean are found to be very sensitive to the 
boundary conditions applied in this study and may be impacted by the TPXO8 derived velocities in the absorption-generation sponge layer (see $§ 5.1$ ).

The spatial distribution of the RMS discrepancies $\left(D_{t g}\right)$ and relative discrepancies $\left(R D_{t g}\right)$ for the Comp $+I T+S V$ model setup against tide gauges are also illustrated (Fig. 3). Overall, tide gauges with similar discrepancies are generally clustered together, and there is a relatively strong spatial correlation between discrepancies against TPXO8 and those at tide gauges. Exceptions to this include much of the inner coast of the Yellow Sea and the Seto Inland Sea where the TPXO8 model may not be reliable. The Comp $+I T+S V$ model setup performs particularly well throughout the western Pacific Ocean including along the Japanese archipelago and northeastern Australia for both constituents. Notable wide spread RMS discrepancies in the $\mathrm{M}_{2}$ tidal wave appear in the Mozambique Channel, north and west Arabian Sea, Red Sea, Sea of Okhotsk, Andaman Sea, Yellow Sea, northern Australian shelf and the Celebes Sea. $K_{1}$ RMS discrepancies are notable in the Sea of Okhotsk, Arabian Sea, South China Sea and Java Seas, and the Arafura Sea. Predominantly large tidal ranges account for the discrepancies shown. For example, $\mathrm{M}_{2} R D_{t g}$ values are relatively small in the Yellow Sea even though $D_{t p x}$ values appear large in the Yellow Sea for the Comp $+I T$ $+S V$ model setup. In fact, the response is improved rather substantially from the Comp + IT + $S C$ model setup here (§5.4). $R D_{t g}$ is also less significant than $D_{t g}$ in the Mozambique Channel and northern Australian shelf. These two regions are heavily influenced by large-scale effects related to lateral boundary conditions $(\S 5.1)$ and internal tide energy conversion $(\S 5.3)$.

On the other hand, both $D_{t g}$ and $R D_{t g}$ are large in the Sea of Okhotsk for both constituents. The importance of bathymetry in the region (which is not well known) has been highlighted by Zaron (2017). The Celebes Sea is also a problem area for $\mathrm{M}_{2}$ that is most likely a result of incorrect flux exchanges through the island chains due to inadequate bathymetry and a poor representation of internal tide energy conversion particularly in shallow waters. It should be noted that the Celebes Sea and surrounding Indonesian seas was a focus of the original TPXO study (Egbert and Erofeeva, 2002) due to its poor forward model responses, and the region has been found to cause problems for three-dimensional ocean circulation models (Robertson and Ffield, 2008; Ngodock et al., 2016). The South China and Java Sea region extending down to the Torres Strait has a relatively large diurnal tidal range and $\mathrm{K}_{1} D_{t g}$ and $R D_{t g}$ values are not small compared to most of the domain. The physics of the $K_{1}$ tidal wave here can be thought of as a standing wave where the response is likely to depend highly on the overall bathymetry and shoreline of the region. The region is also heavily influenced by the energy flux permitted through the Luzon Strait (§4.5) which is largely controlled 
by internal tide energy conversion (§5.3). Note that, in some areas such as between South China Sea and Java Sea, which has a small $\mathrm{M}_{2}$ tidal range because it is close to an amphidrome, $R D_{t g}$ becomes very large, however $D_{t g}$ is relatively small.

\subsubsection{Statistics of Tidal Elevation Discrepancies}

A summary of the global tide gauge errors shown in terms of amplitudes $\left(R^{2}=0.93, \sigma_{\text {std }}=0.09\right.$ $\mathrm{m}, \overline{|E|}=0.04 \mathrm{~m})$ and phases $\left(R^{2}=0.97, \sigma_{s t d}=18.3^{\circ}, \overline{|E|}=10.3^{\circ}\right)$ of up to all eight major tidal constituents from the Comp $+I T+S V$ model setup against the observed values is presented (Fig. 4, see caption for definitions of error metrics). There is a total of 6080 data points on each plot. Just $2.4 \%$ of them represent absolute amplitude errors $>0.2 \mathrm{~m}$, and $2.9 \%$ represent absolute phase errors $>36^{\circ}$ (colored orange to purple in Fig. 4). Outliers in the amplitudes of constituents tend to be

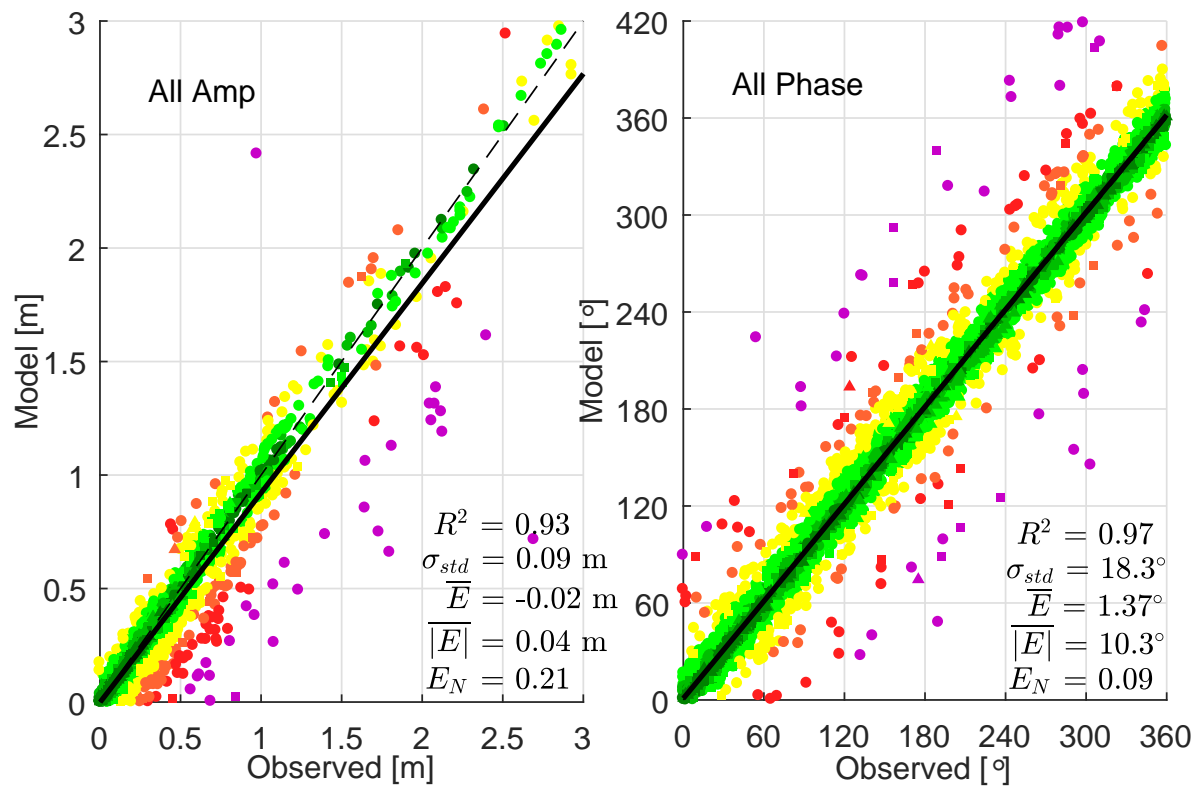

Figure 4: Amplitudes, $A$ (left) and phase lags, $\theta$ (right) of up to all eight major tidal constituents for the $C o m p+I T+S V$ model setup versus observed values at tide gauges. Triangles: deep water gauges, Squares: continental shelf water gauges, Circles: coastal tide gauges. Colors of markers for the amplitude refer to the absolute error $(\mathrm{m})$ between model and observed. Colors of markers for the phase refer to the absolute errors normalized by $180^{\circ}$ between model and observed. The same color scale as Fig. 3(a) is used for both. Statistics shown on the figure are as follows: $R^{2}$ is the coefficient of determination, $\sigma_{s t d}$ is the standard deviation of the error, $\bar{E}$ is the mean error, $\overline{|E|}$ is the mean absolute error, and $E_{N}$ is the normalized mean absolute error. 
underestimates rather than overestimates which may indicate deltaic regions, estuaries, back-bays and rivers where the bathymetry is inadequate and overly dissipative, e.g., the Ganges Delta where large discrepancies are present (Fig. 3). Aside from these regions, there is a consistent spread of errors for both the amplitudes $(\bar{E}=-0.02 \mathrm{~m})$ and phases $\left(\bar{E}=1.37^{\circ}\right)$ indicating a largely unbiased system.

Table 4 compares the mean and standard deviations of the RMS discrepancies between the various IndWPac model setups (different bathymetry datasets, with and without internal tide energy conversion and spatially varying bottom friction coefficients), versus tide gauges observations and the TPXO8 atlas. Note that when the interpolation of TPXO8 to the coastal tide gauges is performed using their native data extraction program OTPS2, a total of 93 locations return a null value. Thus, for a fair comparison we present our model results against this reduced set of stations. The statistics of the IndWPac model are not noticeably different for the full coastal gauge set. Based on dimensional considerations, different physical processes are expected to be important depending on the water depth and proximity to the coast. Thus, the statistics are broken up into three regions; deep water $(h>500 \mathrm{~m})$, continental shelf and slope waters $(25<h<500 \mathrm{~m})$, and coastal waters (includes continental and island coastlines).

At the deep-water tide gauges the total free surface mean discrepancies for the Comp $+I T+$ $S V$ model setup $\left(\bar{D}_{t g}=4.7 \mathrm{~cm}, \overline{R D}_{t g}=13 \%\right)$ are 2.4 times those of the TPXO8 atlas $\left(\bar{D}_{t g}=2.0\right.$ $\left.\mathrm{cm}, \overline{R D}_{t g}=5.5 \%\right)$. The IndWPac model discrepancies in deep water are predominantly affected by the internal tide energy conversion which reduces the total free surface RMS discrepancy by $47 \%$ $\left(\bar{D}_{t p x}\right)$ and $55 \%\left(\bar{D}_{t g}\right)$. Different bathymetry datasets and bottom friction coefficients have little effect. Hot-spots of discrepancy against deep-water tide gauges for the IndWPac model occur in the Celebes Sea and Banda Sea (see Fig. 3) against TOPEX/POSEIDON satellite crossover observations (Robertson and Ffield, 2008), particularly for the $\mathrm{M}_{2}$ tidal wave. Without the crossover points (which are technically not tide gauges) the $\mathrm{M}_{2} \bar{D}_{t g}$ for the Comp $+I T+S V$ model setup is closer to $2 \mathrm{~cm}$ instead of $3.6 \mathrm{~cm}$.

For comparison, in waters deeper than $1000 \mathrm{~m}$, the RMSE against TPXO8 for another nonassimilative hydrodynamic model (Buijsman et al., 2015) is approximately $4 \mathrm{~cm}$ in the Indian and Pacific Oceans. Furthermore, in waters deeper than 500 m, Wilmes et al. (2017) obtains a global RMSE $=3.8 \mathrm{~cm}$, and the Comp $+I T+S V$ model setup here obtains an RMSE $=3.6 \mathrm{~cm}$ in waters deeper than $500 \mathrm{~m}$ versus TPXO8. This cannot be said to be a statistically significant improvement despite generally higher resolution of the grid and nearshore bathymetric data than Buijsman et al. 
Table 4: The mean RMS $\left(\bar{D}_{t g}\right)$ and relative RMS $\left(\overline{R D}_{t g}\right)$ discrepancies of the $\mathrm{M}_{2}, \mathrm{~K}_{1}$, and the total free surface (up to all eight major constituents combined) at tide gauges for various IndWPac model setups plus the TPXO8 atlas (http://volkov.oce.orst.edu/tides/tpxo8_atlas.html), separated into three different regions (deep, continental shelf and slope, and coastal). The mean RMS discrepancy against TPXO8 $\left(\bar{D}_{t p x}\right)$ is shown in deep, and continental shelf and slope waters. Stations numbers, units, and standard deviations are in parentheses

\begin{tabular}{|c|c|c|c|c|c|c|c|c|}
\hline & & & & & & & & \\
\hline Region & $\begin{array}{l}\text { Error } \\
\text { Metric }\end{array}$ & $\begin{array}{l}\text { Tidal } \\
\text { Wave }\end{array}$ & $\begin{array}{c}C o m p+ \\
N o I T+S C\end{array}$ & $\begin{array}{c}G E B C O+ \\
I T+S C\end{array}$ & $\begin{array}{l}S R T M+ \\
I T+S C\end{array}$ & $\begin{array}{l}\text { Comp }+ \\
I T+S C\end{array}$ & $\begin{array}{l}C o m p+ \\
I T+S V\end{array}$ & TPXO8 \\
\hline \multirow{9}{*}{$\begin{array}{l}\text { Deep } \\
(39)\end{array}$} & & $\mathrm{M}_{2}$ & $5.69(4.31)$ & $2.97(2.21)$ & $2.92(2.26)$ & $2.90(2.20)$ & $2.89(2.18)$ & - \\
\hline & $\bar{D}_{t p x}$ & $\mathrm{~K}_{1}$ & $1.39(1.56)$ & $1.08(3.14)$ & $1.01(3.59)$ & $0.95(1.19)$ & $0.95(1.17)$ & - \\
\hline & $(\mathrm{cm})$ & All & $6.91(4.76)$ & $3.85(5.51)$ & $3.82(6.23)$ & $3.67(2.59)$ & $3.67(2.56)$ & - \\
\hline & & $\mathrm{M}_{2}$ & $8.90(9.97)$ & $3.90(4.40)$ & $3.82(4.02)$ & $3.66(4.45)$ & $3.55(4.34)$ & $0.86(0.87)$ \\
\hline & $\bar{D}_{t g}$ & $\mathrm{~K}_{1}$ & $2.16(1.66)$ & $1.03(0.82)$ & $0.94(0.71)$ & $0.93(0.71)$ & $0.92(0.68)$ & $0.50(0.34)$ \\
\hline & $(\mathrm{cm})$ & All & $10.8(11.0)$ & $5.09(5.03)$ & $5.02(4.60)$ & $4.82(4.98)$ & $4.71(4.89)$ & $2.02(2.82)$ \\
\hline & & $\mathrm{M}_{2}$ & $32.7(25.7)$ & $15.7(11.4)$ & $15.7(11.3)$ & $14.2(11.9)$ & $13.9(11.7)$ & $3.82(3.31)$ \\
\hline & $\overline{R D}_{t g}$ & $\mathrm{~K}_{1}$ & $16.4(9.08)$ & $8.40(6.31)$ & $7.72(5.72)$ & $7.67(5.84)$ & $7.69(5.83)$ & $4.29(3.34)$ \\
\hline & $(\%)$ & All & $28.4(19.8)$ & $14.3(10.2)$ & $14.3(9.35)$ & $13.4(10.3)$ & $13.1(10.1)$ & $5.46(5.67)$ \\
\hline \multirow{9}{*}{$\begin{array}{l}\text { Shelf } \\
(62)\end{array}$} & & $\mathrm{M}_{2}$ & $11.2(11.0)$ & $8.05(9.02)$ & $7.58(9.45)$ & $6.76(7.67)$ & $6.48(7.76)$ & - \\
\hline & $\bar{D}_{t p x}$ & $\mathrm{~K}_{1}$ & $5.83(13.7)$ & $6.69(14.4)$ & $6.57(17.2)$ & $4.52(7.08)$ & $4.75(7.71)$ & - \\
\hline & $(\mathrm{cm})$ & All & $16.6(22.1)$ & $15.0(23.6)$ & $14.8(28.7)$ & $10.9(10.8)$ & $11.0(11.4)$ & - \\
\hline & & $\mathrm{M}_{2}$ & $18.4(12.1)$ & $12.3(11.4)$ & $14.9(19.3)$ & $9.70(9.63)$ & $9.35(9.87)$ & $2.91(3.28)$ \\
\hline & $\bar{D}_{t g}$ & $\mathrm{~K}_{1}$ & $5.71(4.54)$ & $4.41(4.05)$ & $4.84(5.04)$ & $3.71(4.13)$ & $4.47(4.78)$ & $1.60(1.56)$ \\
\hline & $(\mathrm{cm})$ & All & $22.8(12.3)$ & $16.0(11.7)$ & $19.4(20.8)$ & $13.0(11.0)$ & $13.4(11.4)$ & $5.41(3.76)$ \\
\hline & & $\mathrm{M}_{2}$ & $76.9(89.1)$ & $53.8(73.3)$ & $52.6(65.4)$ & $42.1(58.5)$ & $40.9(55.8)$ & $12.8(20.9)$ \\
\hline & $\overline{R D}_{t g}$ & $\mathrm{~K}_{1}$ & $24.4(14.5)$ & $21.0(18.9)$ & $21.5(20.0)$ & $19.0(20.0)$ & $19.9(20.0)$ & $7.89(9.37)$ \\
\hline & $(\%)$ & All & $40.2(18.1)$ & $26.8(15.0)$ & $29.9(19.8)$ & $22.1(14.8)$ & $22.6(16.1)$ & $9.24(5.37)$ \\
\hline \multirow{6}{*}{$\begin{array}{l}\text { Coast } \\
(659)\end{array}$} & & $\mathrm{M}_{2}$ & $16.0(17.1)$ & $24.6(33.4)$ & $17.9(24.1)$ & $12.1(15.6)$ & $10.5(14.4)$ & $13.5(39.3)$ \\
\hline & $\bar{D}_{t g}$ & $\mathrm{~K}_{1}$ & $4.58(6.15)$ & $6.95(9.18)$ & $5.45(7.80)$ & $4.09(6.34)$ & $3.90(6.32)$ & $3.12(5.58)$ \\
\hline & $(\mathrm{cm})$ & All & $20.9(19.6)$ & $29.9(37.1)$ & $22.5(27.4)$ & $15.8(18.4)$ & $14.4(17.2)$ & $17.0(47.9)$ \\
\hline & & $\mathrm{M}_{2}$ & $45.9(60.4)$ & $45.7(44.0)$ & $36.3(40.1)$ & $28.5(36.9)$ & $27.2(38.4)$ & $24.7(38.6)$ \\
\hline & $\overline{R D}_{t g}$ & $\mathrm{~K}_{1}$ & $27.0(38.2)$ & $37.9(33.8)$ & $29.0(27.4)$ & $22.4(19.9)$ & $21.6(20.5)$ & $18.1(21.4)$ \\
\hline & $(\%)$ & All & $36.4(22.5)$ & $41.6(31.9)$ & $32.8(26.0)$ & $25.3(18.2)$ & $24.4(19.2)$ & $22.8(30.8)$ \\
\hline
\end{tabular}

\section{Model Setups}

Bathymetry: 'GEBCO' uses GEBCO_2014 bathymetric data, 'SRTM' uses SRTM15_PLUS bathymetric data, 'Comp' uses our comprehensive bathymetric data (Table 1)

Internal Tide Energy Conversion: 'NoIT' does not include internal tide energy conversion, 'IT' uses the optimal internal tide conversion parameters

Bottom Friction: ' $S C$ ' uses a spatially constant $C_{f}=2.5 \times 10^{-3}$, ' $S V^{\prime}$ uses the spatially varying $C_{f}$ map (Fig.15(a)) 
(2015); Wilmes et al. (2017). As shown, only internal tide energy conversion resulted in a notable reduction to the deep-water discrepancies. Better nearshore bathymetry and grid resolutions do not allow for significant improvements in the internal tide energy conversion matrix compared with coarser grid models because the calculation relies mostly on the deep water satellite altimetry data in global bathymetric datasets that are still limited to $>10 \mathrm{~km}$ resolution accuracy (Goff and Arbic, 2010). Furthermore, the topographic roughness can be calculated on the relatively fine $\sim 1 \mathrm{~km}$ bathymetric grid before being interpolated onto the coarser computational grid for parameterization in barotropic models, reducing the requirement for a fine grid in the ocean.

On the continental shelf, the total free surface $\bar{D}_{t g}$ at tide gauges are 2.6 to 2.8 times larger than those in deep water for both the Comp $+I T+S V$ model setup and the TPXO8 atlas. Similar to deep water regions, the Comp $+I T+S V$ model total free surface discrepancies $\left(\bar{D}_{t g}\right.$ $\left.=13 \mathrm{~cm}, \overline{R D}_{t g}=23 \%\right)$ are 2.5 times those of the TPXO8 atlas $\left(\bar{D}_{t g}=5.4 \mathrm{~cm}, \overline{R D}_{t g}=9.2 \%\right)$ at the tide gauges on the continental shelf. The most significant factors in reducing the total free surface discrepancies on the shelf are internal tide energy conversion ( $34 \%$ reduction in $\left.\bar{D}_{t p x}\right)$ and the nearshore bathymetric datasets $\left(26 \%\right.$ reduction in $\left.\bar{D}_{t p x}\right)$. The bottom friction coefficient has a small impact overall, although the discrepancy for the $K_{1}$ constituent increased when using the spatially varying $C_{f}$ map. The GEBCO_2014 bathymetry model gives lower $\bar{D}_{t g}$ than the SRTM15_PLUS model, however $\bar{D}_{t p x}$ is quite similar between the two bathymetric datasets. Note that $\bar{D}_{t p x}$ tends to give a smoother indicator of the change between model setups because it is integrated over the whole domain (where $25<h<500 \mathrm{~m}$ ). Furthermore, $\bar{D}_{t p x}$ is $2.9 \mathrm{~cm}$ or $\sim 30 \%$ smaller than $\bar{D}_{t g}$ for $\mathrm{M}_{2}$. This could be because the shelf gauges tend to be in regions with large tidal ranges such as the northern regions of the Australian shelf and the Yellow Sea.

For comparison, Stammer et al. (2014) report that the global $\mathrm{M}_{2}$ RMSE in shelf waters is 24-49 $\mathrm{cm}$ against tide gauges and 19-28 cm versus TPXO8. Comparatively, the $\mathrm{M}_{2}$ RMSE is $13.1 \mathrm{~cm}$ against tide gauges and $10.1 \mathrm{~cm}$ versus TPXO8 for the Comp $+I T+S V$ model setup. Although it should be kept in mind that the Stammer et al. (2014) errors are global and hence they cannot be treated as a direct comparison, according to the TPXO8 atlas the total energy density (TED, defined in $§ 5.1$ ) of the $\mathrm{M}_{2}$ tidal wave is slightly higher in the IndWPac domain (820 Jm $\mathrm{Jm}^{-2}$ ) compared to the entire globe (695 $\left.\mathrm{Jm}^{-2}\right)$, suggesting a degree of difficulty for the IndWPac domain.

The RMS discrepancies at the coastal tide gauges are only marginally larger than those on the shelf for the Comp $+I T+S V$ model setup. However, the discrepancies increase significantly from the shelf to the coast when only the global bathymetry datasets are used, in particular GEBCO_2014. 

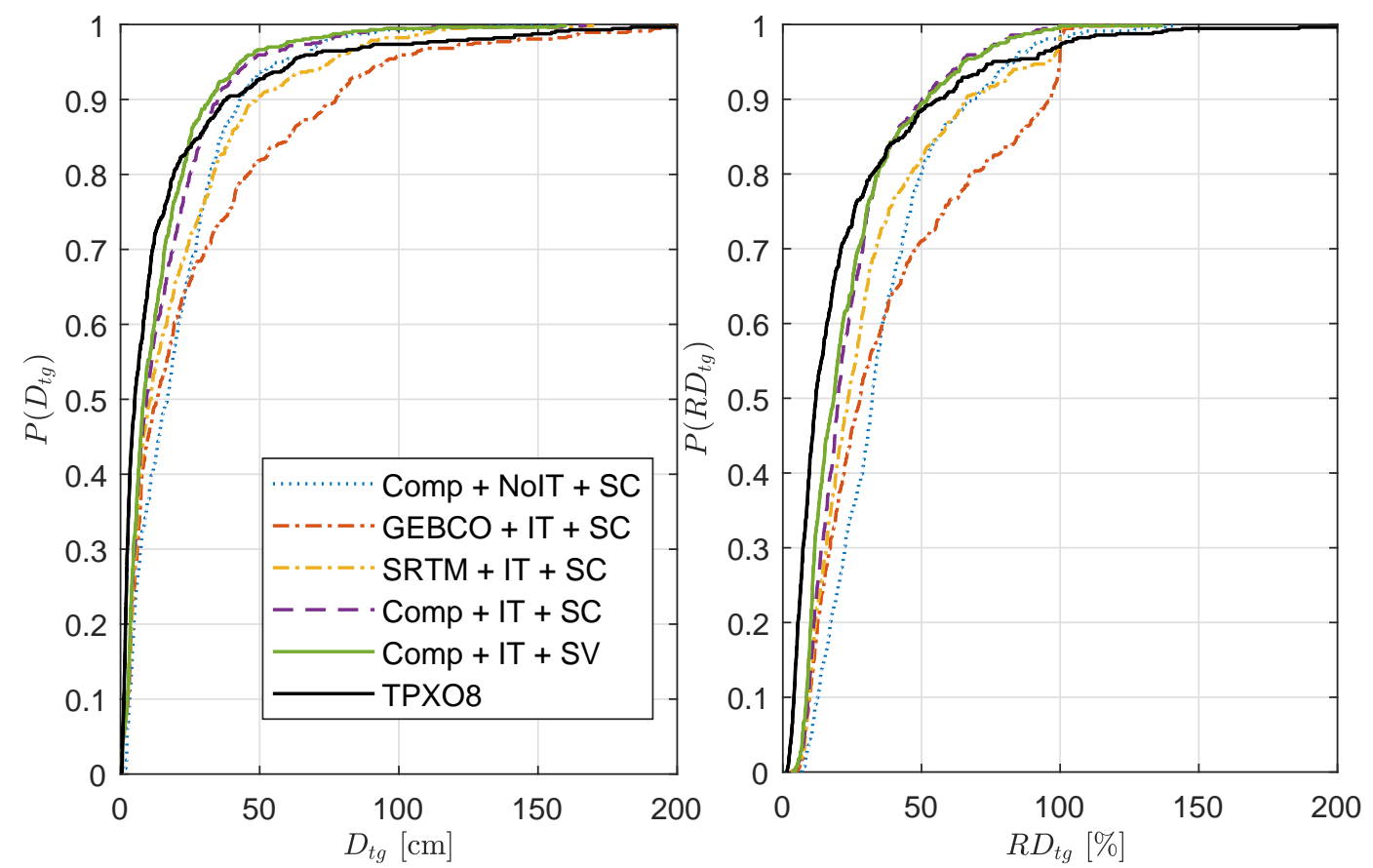

Figure 5: Cumulative distribution functions of the total free surface (up to all eight tidal constituents) RMS discrepancies $D_{t g}$ (left), and relative RMS discrepancies $R D_{t g}$ (right), versus coastal tide gauges for different IndWPac model setups (see explanation in footnotes of Table 4) and the TPXO8 atlas.

The nearshore bathymetry dataset plays a large role in reducing the discrepancy (30\% reduction in total free surface $\bar{D}_{t g}$ ). The spatially varying $C_{f}$ map has a smaller but noticeable global effect (9\% reduction in total free surface $\bar{D}_{t g}$ ). Local effects of $C_{f}$ are detailed in $\S 5.4$. At approximately $77 \%$ of the coastal tide gauge locations the total free surface $\bar{D}_{t g}$ of the Comp $+I T+S V$ model setup is less than $20 \mathrm{~cm}$ (Fig. 5), which was the target metric used for a high-resolution western North Atlantic model (much smaller in scale than IndWPac) where this is satisfied at 324 of $398(81 \%)$ locations (Technology Riverside Inc. and AECOM, 2015).

Even though the total free surface $\bar{D}_{t g}$ for the Comp $+I T+S V$ model setup is 2.5 times that of the TPXO8 atlas on the shelf, $\bar{D}_{t g}$ is $2.6 \mathrm{~cm}(15 \%)$ smaller than the TPXO8 atlas for the Comp $+I T+S V$ model setup at the coast. However, a higher percentage of locations will be within a given target discrepancy up to $\bar{D}_{t g}=24 \mathrm{~cm}\left(\overline{R D}_{t g}=35 \%\right)$ for the TPXO8 model (Fig. 5). On the other hand, the TPXO8 model cdf curves (Fig. 5) have long tails indicating a number of high-magnitude outliers, whereas this is not the case for the IndWPac model with the nearshore bathymetry included. Thus, if the solution is not significantly different from that 
offshore (and where the gauges have been included in the assimilation process), the TPXO8 model is accurate. However, due to coarse resolution and bathymetry, the TPXO8 atlas may perform poorly in areas where small-scale changes in amplitude and/or phase that can occur in bays and harbors or in-behind small islands and peninsulas are important. Comparatively, the high-resolution computational grids and bathymetric data included in the IndWPac model allow it to capture the faster changing characteristics of tides (particularly semi-diurnal ones), hence there are fewer large magnitude outliers and a smaller mean discrepancy compared with the TPXO8 atlas. However, in order to elevate the median performance at the coast it would appear that significant improvements in offshore bathymetric data and internal tide energy conversion dynamics are required if dataassimilation is not involved ( $\$ 5$ describes the sensitivities to these and other factors). In addition, it has been noted that the inclusion of atmospheric forcings and baroclinic components can lead to an improved barotropic tidal response in the region (e.g. Cai et al., 2006).

\subsection{Tidal Currents and Energy Flux Densities}

It is useful to investigate the energy flux densities and tidal currents in order to understand the hydrodynamics of the system that cannot be explained simply through tidal elevations. Furthermore, even though tidal elevations may be accurate it does not always follow that tidal currents are well represented. However, since this model has been designed to be as physically-driven a shallow water model as possible (ignoring baroclinic and atmospheric forcings for now), it is expected that the barotropic flow including tidal currents can be reasonably represented. We concentrate on the marginal seas separating the Indian Ocean and the western Pacific Ocean because this is where tidal energy is transported between the two oceanic basins, and dissipated in the process. Note that the energy flux density of the $k^{t h}$ tidal wave is computed as (Wei et al., 2016):

$$
\boldsymbol{P}^{k}=\frac{1}{2} g \rho_{0} h A^{k} \boldsymbol{U}^{k} \cos \left(\mathbf{\Theta}^{k}-\theta^{k}\right)
$$

where $\rho_{0}$ is the reference density of sea water.

$\boldsymbol{P}^{k}$ and $\boldsymbol{U}^{k}$ of the $\mathrm{M}_{2}$ and $\mathrm{K}_{1}$ tidal waves are illustrated in Fig. 6. Although not shown, the energy flux densities qualitatively agree well with those from TPXO8. Predominantly, a large amount of $\mathrm{M}_{2}$ tidal energy flows from the Indian Ocean through the Indonesian Seas, up into the Yellow Sea and around into the South China Sea. In contrast, $\mathrm{K}_{1}$ tidal energy flows down from the northeast of the western Pacific Ocean into the South China Sea and the Indonesian Sea. Thus, the Luzon Strait and the Indonesian Seas play a large role with regards to the tidal dynamics of the domain. The Luzon Strait is known for the generation of large internal tides, where the energy conversion of 


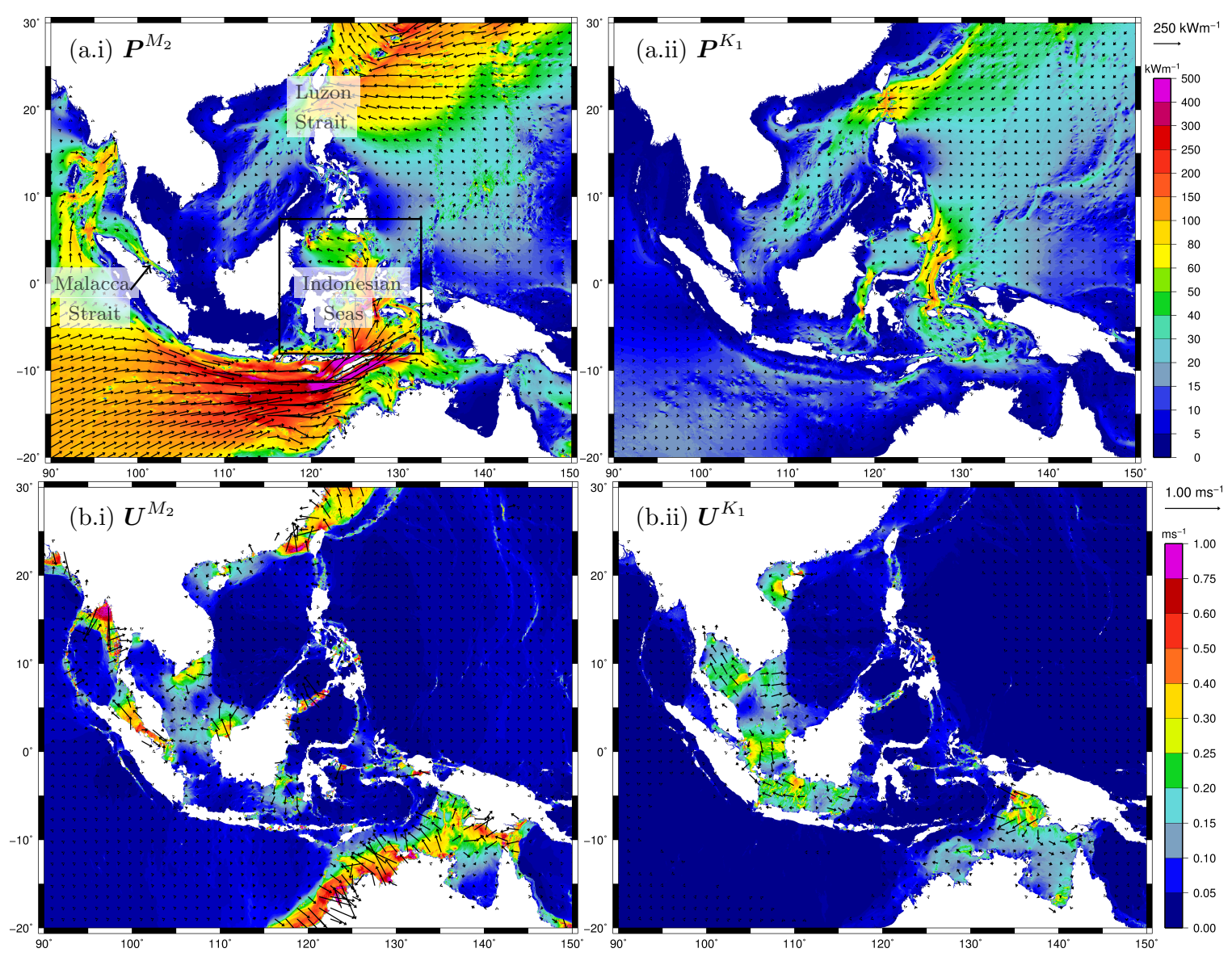

Figure 6: (a) Energy flux densities $\boldsymbol{P}^{k}$, and (b) amplitudes of the east and north components of the tidal currents $\boldsymbol{U}^{k}$ of the (i) $\mathrm{M}_{2}$ and (ii) $\mathrm{K}_{1}$ tidal waves in the marginal seas separating the Indian Ocean from the western Pacific Ocean.

this effect is parameterized in this study (see §5.3.3). In addition, the Indonesian Seas (e.g. Celebes Sea and Banda Sea) are fairly deep compared to the shelves of the Java Sea and the South China, so bottom friction dissipation does not play a large role as confirmed by the presence of mostly small tidal currents throughout this region (Fig. 6). Instead, internal tide conversion parameterization over the high gradient shallow island chains where tidal currents become locally large is likely to be important here. A portion of the $\mathrm{M}_{2}$ tidal energy also flows through the shallow and narrow Malacca Strait where high magnitude tidal currents are generated (Fig. 6), thus bathymetry and bottom friction are expected to be important here. 

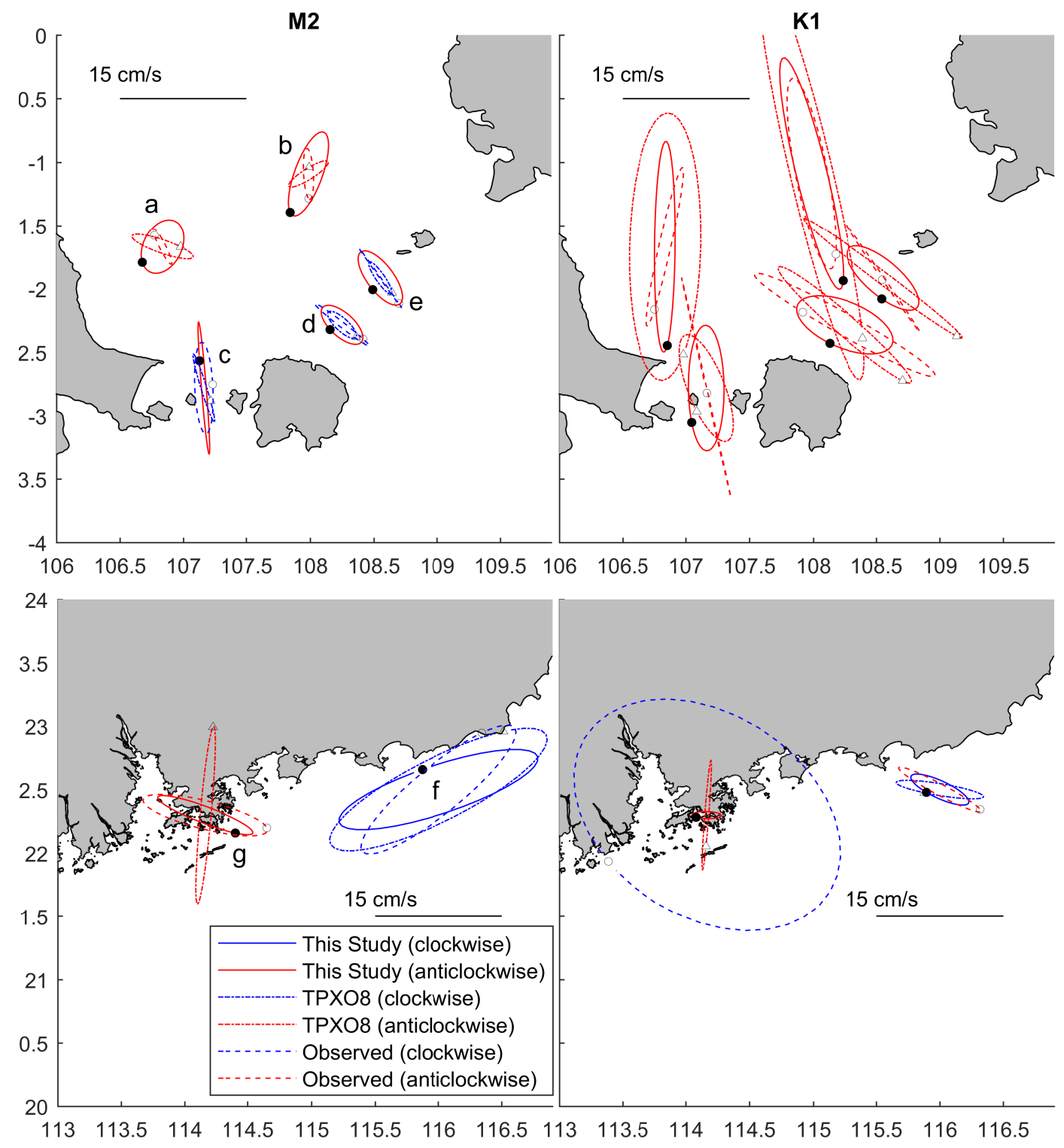

Figure 7: Comparisons of the tidal ellipses of the $\mathrm{M}_{2}$ (left) and $\mathrm{K}_{1}$ (right) tidal waves in the region between the Java Sea and the South China Sea (top) and in the northern South China Sea near Hong Kong (bottom), between the Comp $+I T+S V$ model setup in this study, TPXO8 and observations. The dots on the ellipses indicate the tips of the tidal current vectors at 00:00 GMT.

Tidal current harmonic constituent observations were obtained in the region between the Java

Sea and the South China Sea (locations a-e), and in the northern South China Sea near Hong Kong 
Table 5: The RMS discrepancy of the $\mathrm{M}_{2}$ and $\mathrm{K}_{1}$ tidal current ellipses $D_{T C}$ (units: $\mathrm{cm} \mathrm{s}^{-1}$ ) versus observations for our best model setup $(C o m p+I T+S V)$ and the TPXO8 atlas. The locations are indicated in Fig 7.

\begin{tabular}{|c|l|cc|}
\hline Location & Model & $D_{T C}^{\mathrm{M}_{2}}$ & $D_{T C}^{\mathrm{K}_{1}}$ \\
\hline \multirow{2}{*}{$\mathrm{a}$} & Comp $+I T+S V$ & 2.58 & 3.40 \\
& TPXO8 & 4.06 & 5.30 \\
\hline \multirow{2}{*}{$\mathrm{b}$} & Comp $+I T+S V$ & 2.15 & 2.37 \\
& TPXO8 & 3.38 & 9.68 \\
\hline \multirow{2}{*}{$\mathrm{c}$} & Comp $+I T+S V$ & 2.58 & 5.68 \\
& TPXO8 & 1.87 & 5.47 \\
\hline \multirow{2}{*}{$\mathrm{d}$} & Comp $+I T+S V$ & 2.87 & 5.04 \\
& $T P X O 8$ & 1.94 & 11.3 \\
\hline \multirow{2}{*}{$\mathrm{e}$} & Comp $+I T+S V$ & 2.73 & 2.96 \\
& $T P X O 8$ & 1.56 & 8.56 \\
\hline \multirow{2}{*}{$\mathrm{f}$} & Comp $+I T+S V$ & 6.55 & 4.96 \\
& TPXO8 & 2.79 & 5.59 \\
\hline \multirow{2}{*}{$\mathrm{g}$} & Comp $+I T+S V$ & 5.02 & 14.8 \\
& $T P X O 8$ & 9.84 & 12.5 \\
\hline
\end{tabular}

(locations $f-g$ ), in which tidal ellipses are plotted in Fig. 7, and their RMS discrepancies $D_{T C}$ at each location for the IndWPac model and for the TPXO8 atlas are summarized in Table 5. These observations are in fairly low energy regions (Fig. 6), which in some cases may make a model more susceptible to discrepancies without constraints on the solution. In particular, for the $\mathrm{M}_{2}$, although the direction and magnitude of the flow is fairly accurate in locations $c-e$ in the Java Sea where the $\mathrm{M}_{2}$ tide is very small, the rotation of the tidal ellipse is anticlockwise in the IndWPac model, but is clockwise according to observations and TPXO8. As $D_{T C}^{\mathrm{M}_{2}}$ is smaller for TPXO8 at locations $c$-e, but is smaller in the IndWPac model at $a-b$. On the other hand, the $\mathrm{K}_{1}$ tide is larger than $\mathrm{M}_{2}$ in the Java Sea region, and the rotation of the tidal ellipse is in agreement at all locations a-e. Furthermore, $D_{T C}^{\mathrm{K}_{1}}$ for the IndWPac model is significantly smaller than those for TPXO8 at most locations.

In the northern South China Sea, there is good qualitative agreement in the tidal ellipses between 
the IndWPac model and the observations for the $\mathrm{M}_{2}$ tide, but less so for $\mathrm{K}_{1}$. Note that location $g$ is in a coastal region near Hong Kong, and that the observations are surface currents, where both the IndWPac model and TPXO8 have large $D_{T C}^{\mathrm{K}_{1}}$. Thus, perhaps for the $\mathrm{K}_{1}$ constituent there is a significant 3D effect or atmospheric-driven response at this location given Cai et al. (2006) was able to obtain a tidal current solution closer to observations than our model when using a 3D model forced with winds and baroclinicity. Based on the plots and discrepancies of the tidal ellipses, the tidal currents in the northern South China Sea are not clearly better or worse in the IndWPac model compared with TPXO8.

\section{Sensitivities to Lateral Boundary Conditions, Bathymetry, and Dissipative Controls}

\subsection{Lateral Boundary Conditions}

In this study it was found that the most dramatic effect on the solution occurred when modifying the position and/or lateral boundary condition type (Fig. 8). It turns out that the boundaries used in the final IndWPac model (which we call the 'two-open-boundaries domain' in this section) are well placed. In the initial stages of the IndWPac model, the domain was set up so that the western Pacific boundary was split into two separate boundaries where one of the boundaries was defined spanning from the Great Australian Bight down to Antarctica parallel with latitude (designated as the 'three-open-boundaries domain'). The impact of the absorption-generation sponge layer is also of concern with regards to the ability to absorb outgoing waves, reduce reflections and instabilities, and generate tidal solutions at the boundary. To help evaluate the effect of the lateral boundary position and boundary condition type we quantify the total energy, $T E$ and total energy dissipation, $T D$ of the $k^{\text {th }}$ tidal constituent, which are computed by:

$$
\begin{aligned}
T E^{k} & =\frac{\rho_{0}}{2} \iint\left(h\left|\boldsymbol{U}^{k}\right|^{2}+g\left(A^{k}\right)^{2}\right) d A \\
T D^{k} & =\iint\left(W^{k}-\nabla \cdot \boldsymbol{P}^{k}\right) d A
\end{aligned}
$$

where $W$ is the work rate (c.f. Egbert and Ray, 2001), and $\boldsymbol{P}$ is the energy flux (15). Since the numerical calculation of $\nabla \cdot \boldsymbol{P}$ with finite precision is very noisy, in this work the area-integral is computed using the divergence theorem. Note that the absorption-generation sponge layer region is omitted from the above area-integrals, and we quote $T E$ and $T D$ values per unit area to help in enabling comparisons across the domains which have different total areas. Four simulations are conducted: the two-open-boundaries domain with and without an absorption-generation sponge 

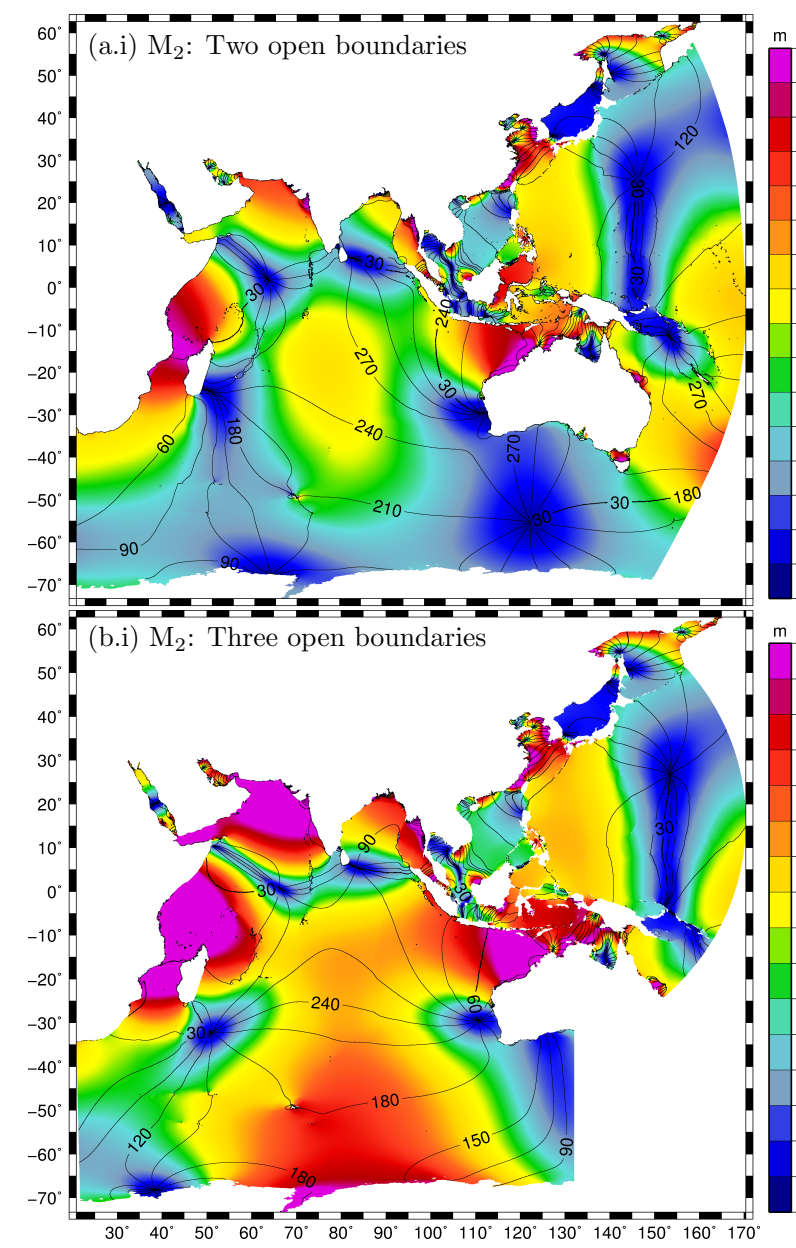

layer, and the three-open-boundaries domain with and without a sponge layer. None of these simulations use internal tide energy conversion and a spatially constant $C_{f}=2.5 \times 10^{-3}$ is employed.

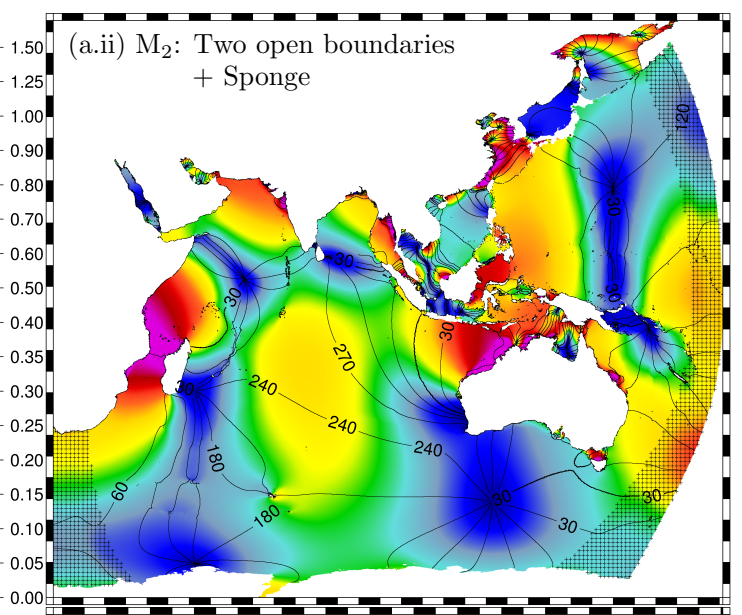

Figure 8: Responses of the $\mathrm{M}_{2}$ tidal wave with no internal tide energy conversion, and spatially constant $C_{f}=2.5 \times 10^{-3}$; (i) no absorption-generation sponge layer, (ii) with absorption-generation sponge layer (' + ' hatched regions indicate sponge layer), (a) two-open-boundaries domain, (b) three-open-boundaries domain.

\subsubsection{Boundary Placement Effects without Sponge Layer}

For simulations without the sponge layer, $T E^{\mathrm{M}_{2}}=900 \mathrm{Jm}^{-2}$ for the two open boundaries domain and $T E^{\mathrm{M}_{2}}=3210 \mathrm{Jm}^{-2}$ when using the three open boundaries domain, essentially a $250 \%$ increase. Similarly, $T D^{\mathrm{M}_{2}}=4.5 \mathrm{~mW}^{-2}$ and $T D^{\mathrm{M}_{2}}=8.5 \mathrm{~mW}^{-2}$ for the two and three open boundaries 
domain, respectively. For comparison, $T E^{\mathrm{M}_{2}}=830 \mathrm{Jm}^{-2}$, and $T D^{\mathrm{M}_{2}}=7.2 \mathrm{~mW}^{-2}$ in the TPXO8 atlas within the two open boundaries domain. In this experiment the excess in total energy and deficit in the total dissipation (per unit area) respectively, between the two open boundaries domain IndWPac and TPXO8 solutions is at least partly explained by the absence of internal tide energy conversion. The effect on the solution due to boundary placement is not nearly as prominent for the diurnal $\mathrm{K}_{1}$ tidal wave. For example, $T E^{\mathrm{K}_{1}}=288 \mathrm{Jm}^{-2}$ for the two open boundaries domain and $298 \mathrm{Jm}^{-2}$ for the three open boundaries domain, representing a small $3.5 \%$ increase. Most other constituents also show single digit percent increases in the total energy except for the other two lunar semi-diurnal tides, $\mathrm{K}_{2}$ and $\mathrm{N}_{2}$. In particular, $\mathrm{K}_{2}$, whose response is most similar looking to $\mathrm{M}_{2}$, has a $231 \%$ increase. $\mathrm{N}_{2}$ is increased by $31.4 \%$.

\subsubsection{Effects of Sponge Layer}

It is found that applying the absorption-generation sponge layer even for the three open boundaries domain can result in improved responses (Fig. 8(b.ii)) reducing $T E^{\mathrm{M}_{2}}$ to $1040 \mathrm{Jm}^{-2}$, and $T D^{\mathrm{M}_{2}}$ to $5.3 \mathrm{~mW}^{-2}$. The sponge layer thus allows for significant leeway in boundary positioning but it does not necessarily entirely eliminate issues in the response. Note how in the two-open-boundaries domain the amphidrome in the Southern Ocean below Australia is located near where the third open boundary is. The sponge acts to push this amphidrome away from the boundary because the three-open-boundaries IndWPac model solution and the TPXO8 solution are incompatible here. This indicates reliance on internal dissipative mechanisms to ensure compatibility with each other. For example, in our best model setup (with the sponge layer applied) when appropriate internal tide energy conversion is included better compatibility is obtained leading to $T E^{\mathrm{M}_{2}}=780 \mathrm{Jm}^{-2}$, and $T D^{\mathrm{M}_{2}}=7.1 \mathrm{~mW}^{-2}$, which are rather similar to the values from the TPXO8 atlas quoted in $\S 5.1 .1$.

\subsubsection{Discussion}

What to make of the dramatic results to the solution due to boundary placement and condition types? Firstly, even though there should not be an amphidrome right next to the boundary according to the TPXO8 solution (although the elevations are still fairly small), our model without adequate internal dissipative effects expects there to be one. Instabilities and problems may arise near amphidromes because a physically incorrect solution that satisfies the governing equations can be obtained. Mathematically, both boundary conditions and initial conditions are required to get the correct solution. Instead, the method commonly adopted (including in this study) is to impose the elevation boundary conditions and ramp up the system from a completely zero state. We found from 
a simple test case that, when internal dissipative effects are low, ramping generates spurious modes that persist for very long periods of time. Secondly, the Indian Ocean and the Australian/Indonesian marginal seas appear very sensitive to fluctuations in fluxes on the boundary, in particular without adequate abyssal dissipation, but even when internal tide energy conversion was included the three-open-boundaries domain without the sponge layer did not converge to a suitable solution. In studies of free barotropic oscillations (Platzman, 1975; Zahel and Müller, 2005), resonant modes around 9.20-11.65 hour show similar patterns to the lunar semi-diurnal tides in the Indian Ocean. Furthermore, the energy density of the 11.65 hour mode is 2.2 times the global average in the Indian Ocean (Zahel and Müller, 2005). Hence the resonant nature of the lunar semi-diurnal tides in this basin causes the total energy to increase wildly in response to the poor boundary conditions.

The absorption-generation sponge layer reduces reflections at the boundary allowing the spurious modes to exit the domain. By introducing external information as part of the governing equations, the sponge layer is applicable to a wide range of conditions. In contrast, a radiation type condition is difficult to devise in the case where actively imposing external information is required because you need to identify regions of inflow (Lavelle and Thacker, 2008), which may be time dependent. However, one of the main issues with using the absorption-generation sponge layer is the reliance on the reference solution. In particular, because only the sea surface is assimilated, tidal fluxes obtained from TPXO8 may be less likely to be as accurate or compatible with the IndWPac model as the tidal elevations.

\subsection{Bathymetry}

Bathymetry is a boundary condition for oceanic models hence its importance to the solution is clear. Recent years have shown marked improvements in global bathymetric databases such as SRTM15_PLUS and GEBCO_2014. This section begins by outlining the effects of using one of these databases over the other, followed by effects between SRTM15_PLUS and our more comprehensive bathymetric data (Table 1). The section concludes with a discussion on the results and implications.

\subsubsection{Comparisons between Global Bathymetric Databases}

Current global bathymetric databases SRTM15_PLUS and GEBCO_2014 are sufficiently accurate that they do allow us to obtain mean RMS discrepancies $\sim 3 \mathrm{~cm}$ for the $\mathrm{M}_{2}$ tidal wave in the deep ocean. Nevertheless, there is still a reasonable level of uncertainty between them (Fig. 9(a)). For example, on the abyssal hills the use of statistical roughness (Goff and Arbic, 2010) to calculate a new bathymetry set (Timko et al., 2017) has been undertaken to account for the effective coarseness 
of satellite altimetry-derived bathymetry (note that the SRTM15_PLUS database used here is a combination with SRTM30_PLUS that contains the synthetic realization of the abyssal hill roughness but GEBCO_2014 is without it). To investigate the effects of the global bathymetric databases we compute one simulation using SRTM15_PLUS with abyssal hill roughness everywhere $(S R T M I T+$ $S C$ ) and another using GEBCO_2014 everywhere $(G E B C O I T+S C$ ). RMS differences between the simulations for the $\mathrm{M}_{2}$ tidal wave are plotted in Fig. 9(b). Optimal internal tide energy conversion factors $(I T)$ and spatially constant $C_{f}=2.5 \times 10^{-3}(S C)$ are employed for both.

Along the ocean ridges that include a synthetic realization of the abyssal hill roughness, the normalized bathymetric differences are in the range 5-25\%, except for the Southwest Indian Ocean Ridge, where the normalized bathymetric differences can exceed $50 \%$ in spots (Fig. 9(a)). Despite this, $M_{2}$ RMS differences in deep water do not exceed $2 \mathrm{~cm}$ anywhere except east of Australia and New Guinea (Fig. 9(b)), i.e. the RMS differences between responses resulting from the two global bathymetric databases tend to be much less than RMS discrepancies between Comp $+I T+S V$ model setup and TPXO8 (Fig. 2(c.i)). Note that, although differences in the bathymetry should change the internal tide energy conversion matrix, we use the same matrix as the Comp $+I T+S V$ model setup for both simulations to help identify strictly bathymetric effects.

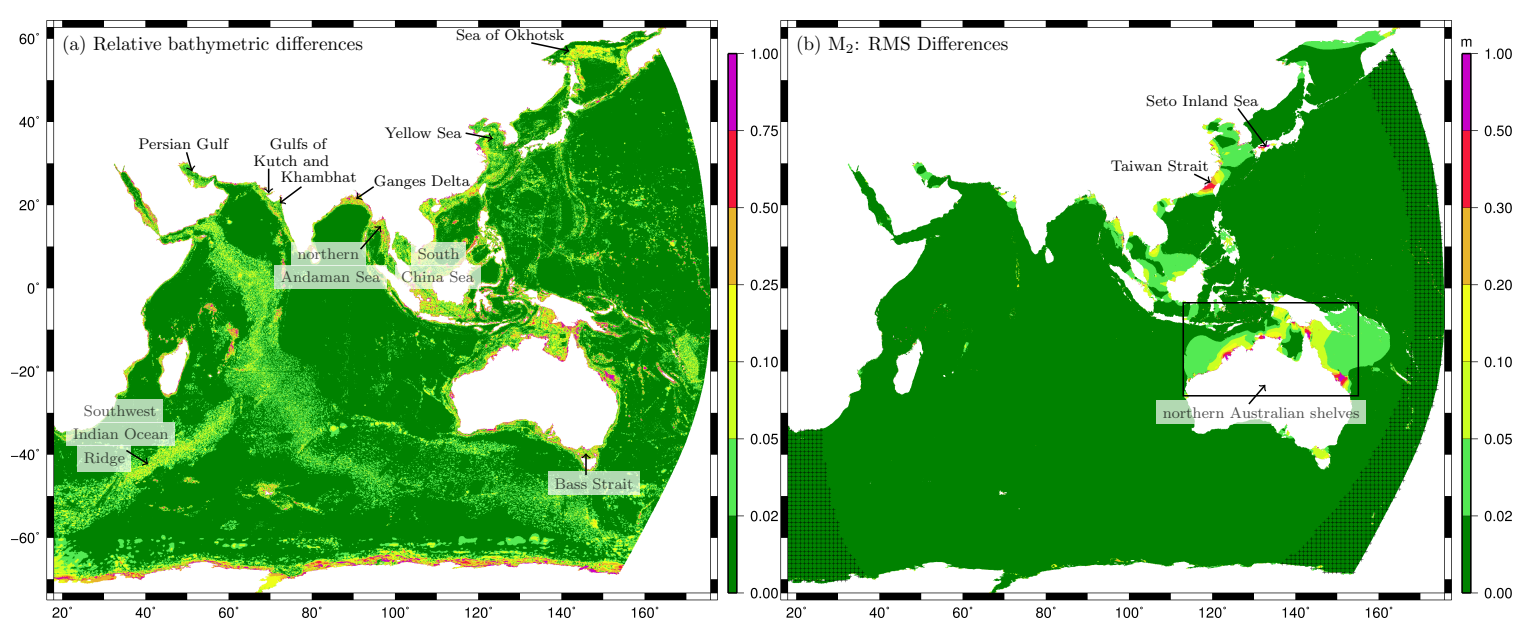

Figure 9: Differences between SRTM15_PLUS with abyssal hill roughness (Goff and Arbic, 2010) and GEBCO_2014 global bathymetric databases. (a) Normalized differences in the bathymetry, (b) $\mathrm{M}_{2}$ RMS differences in the responses between the GEBCO IT $+S C$, and SRTM IT $+S C$ model setups (see Table 4 for description of model setups). '十' hatched regions indicate absorption-generation sponge zone. 
Major normalized bathymetric and RMS differences are unsurprisingly found in shallow waters such as the South China Sea, Bass Strait, Yellow Sea, Sea of Okhotsk, Ganges Delta, northern Andaman Sea, Persian Gulf, and the Gulfs of Khambhat and Kutch (Fig. 9). The most astounding RMS differences are located on the northern Australian shelves, the Taiwan Strait and the Seto Inland Sea (Fig. 9(b)). In particular, the RMS differences in the Coral Sea and around Torres Strait (Fig. 9(b)) are larger than the discrepancies between the Comp $+I T+S V$ model setup and TPXO8 (Fig. 2(c.i)). According to the sources of GEBCO_2014, the 2009 Australian Bathymetry and Topography Grid (Whiteway, 2009) is used around the Australian continent. Within this dataset, some of the nearshore bathymetry is made up of multibeam, Laser Airborne Depth Sounder, and nautical charts, with the rest based on 1 arc min and 2 arc min ETOPO satellite derived bathymetry. In comparison, SRTM15_PLUS is said to include $50 \mathrm{~m}$ multibeam datasets from 2012 as well as the Deepreef Explorer GBR dataset from 2010 (both newer than the 2009 Australian Bathymetry and Topography Grid).

\subsubsection{Comparisons between SRTM15_PLUS and Local High-Resolution Bathymetry}

Another issue with a global bathymetric dataset such as SRTM15_PLUS is that on the shelf and nearshore the resolution can be too coarse and it may contain holes in the bathymetry, thus it is not completely reliable for accurate regional simulations. This section outlines the differences between SRTM15_PLUS and our more comprehensive bathymetric data (Table 1) containing local high-resolution datasets. We focus on three regions: the East China Sea including the Yellow Sea and southern Japan; the South China Sea including the Philippines Seas and north Java Sea; and the Coral Sea including the Torres Strait (Fig. 10).

All nearshore areas in the East China Sea show significant normalized bathymetric differences aside from Hong Kong which contains our smallest element sizes (Fig. 10(a.i)). Due to numerous spurious large depths in the SRTM15_PLUS dataset in this region we replace this area with the local high-resolution bathymetry in order to avoid instabilities due to violation of the CFL condition. This is not thought to have a large effect on the results of the comparisons between the bathymetric datasets and the conclusions that we draw from them. The simulations show large RMS differences of the $\mathrm{M}_{2}$ tidal wave in the Taiwan Strait and Seto Inland Sea (Fig. 10(a.ii)) but interestingly they are not as large as those between GEBCO and SRTM15_PLUS (Fig. 9(b)), nor are differences in the Gulf of Tonkin as pronounced. It should be mentioned that we noticed reduced discrepancies at tide gauges in the Seto Inland Sea when using the high-resolution bathymetry. It is a complicated region with many small islands and channels and requires accurate connectivity of the energy fluxes 


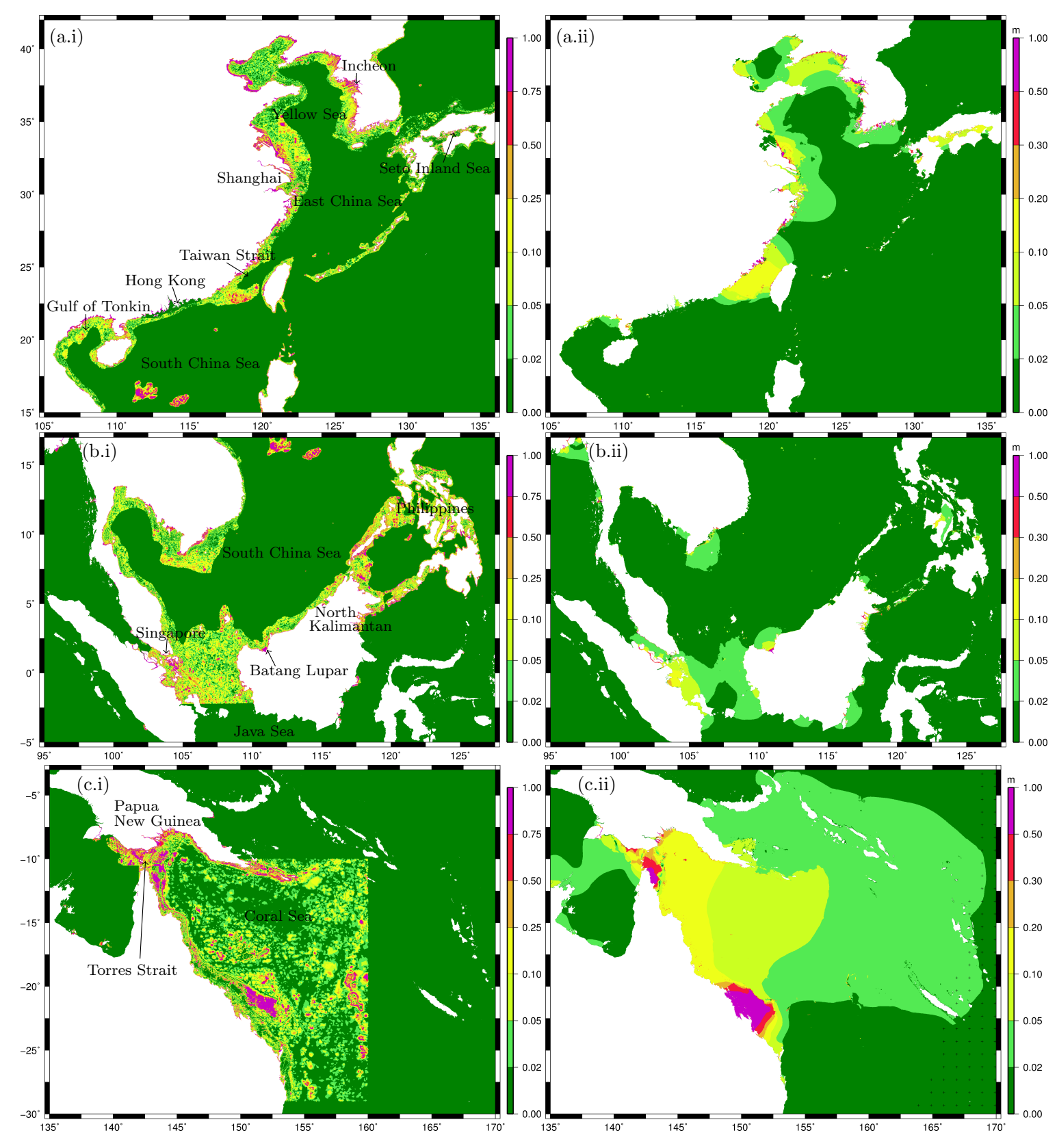

Figure 10: Differences between SRTM15_PLUS with abyssal hill roughness (Goff and Arbic, 2010) and our comprehensive bathymetric data (Table 1) containing local high-resolution datasets. (i) Normalized differences in the bathymetry, (ii) $\mathrm{M}_{2}$ RMS differences in the responses between $S R T M+I T+S C$ and Comp $+I T+S C$ model setups (see Table 4 for description of model setups). (a) East China Sea, (b) South China Sea, (c) Coral Sea. 
to improve results. Most of the RMS differences in the Yellow Sea between SRTM15_PLUS and the local high-resolution bathymetry (Fig. 10(a.ii)) are larger than those between GEBCO and SRTM15_PLUS (Fig. 9(b)), in particular north of Shanghai and in the Incheon area. However, generally these differences are smaller than the discrepancies between TPXO8 and the Comp + IT $+S V$ model setup.

Despite widespread normalized bathymetric differences in the Philippines and the region between the South China Sea and Java Sea (Fig. 10(b.i)), small RMS differences in the $\mathrm{M}_{2}$ tidal wave result with the exception of a few channels near Singapore, and in the gulfs near Batang Lupar and North Kalimantan, both on Borneo (Fig. 10(b.ii)). This is perhaps partly because the $\mathrm{M}_{2}$ amplitudes are relatively small in the region between the South China Sea and Java Sea (Fig. 2(a.i)). Although it is not shown, the larger $\mathrm{K}_{1}$ (Fig. 2(a.ii)) produces up to 10-30 cm RMS difference in the area south of Singapore but is not notable elsewhere. In the two gulfs on Borneo, which have fairly large $\mathrm{M}_{2}$ tidal ranges (up to $1.7 \mathrm{~m}$ in the gulf near Batang Lupar, Fig. 2), the differences result not only from local high-resolution bathymetric datasets but are due to hand-edits vis-à-vis FUGAWI navigational charts. Areas like the gulf near Batang Lupar can be extremely sensitive to bathymetry particularly deep in the gulf where the v-shape concentrates the tidal energy. The effect of our hand-edits is to deepen the area near Batang Lupar allowing the tidal range to reach close to the measured one.

The final region is the Coral Sea which demonstrably shows large widespread normalized bathymetric differences (Fig. 10(c.i)). This is slightly perplexing as SRTM15_PLUS should include the Deepreef Explorer GBR dataset according to their references (ftp://topex . ucsd.edu/pub/srtm15_ plus/). However, the SRTM15_PLUS version used in this study does not seem to have it incorporated. The bathymetry in the Torres Strait and Papua New Guinea region is also very different from SRTM15_PLUS, where we have used GEBCO_2014 in our more comprehensive bathymetric dataset. This is because GEBCO_2014 matches rather well with Deepreef Explorer GBR at the interface whereas SRTM15_PLUS does not. The resulting $\mathrm{M}_{2}$ RMS differences shown here (Fig. 10(c.ii)) are certainly large and often well exceed discrepancies between our model and TPXO8 (Fig. 2). In fact, in most of the Coral Sea the Comp $+I T+S V$ model setup is performing rather well with respect to TPXO8 which could be largely attributed to the Deepreef Explorer GBR dataset. Significant discrepancies for our model against TPXO8 and tide gauges are still present near the Torres Strait (Fig. 10(c.ii)) where opposing $\mathrm{M}_{2}$ energy fluxes meet over the strait (Fig. 6). The residual discrepancy here is likely a combination of the remaining uncertainties in the GEBCO_2014 bathymetry (based on 2009 Australian Bathymetry and Topography Grid), and bottom friction dissipation. 


\subsubsection{Discussion}

The effect of different bathymetric datasets is not shown to be an important factor in the deep ocean, but on the shelf and nearshore there are certain regions where bathymetry plays a large role. This has been also highlighted in terms of the global RMS discrepancies presented in $\S 4.4 .2$ (summarized in Table 4). In some cases, the RMS differences between simulations using different bathymetric datasets are greater than discrepancies between TPXO8 and the Comp $+I T+S V$ model setup, particularly between the two global bathymetric datasets. Our more comprehensive bathymetric data and SRTM15_PLUS are mostly the same except nearshore in certain regions which is likely the reason for smaller RMS differences in general.

As discussed in previous studies (e.g. Egbert et al., 2004; Green, 2010; Zaron, 2017), bathymetry has the potential to control the tidal elevation particularly through resonant effects that are in general nonlocal. For example, the effect of the Deepreef Explorer GBR high-resolution bathymetry is to change the $\mathrm{M}_{2}$ elevation over a large area beyond the Coral Sea out into the deep ocean. Conversely only small changes are noted throughout the region between the South China Sea and Java Sea. More locally, in a resonant basin such as the gulf near Batang Lupar, hand-edits of the bathymetry based on FUGAWI navigational charts allow the tidal elevation to reach close to the measured $\mathrm{M}_{2}$ amplitude. Clearly, greater availability and quality of nearshore and shelf bathymetry has the potential to greatly improve the modeling not only of tides but all shallow water flows.

With regards to the effect of the bathymetry in the deep ocean, it should be noted that bathymetry will affect internal tide energy conversion as the dissipation matrix is based on topographic depths and slopes. So technically, the deep ocean may be more impacted than is shown here taking this aspect into account. Nevertheless, addition of the abyssal hill roughness, for example, has only marginally increased the fidelity of ocean models (Buijsman et al., 2015; Timko et al., 2017). In 3D baroclinic models (Arbic et al., 2010, 2012; Timko et al., 2017) this can be explained in part by limitations of resolution. On the other hand, 2D barotropic models such as IndWPac can achieve high resolution over a wide-scale, but may be somewhat limited by the underlying assumptions of internal tide energy conversion no matter the bathymetric data. Greater discussion on this aspect is presented in the next section.

\subsection{Internal Tide Energy Conversion}

In the two internal tide energy conversion parameterizations ( $\S 3.3)$, it is necessary to calibrate a global amplification factor due to unknowns involved with the resolution of the bathymetric data 
and the way in which dissipation that is overestimated at supercritical slopes is handled, due to their linear assumptions. In addition to finding these amplification factors, this section discusses the differences between the two parameterization methods, introduces multiplier coefficients due to semi-diurnal resonance in the Luzon Strait, and concludes with some final remarks on reasons for differences between the methods and remaining issues for the parameterization of internal tide energy conversion.

\subsubsection{Calibrating Amplification Factors}

We begin by trying to determine the optimal values of $C_{N y c}$ and $C_{D i r}$ for the IndWPac model before comparing the performance of both parameterization methods. This is evaluated by looking at $\bar{D}_{t p x}$ for the $\mathrm{M}_{2}$ and $\mathrm{K}_{1}$ tidal waves in deep water $(h>500 \mathrm{~m})$ with a spatially constant bottom friction, $C_{f}=2.5 \times 10^{-3}$. To a lesser degree, we are also interested in the total dissipation $T D$ of individual tidal constituents. Comparisons of $\bar{D}_{t p x}$ versus $T D$ in deep water for the $\mathrm{M}_{2}$ and $\mathrm{K}_{1}$ tidal waves are shown in Fig. 11(a),(b) using four different values of amplification factors for each method.
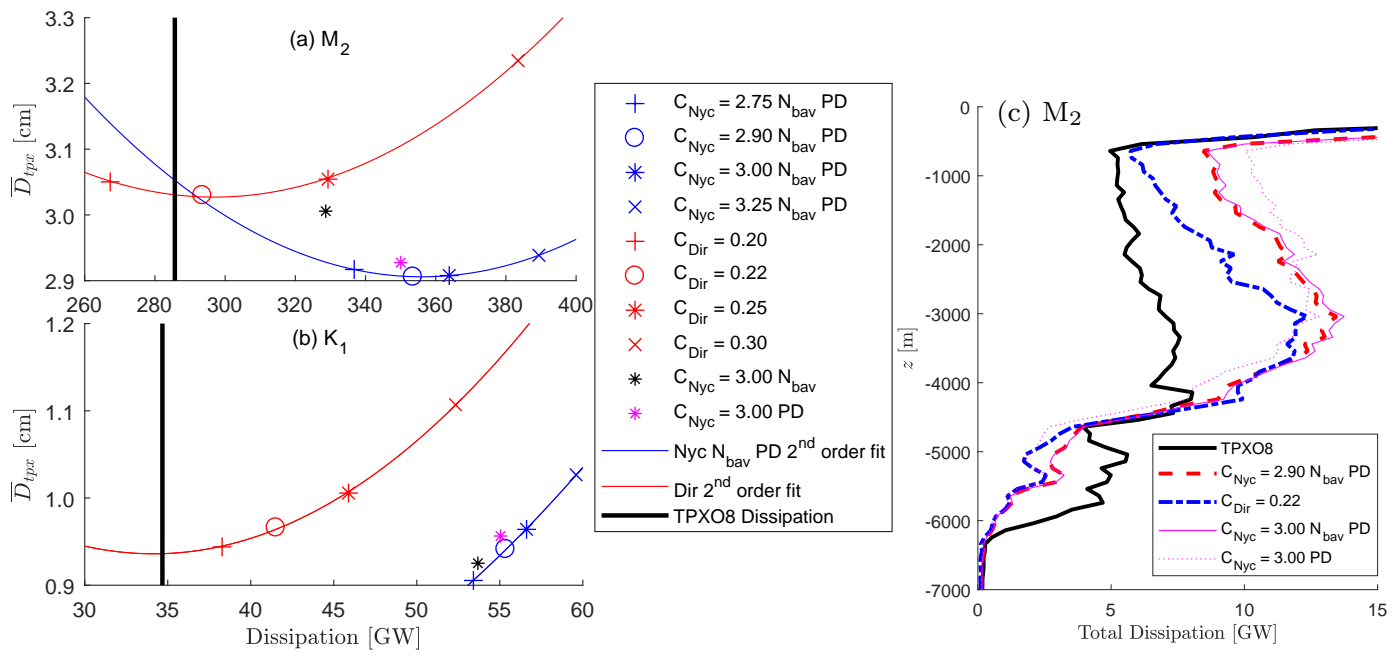

Figure 11: Deep water total dissipation $T D$ for the IndWPac model using different internal tide parameterization methods and amplification factors, and for the TPXO8 model. (a) $\mathrm{M}_{2}$, (b) $\mathrm{K}_{1}$; TD versus RMS discrepancy in deep water $(h>500 \mathrm{~m})$ with $2^{\text {nd }}$ order polynomial fits. (c) Bathymetric depth versus total dissipation TD (summed in $100 \mathrm{~m}$ depth bins) for the $\mathrm{M}_{2}$ tidal wave.

Regarding the $\mathrm{K}_{1}$ tidal wave, amplification factors slightly smaller than the values tested appear optimal in both parameterization methods. However, we focus on the results of the $\mathrm{M}_{2}$ tidal wave to 
determine the optimal amplification factors. This leads to $C_{N y c} \approx 2.9$ and $C_{D i r} \approx 0.22$ based on a second-order polynomial best fit. For comparison, Buijsman et al. (2015) determined $C_{N y c} \approx 2.75$, which is in close agreement. Furthermore, two modifications are applied to the Nonlocal method. The first modification simply ensures that the dissipation matrix is positive definite (PD). A second modification involves applying Gaussian smoothing of $N_{b}$ (to obtain a variable denoted as $N_{\text {bav }}$ ) using the same radius and scaling as the convolution integral for $J$, the argument being that nonlocal effects of buoyancy may be just as important as nonlocal effects of topography. Both modifications create more dissipation and make $\bar{D}_{t p x}$ for $\mathrm{M}_{2}$ smaller for the same value of $C_{N y c}$ (Fig. 11), with the PD modification having the largest effect.

\subsubsection{Differences between Parameterization Methods}

Two opposing outcomes result from the comparison between the Nonlocal and Local methods. For both constituents, the Nonlocal method leads to slightly smaller values of $\bar{D}_{t p x}$, while $T D$ at the optimal amplification factor matches TPXO8 in deep water more closely for the Local method. Since TPXO8 can be reliably validated for elevations but not for dissipation we are inclined to prefer the Nonlocal method, thus it is incorporated into our best model results presented in $\S 4$. It is however worth pointing out that the difference between the methods is no more than $15 \mathrm{~mm}$ in $\bar{D}_{t p x}$ for $\mathrm{M}_{2}$, thus the Local method can be considered a very useful parameterization in its own right - not least because it can be quickly calculated and introduced to a numerical model.

With regards to total dissipation, the optimal Nonlocal method results in $24 \%$ greater $\mathrm{M}_{2} T D$ compared with TPXO8 (see Fig. 12 for a comparison of the dissipation densities computed through (17) sans the area-integral). The global HYCOM model has a similar $T D$ ratio (23\% greater) versus TPXO8 (Buijsman et al., 2015), who note that the TPXO8 dissipation rates are diffused over large areas in comparison to the parameterized internal tide energy conversion in their model (we also see this in Fig. 12). In that sense it is somewhat unclear how reliable TPXO8 dissipation in deep water may be. Issues with tidal dissipation in global data-assimilated models have been previously highlighted (Lyard et al., 2006; Le Provost and Lyard, 1997), and there are large regions of negative dissipation rates when computing this with the TPXO8 solutions (Fig. 12(b)).

Depth-wise the characteristics of local and large-scale nonlocal topographic effects tend to translate into the Nonlocal method creating greater dissipation in shallower depths (Fig. 11(c)). Both methods give large amounts of dissipation in the 3000 - $4000 \mathrm{~m}$ range corresponding to abyssal hills, but a general observation we find is that the Nonlocal method focuses dissipation towards the center peaks of the ridges whilst the Local method tends to spread dissipation over the width of the ridge. 


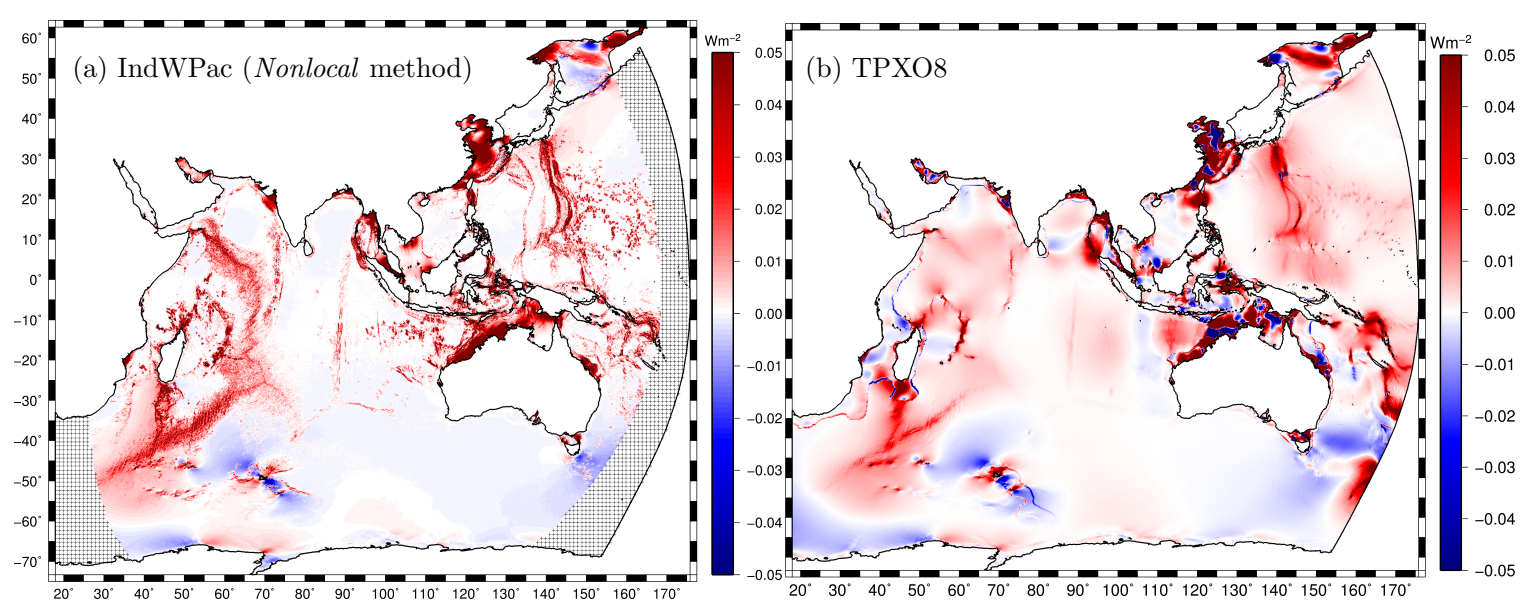

Figure 12: Total dissipation densities (computed using (17) with the area-integral omitted) of the $\mathrm{M}_{2}$ tidal wave for; (a) IndWPac model (Nonlocal method, $C_{N y c}=2.90$ with PD and $N_{\text {bavg }}$ corrections); (b) the TPXO8 model atlas.

As mentioned above, it remains unclear whether the overestimate in dissipation from both schemes in the $500-4000 \mathrm{~m}$ depth range (and underestimate in the $4500-6000 \mathrm{~m}$ range) is a major cause of concern or it simply reflects the coarseness of the data-assimilated model. Buijsman et al. (2015) found similar trends (to this study) for their global model.

The differences in amplitudes of the $\mathrm{M}_{2}$ tidal wave between the Nonlocal and Local methods are illustrated in Fig. 13. There is a clear divide between amplitudes in the Indian Ocean and those in the western Pacific Ocean. This indicates disparity in the way the $\mathrm{M}_{2}$ tides are balanced between basins depending on the method. The Nonlocal method dissipates more in shallower depths (Fig. 11(c)), so it is perhaps unsurprising that the amplitudes will be smaller in the western Pacific basin which contains many shallow shelves and island chains. Moreover, the energy flux density $\boldsymbol{P}$ of the $\mathrm{M}_{2}$ tidal wave predominantly flows from the Indian Ocean into the western Pacific basin through the Indonesian Seas, and to a lesser extent through the Malacca Strait (Fig. 6). Due to the greater dissipation in shallow depths in the passages through the island chains and shallow seas, more energy remains on the Indian Ocean side instead of flowing into the western Pacific basin compared with the Local method. 


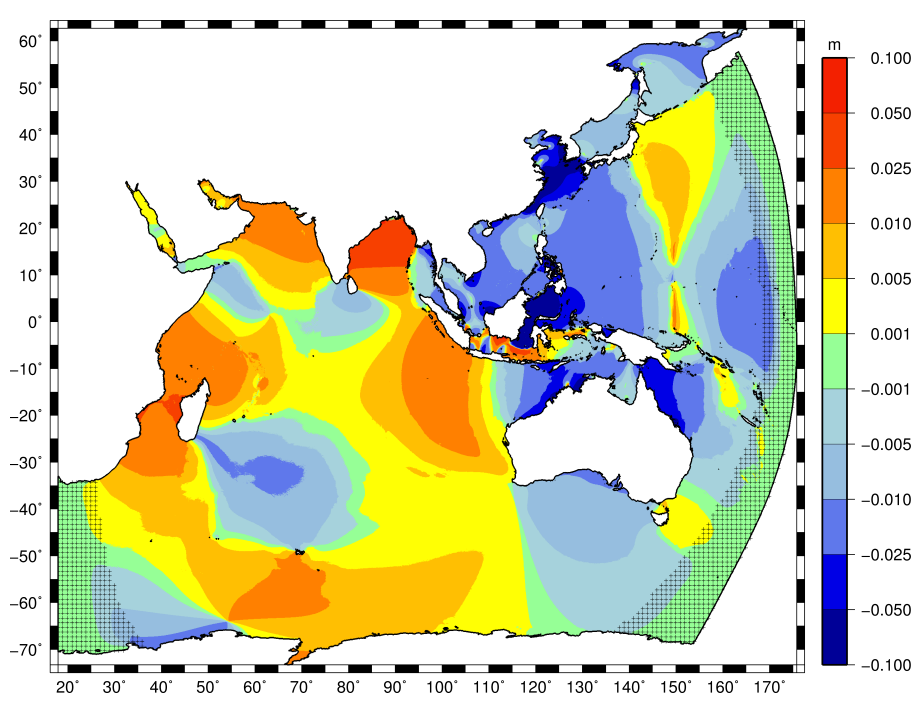

Figure 13: $\mathrm{M}_{2}$ amplitude differences between the two internal tide energy conversion methods; "Nonlocal method, $C_{N y c}=2.90$ with PD and $N_{\text {bavg }}$ corrections" minus "Local method, $C_{D i r}=0.22$ ". ' + ' hatched regions indicate absorption-generation sponge zone.

\subsubsection{Multiplier due to Semi-diurnal Resonance over the Luzon Strait}

A local improvement to internal tide energy conversion is applied over the Luzon Strait. The Luzon Strait controls the amount of energy into the South China Sea for both the $\mathrm{M}_{2}$ and $\mathrm{K}_{1}$ tidal waves (Fig. 6). Here, the amplitude of $\mathrm{K}_{1}$ is mostly larger than $\mathrm{M}_{2}$ (Fig. 2). Because the separation of the double-ridge topography in the strait is similar to the semi-diurnal internal tide wavelength, it has been shown that resonance dramatically increases the barotropic to baroclinic energy conversion (Buijsman et al., 2014). In comparison to the sum of the two ridges considered separately, the double-ridge produces up to as much as four times the energy conversion for the first-internal mode (Buijsman et al., 2014). Since our internal tide energy conversion parameterizations do not include such resonance behavior we deem it appropriate to apply a multiplier to the amplification coefficients in the region $19.5^{\circ}-21.5^{\circ} \mathrm{N}$ and $120^{\circ}-122.5^{\circ} \mathrm{E}$. The multiplier coefficients $C_{\text {Luzon }}$ are defined using a skewed Gaussian curve as a function of latitude $\phi$ to approximate the data points presented in Buijsman et al. (2014):

$$
C_{\text {Luzon }}=1+\frac{a_{L}}{2 \sigma_{L} \pi} \exp \left(\frac{-\xi_{L}^{2}}{2 \sigma_{L}^{2}}\right)\left[1+\operatorname{erf}\left(\frac{\alpha_{L} \xi_{L}}{\sqrt{2} \sigma_{L}}\right)\right]
$$

with $a_{L}=5.0, \sigma_{L}=0.3, \alpha_{L}=-1.0$, and $\xi_{L}=\phi-20.9^{\circ} \mathrm{N}$. $C_{\text {Luzon }}$ reaches a maximum of 4.24 at $20.75^{\circ} \mathrm{N}$ 
Fig. 14 shows the amplitude differences for the $\mathrm{M}_{2}$ and $\mathrm{K}_{1}$ tidal waves in the South China Sea and surroundings from the optimal Nonlocal method with and without the multiplier coefficients $C_{\text {Luzon. }}$. As expected, the increase to the internal tide coefficients reduces the amplitudes inside most of the South China Sea for both constituents. The decrease is on the order of $0.5-1 \mathrm{~cm}$ for $\mathrm{M}_{2}$ in most areas with a few pockets of $2.5-5 \mathrm{~cm}$ reductions. Additionally, the blockage increases amplitudes slightly to the east of the strait and in the Sulu Sea. The $K_{1}$ amplitude is decreased in the South China Sea by 1-2.5 cm almost uniformly. Furthermore, due to the blockage at the Luzon Strait, more of the energy flux is now diverted down into the Indonesian seas (Fig. 6) increasing amplitudes uniformly by $0.5-1 \mathrm{~cm}$.

$\mathrm{M}_{2}$ RMS discrepancies at coastal tide gauges are generally decreased about $1 \mathrm{~cm}$ within the South China Sea due to the $C_{\text {Luzon }}$ multiplier coefficients. The discrepancy is increased slightly in the Sulu Sea and near the Taiwan Strait. The changes in $\mathrm{K}_{1}$ discrepancies do not follow a clear pattern aside from the Gulf of Thailand and Celebes Sea regions (decrease and increase respectively). The RMS discrepancies against tide gauges and TPXO8 in the plotted region (Fig. 14) are summarized in Table 6. Overall, only small decreases in discrepancies are found when using the $C_{L u z o n}$ multiplier

Table 6: The mean RMS discrepancies (units: cm) versus coastal tide gauges $\bar{D}_{t g}$ and TPXO8 $\bar{D}_{t p x}$ (in all depths) of the $\mathrm{M}_{2}, \mathrm{~K}_{1}$, and the total free surface (up to all eight major constituents) within each of the regions plotted in Figs. 14 and 16. Standard deviations in parentheses. See Table 4 for model setup descriptions.

\begin{tabular}{|c|l|cccccc|}
\hline \multirow{2}{*}{ Region } & Model & $\bar{D}_{t g}^{\mathrm{M}_{2}}$ & $\bar{D}_{t g}^{\mathrm{K}_{1}}$ & $\bar{D}_{t g}^{\text {all }}$ & $\bar{D}_{t p x}^{\mathrm{M}_{2}}$ & $\bar{D}_{t p x}^{\mathrm{K}_{1}}$ & $\bar{D}_{t p x}^{\text {all }}$ \\
\hline \multirow{2}{*}{$\mathrm{SCS}$} & $C o m p+I T(L Z)+S V$ & $7.35(6.75)$ & $6.92(5.88)$ & $14.3(10.2)$ & $3.76(7.56)$ & $3.63(3.37)$ & $6.70(10.4)$ \\
& $C o m p+I T(N o L Z)+S V$ & $7.55(6.63)$ & $6.96(5.73)$ & $14.2(10.0)$ & $4.07(7.53)$ & $3.74(3.56)$ & $6.90(10.4)$ \\
\hline \multirow{2}{*}{$\mathrm{YS}$} & $C o m p+I T+S C$ & $17.2(17.7)$ & $3.74(3.74)$ & $20.8(20.3)$ & $8.58(16.9)$ & $1.70(9.53)$ & $10.3(18.4)$ \\
& $C o m p+I T+S V$ & $12.3(15.6)$ & $3.04(3.31)$ & $16.1(17.7)$ & $6.51(17.1)$ & $1.41(9.81)$ & $8.43(18.2)$ \\
\hline \multirow{2}{*}{$\mathrm{JS}$} & $C o m p+I T+S C$ & $10.5(9.50)$ & $5.98(5.41)$ & $16.5(11.6)$ & $6.02(7.11)$ & $5.47(7.08)$ & $10.6(7.39)$ \\
& $C o m p+I T+S V$ & $11.5(10.8)$ & $6.54(5.39)$ & $17.9(12.6)$ & $5.97(7.05)$ & $6.60(6.66)$ & $11.5(7.58)$ \\
\hline \multirow{2}{*}{$\mathrm{TAS}$} & $C o m p+I T+S C$ & $18.8(24.6)$ & $9.49(8.16)$ & $25.9(28.2)$ & $6.46(9.68)$ & $4.03(8.50)$ & $9.71(11.1)$ \\
& \multirow{2}{*}{$\mathrm{Comp}+I T+S V$} & $19.9(24.8)$ & $10.2(8.63)$ & $27.6(28.6)$ & $6.81(9.86)$ & $4.28(8.62)$ & $10.3(11.7)$ \\
\hline
\end{tabular}

*SCS: South China Sea region plotted in Fig. 14. LZ refers to the use of multiplier coefficients, $C_{\text {Luzon }}$ from (18), over the Luzon Strait. NoLZ is without applying $C_{\text {Luzon }}$

*YS: Yellow Sea and southern Japan region plotted in Fig. 16 (i)

*JS: Area between the Java Sea and South China Sea plotted in Fig. 16 (ii)

*TAS: Timor and Arafura Seas region plotted in Fig. 16 (iii) 


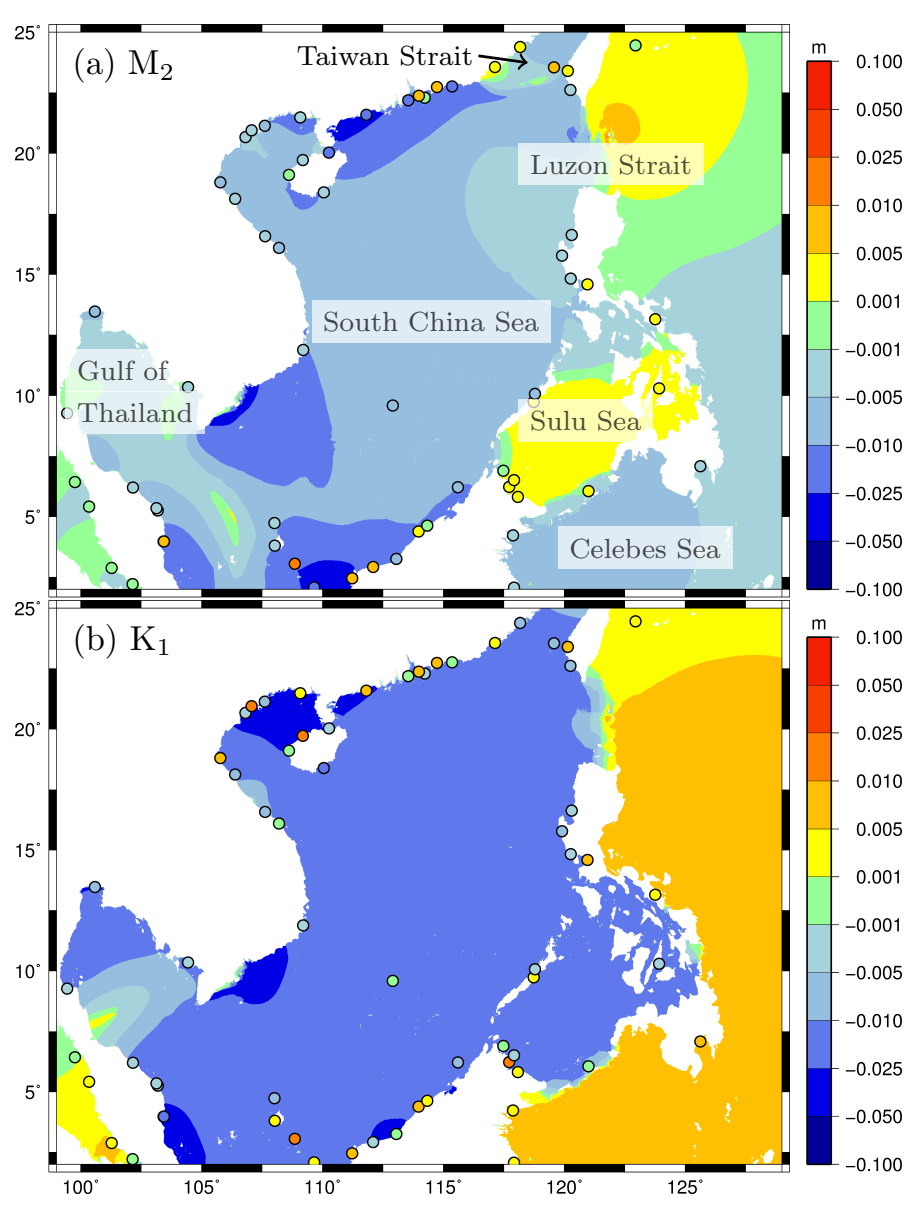

Figure 14: (a) $M_{2}$ and (b) $K_{1}$ amplitude differences in the South China Sea and surrounds when using the multiplier coefficients $C_{\text {Luzon }}$ over the Luzon Strait (case with $C_{\text {Luzon }}$ from (18) minus case without $C_{\text {Luzon }}$ applied). Circles indicate the change in RMS discrepancies at coastal tide gauges (negative indicates reduction in discrepancy when using $C_{\text {Luzon }}$ ).

coefficients. The magnitude of discrepancies are comparable to local hydrodynamic models for the South China Sea region (Green and David, 2013; Gao et al., 2015) (we obtain $8.5 \mathrm{~cm}$ and $5.0 \mathrm{~cm}$ RMSE for $\mathrm{M}_{2}$ and $\mathrm{K}_{1}$ versus TPXO8 respectively, Green and David (2013) quote $9 \mathrm{~cm}$ and $10 \mathrm{~cm}$ ). In Green and David (2013), $C_{f}$ had to be raised to an unphysical value of 0.01 to achieve optimal results for $\mathrm{M}_{2}$. It was speculated that this is because the internal tide energy conversion rates in, e.g. the Luzon Strait, are underestimated for $\mathrm{M}_{2}$. Perhaps the increased $C_{f}$ may have accounted for additional dissipation in the Luzon Strait that the $C_{\text {Luzon }}$ multiplier coefficients applied here are trying to achieve, although it is shown here that the effects of applying $C_{\text {Luzon }}$ are somewhat small. 
Furthermore, Green and David (2013) use a different method to cap dissipation at supercritical slopes (in which this is the case in parts of the Luzon Strait) that may not be appropriate locally. Bathymetric differences and the higher grid resolution in IndWPac also likely play a role in helping to obtain relatively accurate tidal elevations in the IndWPac model. In addition, by including wind and baroclinic forcing Cai et al. (2006) were able to obtain smaller RMSE values compared to a barotropic model without atmospheric forcing in the South China Sea, thus our model may further improve if these forcings are included.

\subsubsection{Discussion}

As a result of the dissipation dynamics we find that the Local method gives better results in the western Indian Ocean, but elsewhere the Nonlocal method is generally preferable. It is worth noting that the $\mathrm{M}_{2}$ amplitude differences (Fig. 13) in the Indian Ocean between the two methods is in the range 0.5-2.5 cm, and greater in the Bay of Bengal. This is a rather large amplitude difference in the deep ocean since $\bar{D}_{t p x}=2.9 \mathrm{~cm}$, indicating that there is some scope to improve deep-water solutions further through better parameterization of internal tide energy conversion. Perhaps some of the remaining issues for the Nonlocal method can be explained by the fact that bathymetry is still rather uncertain and coarse in much of the deep ocean (most of the Indian Ocean is deep with very narrow shelves, and internal tide energy conversion is an important dissipation mechanism). Furthermore, internal tide energy conversion in shallow regions is less reliable because of larger tidal velocities and uncertainties, and there is a greater chance of the flow being supercritical (Melet et al., 2013). In fact, one of the main effects of the $N_{b a v}$ modification to the Nonlocal method is to move some dissipation away from shallow regions into deeper regions (Fig. 11(c)). Additional investigation into the parameterization of internal tide energy conversion in shallow regions is warranted especially because the shallow areas of the Indonesian seas provide a critical connection between the basins, a region that has created issues previously (Melet et al., 2013).

Finally, it is worth highlighting that the internal tide energy conversion matrices used here have been derived based on the $\mathrm{M}_{2}$ tidal wave. That is, $\omega=2 \pi / 12.42 \mathrm{rad} / \mathrm{hr}$ are used in (4) and (5), and the optimal amplification factors are determined from results for $\mathrm{M}_{2}$. However, theoretically diurnal internal tides become trapped in latitudes higher than $\sim 30^{\circ}$ as $f>\omega$, and no barotropic to baroclinic energy conversion due to freely propagating internal waves results. Because we apply the dissipation matrix for $\mathrm{M}_{2}$, some energy conversion of diurnal tides does occur at these higher latitudes in our model. However, without separating the modes and taking into account the influences from the other constituents similar to methods for bottom friction (e.g. Le Provost and Lyard, 1997), it is 
unclear how selective dissipation for each mode is possible using this type of parameterization in a forward model. Instead, Jayne and St. Laurent (2001) decided to ignore the relationship between $\omega$ and $f$. Here, our assumption for internal tide energy conversion is that the $\mathrm{M}_{2}$ tidal wave dominates the signal. Nevertheless, smaller amplification factors are optimal for the $\mathrm{K}_{1}$ tidal wave (Fig. 11(b)) than those for $\mathrm{M}_{2}$ (Fig. 11(a)), although using the internal tide energy conversion parameterization does improve the $\mathrm{K}_{1}$ tides versus not including it. Furthermore, in the Luzon Strait only resonance of the semi-diurnal internal tides occurs, so theoretically the multiplier coefficients $C_{L u z o n}$ should not be applied to the diurnal tides. Perhaps, including information from measurements and operational baroclinic 3D models, e.g. HYCOM (Chassignet et al., 2007), may provide us with an opportunity to locally improve dissipation matrices for depth-integrated barotropic models, although we are still somewhat limited by the assumptions of the underlying parameterization.

\subsection{Bottom Friction Dissipation}

This section summarizes the effect of implementing the spatially varying $C_{f}$ map (Fig. 15(a)) based on sediment types and tidal current speeds (Fig. 6) into the IndWPac model. Firstly, it is useful to highlight regions where we expect bottom friction to have a large effect. Zaron (2017) recently introduced a bottom friction number, $Z_{f}$ for the $\mathrm{k}^{\text {th }}$ constituent to quantitatively illustrate this:

$$
\left(Z_{f}^{k}\right)^{2}=\frac{\left(C_{f} u_{f}\left|\boldsymbol{U}^{k}\right| / h\right)^{2}}{\left(\omega^{k}\left|\boldsymbol{U}^{k}\right|\right)^{2}+\left(C_{f} u_{f}\left|\boldsymbol{U}^{k}\right| / h\right)^{2}}
$$

where $\omega^{k}$ is the tidal frequency of the $\mathrm{k}^{t h}$ constituent. The term $\omega^{k}$ corresponds to local acceleration. Since depth and velocities are highly correlated (velocity and $C_{f}$ are to some extent also correlated but much less so) it is clear from (19) that the effect of $C_{f}$ is in fact secondary to the effects of $h$. Thus, a global map of $Z_{f}$ based on the spatially constant $C_{f}=2.5 \times 10^{-3}$ simulation ought to suffice for visualization purposes (Fig. 15(b)).

$Z_{f}$ shows a similar pattern for the $\mathrm{K}_{1}$ tidal wave (not shown) as the plotted $\mathrm{M}_{2}$ tidal wave. On the continental shelves at depths $\sim 100 \mathrm{~m}, Z_{f}$ is generally in the 0.1-0.5 range, and only becomes larger than 0.5 close to the coast in depths much less than $50 \mathrm{~m}$ (see also Zaron, 2017). Regions where $Z_{f}$ is large correlate to areas where the tidal solutions will be most impacted by any variability in $C_{f}$. When implementing the spatially varying $C_{f}$ map (Fig. 15(a)), specific areas with relatively large $Z_{f}$ that are noticeably different to $C_{f}=2.5 \times 10^{-3}$ include: the Yellow Sea and southern Japan (small $C_{f}$ in the Yellow Sea, large $C_{f}$ just south of the Yellow Sea and in the Seto Inland Sea); the 


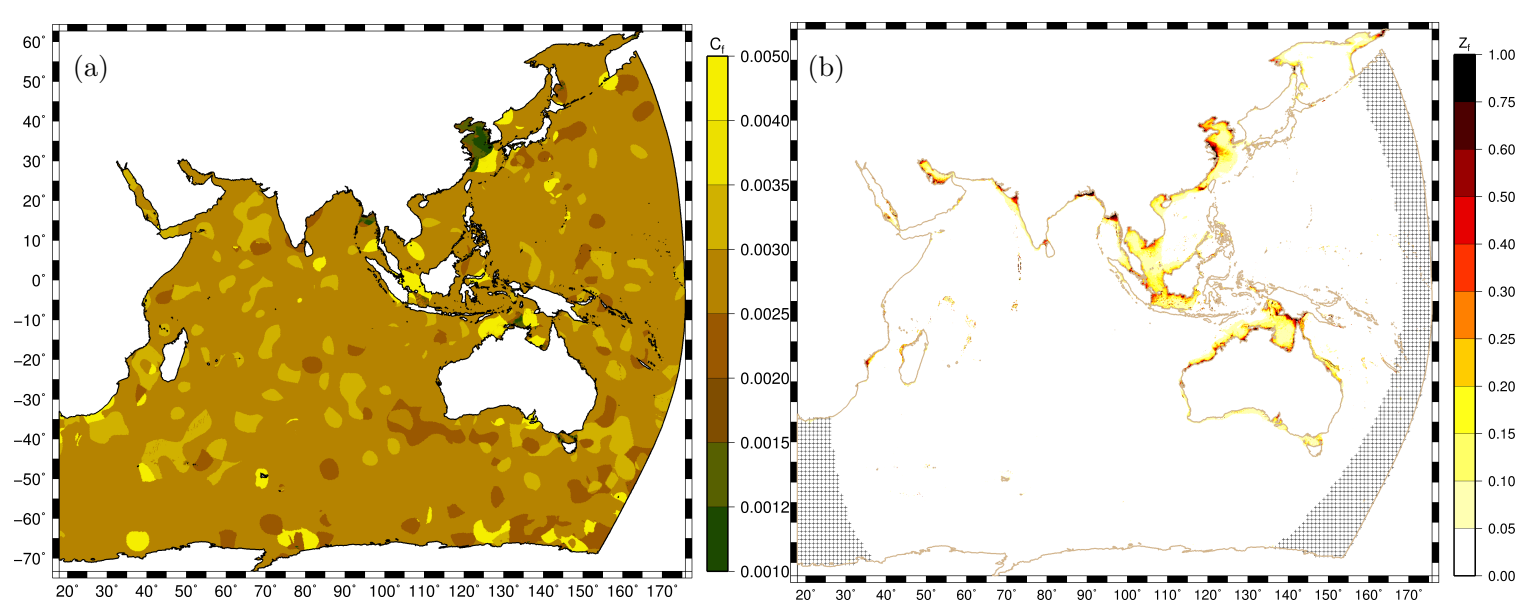

Figure 15: (a) Map of bottom friction coefficients $C_{f}$ based on sediment types (Dutkiewicz et al., 2015) with assumed grain size and sediment density (Table 2); the empirical equations (van Rijn, 2007) also take into account depth and tidal velocities. (b) $\mathrm{M}_{2}$ bottom friction number $Z_{f}$ based on the Comp $+I T+S C$ model setup; '+' hatched regions indicate absorption-generation sponge zone.

area between the Java Sea and South China Sea near Singapore (mostly large $C_{f}$ with pockets of small $C_{f}$ ); and Timor and Arafura Seas (both large and small $C_{f}$ ). The change in amplitudes for the $\mathrm{M}_{2}$ and $\mathrm{K}_{1}$ tidal waves in these three regions when using the spatially varying $C_{f}$ map over the spatially constant $C_{f}=2.5 \times 10^{-3}$ are illustrated in Fig. 16. Changes in the RMS discrepancy at the coastal tide gauges are also plotted. The mean discrepancies at the coastal tide gauges within the boxed regions are summarized in Table 6 . The following sections detail the findings at each region individually, followed by a discussion of the results.

\subsubsection{Yellow Sea and southern Japan}

In the census sediment database, the Yellow Sea is designated as a mud sediment type (we also modified the database to ensure that Bohai Sea and Hangzhou Bay are designated as mud sediment types) and the tidal currents are very large over the shallow basin. This leads to small values of $C_{f}$ between $7.5 \times 10^{-4}$ and $2.0 \times 10^{-3}$, except close to the coastline where $C_{f}$ becomes large due to small depths in (6). A patch of sand just south of the Yellow Sea causes $C_{f}$ to exceed $4.0 \times 10^{-3}$ here. Additionally, a sand zone throughout most of the Seto Inland Sea induces a large $C_{f}\left(>4.0 \times 10^{-3}\right)$.

The tidal amplitudes increase due to the spatially varying $C_{f}$ in most of the Yellow Sea, and decrease just south of the Yellow Sea due to the mud and sand zones respectively for both constituents. 


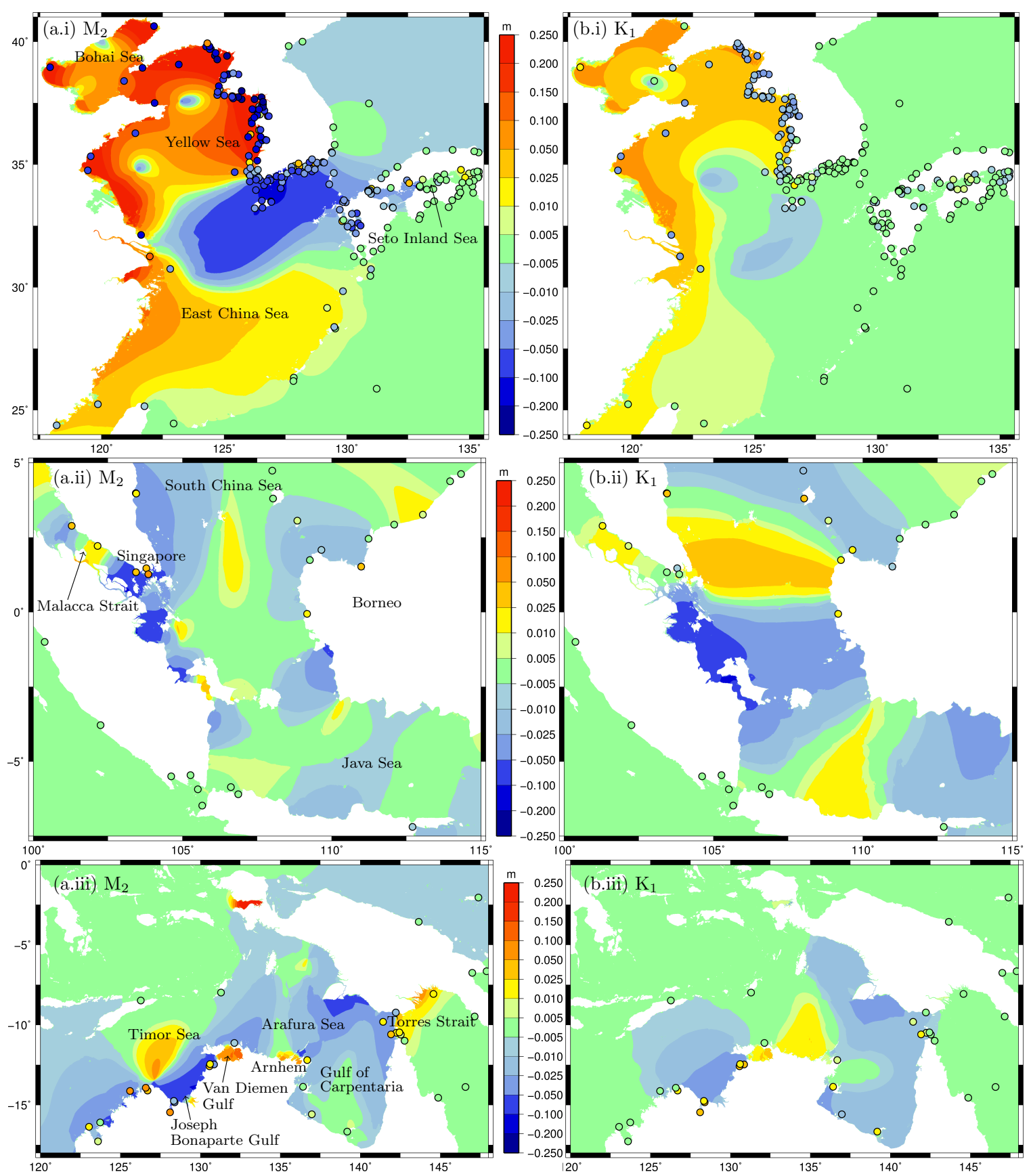

Figure 16: (a) $\mathrm{M}_{2}$ and (b) $\mathrm{K}_{1}$ amplitude differences due to changes in bottom friction coefficients $C_{f}$ (case with spatially varying $C_{f}$ map minus case with spatially constant $C_{f}=2.5 \times 10^{-3}$ ). Circles indicate the change in RMS discrepancies at coastal tide gauges (negative indicates reduction in discrepancy for spatially varying $C_{f}$ model setup); (i) Yellow Sea and southern Japan, (ii) area between the Java Sea and South China Sea, (iii) Timor and Arafura Seas. 
The $\mathrm{M}_{2}$ amplitude is also decreased in the western Seto Inland Sea but there is no noticeable change for $\mathrm{K}_{1}$. Impressively, the RMS discrepancy is decreased almost everywhere for both constituents aside from a couple of outliers in the Yellow Sea and for a group of stations in the eastern Seto Inland Sea for $\mathrm{M}_{2}$. For example, the discrepancy is decreased by up to $25 \mathrm{~cm}$ and $5 \mathrm{~cm}$ for $\mathrm{M}_{2}$ and $K_{1}$ respectively at many Yellow Sea locations. It appears that the combination of the small friction in the Yellow and Bohai Seas and the large friction just south of the Yellow Sea and in the Korea-Japan strait results in systematic positive changes to the solution. Overall, the mean RMS discrepancies versus coastal tide gauges decrease by $4.9 \mathrm{~cm} \mathrm{(28 \% )} \mathrm{for} \mathrm{M}_{2}$ and $0.71 \mathrm{~cm}(19 \%)$ for $\mathrm{K}_{1}$ due to the spatially varying $C_{f}$ here.

\subsubsection{Area between the Java Sea and South China Sea}

The region in between the Java Sea and South China Sea is predominantly designated as a sand zone $\left(C_{f}>4.0 \times 10^{-3}\right)$ with pockets of fine-grain calcareous sediment $\left(C_{f} \approx 2.0 \times 10^{-3}\right)$ and volcanic ash $\left(C_{f} \approx 3.0 \times 10^{-3}\right)$ in the census sediment database. There is only a small number of data points in the census to back up these sediment types.

The $\mathrm{M}_{2}$ amplitudes decrease most significantly in the region close to Singapore due to the higher values of $C_{f}$ and $Z_{f}$ here. In response to this decrease in amplitude, the $\mathrm{M}_{2}$ RMS discrepancies in this region increase by approximately $5 \mathrm{~cm}$. A large-scale decrease in $\mathrm{K}_{1}$ amplitudes occurs southeast of Singapore but there are no coastal tide gauges there to measure the effect on the discrepancy. A band of increased $K_{1}$ amplitude in between Singapore and Borneo which increases the RMS discrepancies at the tide gauges is also present. The mean total free surface RMS discrepancies are increased versus tide gauges by $1.4 \mathrm{~cm}(8.5 \%)$ overall (Table 6). Thus, increasing $C_{f}$ from the base value of 0.025 to the sediment/current informed estimate clearly degrades the accuracy in both the semi-diurnal and diurnal constituents suggesting that either the census sediment database is not correct or that the high current speeds in the Malacca Strait artificially increase the friction coefficient for the sand sediment type. We believe that the comprehensive bathymetry in this heavily trafficked region is reliable in that it matches navigation charts well.

\subsubsection{Timor and Arafura Seas}

The Timor Sea is designated as a sand sediment type in the census sediment database while the Arafura Sea is designated as mainly fine-grained calcareous sediment with a couple of pockets of sand types. As a result, in most of the Timor Sea $C_{f}>4.0 \times 10^{-3}$ except for nearshore in the Joseph Bonaparte Gulf where the tidal velocities are very large causing $C_{f}$ to decrease as the fine- 
grained sediment bedforms are washed out. Tidal current speeds are fairly small in the Gulf of Carpentaria (Fig. 6) so even though some of sediment is fine-grained, $C_{f}$ is similar to the standard value $\left(2.5 \times 10^{-3}\right)$. North of Arnhem the sediment is fine-grained and the tidal current speeds are fairly large (Fig. 6), hence $C_{f}$ becomes smaller than the standard value.

Because most of the region has larger values of $C_{f}$ than the standard value, tidal amplitudes tend to decrease for both constituents on the whole (Fig. 16 (iii)). Exceptions are the Van Diemen Gulf (small $C_{f}$ ), north of Arnhem (small $C_{f}$ nearshore with high $C_{f}$ just offshore), and east of the Torres Strait, but only for $\mathrm{M}_{2}$. The mechanism for the latter is mainly through dampening of the energy fluxes traveling east towards the Torres Strait as they encounter the sand zones in the Timor and Arafura Seas. This results in less resistance to the westward directed energy fluxes into the Torres Strait (see Fig. 6), increasing amplitudes to the east of the strait. In general, using the spatially varying $C_{f}$ leads to poorer results for both constituents. Only deep in the Joseph Bonaparte Gulf and at a couple of stations near the Van Diemen Gulf with smaller $C_{f}$ values does the $\mathrm{M}_{2} \mathrm{RMS}$ discrepancy decrease. Mean total free surface RMS discrepancies at tide gauges increase by $1.7 \mathrm{~cm}$ $(6.6 \%)$ due to the spatially varying $C_{f}$. Again, this could be related to the sediment information derived from the census sediment data or from the friction coefficient estimation. In addition, the degree of uncertainty of the bathymetry is high as explored in $\S 5.2$, which will substantially influence the dissipation and the energy fluxes.

\subsubsection{Discussion}

Results summarized in the above sections highlight one region (the Yellow Sea and southern Japan) that experienced wholesale decreases in the discrepancies at tidal stations by significant magnitudes, and two regions with small increases in discrepancies, when using the spatially varying $C_{f}$ map over the standard $C_{f}=2.5 \times 10^{-3}$. The Yellow Sea region represents a flagship result of the possibilities of using a data-informed approach to estimating bottom friction coefficients over using a standard value. Furthermore, the distribution of $C_{f}$ used in the region is in close agreement to previous studies. For example, Lefevre et al. (2000) found a small value of $C_{f}\left(1.5 \times 10^{-3}\right)$ to be optimal throughout the East China Sea/Yellow Sea region. More interestingly the distribution of $C_{f}$ closely resembles the optimal one determined through the adjoint method (Lu and Zhang, 2006). This may appear to indicate that the adjoint method can estimate $C_{f}$ values that correspond to physical characteristics of the seabed such as the muddy nature throughout most of the Yellow Sea. However, it is not clear whether the sand zone south of the Yellow Sea creating an increase in $C_{f}$ similar to the optimal distribution of $C_{f}$ in Lu and Zhang (2006) is simply a coincidence or not due 
to the sparseness of data points in the census here and the tendency of sand zones in the other two regions to in fact increase discrepancies.

The Arafura Sea in the census is mainly fine-grained calcareous but there are two pockets of sand zones. However, according to the grain size map presented in Porter-Smith et al. (2004), we expect the Arafura Sea and Gulf of Carpentaria to be fairly muddy with small grain sizes. In the Timor Sea the census contains many data points that are used to determine that the sediment is sandy here. This may be the case, but our definition of the sediment grain size of sand does not seem to match Porter-Smith et al. (2004), who indicate fairly small grain sizes for the region. The rest of the Australian shelf has fairly large grain sizes (Porter-Smith et al., 2004), but they are mainly designated as ooze types in the census. It can be assumed that there are similar issues with sediment types and the correlation of these to physical sediment characteristics in the area between the Java Sea and South China Sea. This indicates that the census is generally insufficient for our purpose due to the relative sparseness of the data, particularly of terrestrial type sediments, and because it requires us to estimate the grain size and density from the sediment types. The physical characteristic of sand, for example, can vary considerably.

We have experimented with changing some of the sediment type definitions of the census. For example, the sandy sediment definition in the area between Java Sea and South China Sea is changed to fine-grained calcareous sediment which decreases the discrepancies around Singapore for $\mathrm{M}_{2}$. Similarly, all of the Arafura Sea is changed to a muddy sediment type and Timor Sea to finegrained calcareous sediment (based on the grain size figure in Porter-Smith et al. (2004)). This leads to generally improved results. In future studies if actual physical sediment characteristics from databases (e.g. Porter-Smith et al., 2004; Buczkowski et al., 2006) could be adopted, with a focus on regions where $Z_{f}$ exceeds $0.4-0.5$, there are indications that non-trivial improvements to tidal solutions can be achieved (e.g. Yellow Sea, Bohai Sea, and Seto Inland Sea).

\section{Conclusions}

This study has presented a finite-element barotropic model of the Indian and western Pacific Oceans with elemental resolution ranging from as small as $100 \mathrm{~m}$ (in Hong Kong) up to $25 \mathrm{~km}$ in less barotropically interesting areas of the deep ocean. Most of the resolution at the coast is 1 $\mathrm{km}$. Bathymetry has been sourced predominantly from the global SRTM bathymetric database in addition to local high-resolution datasets and hand-edits. At first, comparisons of the IndWPac model results with both the data-assimilated TPXO 8 atlas and tidal constituents at tide gauges in 
deep, continental shelf and slope waters, and at the coast have been shown. This has been followed by a presentation of the sensitivities to lateral boundary conditions, bathymetry, internal tide energy conversion, and bottom friction dissipation. Within each of these sections a discussion of the findings and implications with regards to the sensitivity for that component has been presented. The key results (e.g. RMS discrepancies for the Comp $+I T+S V$ model setup) and conclusions for each region (deep, shelf, and coastal) follows.

Deep water $\mathrm{M}_{2}$ mean RMS discrepancies against TPXO8 are $2.9 \mathrm{~cm}(\mathrm{RMSE}=3.6 \mathrm{~cm})$, which is marginally better than reported for other forward hydrodynamic models. However, the total free surface RMS discrepancies at deep water tide gauges are 2.3 times those of the TPXO8 atlas. Poorly placed elevation specified lateral boundaries lead to global resonant amplifications of the lunar semidiurnal modes. An absorption-generation sponge zone suppresses the resonant amplifications but it relies on data-assimilated model fluxes (e.g. TPXO8 and similar models), which may not be as reliable as the elevations from these models. A comprehensive global forward model may have advantages in eliminating the uncertainties from the boundary conditions. Strictly bathymetric effects are not of great importance to the deep water solution, however internal tide energy conversion (that relies on topographic features and slopes for parameterization) is shown to be the key control in deep water. The Nonlocal method for internal tide energy conversion is shown to obtain marginally superior results to the Local method, but the latter is more dissipative in the Indian Ocean and hence results in smaller $\mathrm{M}_{2}$ amplitudes there (which match TPXO8 slightly better). There is evidence that there is scope to further improve the deep water solution through internal tide energy conversion but it is probably not possible using the same paradigm (strict reliance on the Nonlocal equation and calibration of a global amplification factor) as presented here. Significant local modifications based on 3D baroclinic models and measurements, including improvements to internal tide energy conversion in shallower waters are likely required.

Continental shelf and slope water $\mathrm{M}_{2}$ mean RMS discrepancies against TPXO8 are $6.5 \mathrm{~cm}$ (RMSE $=10.1 \mathrm{~cm})$. This is shown to be significantly superior to those reported for other forward hydrodynamic models (RMSE $=19-28 \mathrm{~cm}$ (Stammer et al., 2014), albeit these are global errors, the total energy density is at least as large in the IndWPac domain compared to the rest of the world's ocean). One of the most important factors for improvement is shown to be the inclusion of local high-resolution bathymetry. Notable changes in the $\mathrm{M}_{2}$ amplitude and a corresponding reduction in the RMS discrepancies against TPXO8 and at tide gauges are evident in the greater Yellow Sea region due to changes in bottom friction coefficients based on combinations of muddy and sandy 
sediment types. However, the regions around the Java and South China Seas, and Timor and Arafura Seas do not generate significant nor positive changes to the discrepancy. If more complete databases of physical characteristics of sediment are made available, combined with accurate local bathymetric data it may be possible to improve solutions elsewhere, particularly in resonant basins (e.g. Gulfs of Khambhat and Kutch on the west coast of India; King Sound, Joseph Bonaparte Gulf and Van Diemen Gulf in northern Australia, among others) due to spatially varying bottom friction coefficients. Nevertheless, we are still limited by residual discrepancies from deeper waters and the uncertainties of internal tide energy conversion in shallower waters.

The discrepancies at the coast for the IndWPac model are not significantly different from those obtained further offshore on the shelf. Furthermore, the mean total free surface RMS discrepancies at coastal tide gauges $\left(\bar{D}_{t g}=14 \mathrm{~cm}\right)$ are $2.6 \mathrm{~cm}$ smaller than those of the TPOX8 atlas. However, the discrepancies at the majority of locations are smaller for the TPXO8 atlas due to data assimilation offshore and at selected tide gauges. The large mean RMS discrepancy for the TPXO8 atlas is likely related to TPXO8's coarser resolution not resolving certain nearshore features and harbor complexes in detail and therefore not correctly propagating the tides into them. For example, bathymetric and bottom friction controls are both found to play a very important role nearshore, and in some cases dominate the reasons for discrepancy due to resonance in a basin or inadequate connectivity into a bay. In contrast, the IndWPac model does not have such a large number or magnitude of outlier locations. These results are an indication that the model adequately captures a large amount of the nearshore physics throughout the domain. Thus, the model is potentially suitable to simulate a great range of shallow water physics within the region, specifically into detailed harbor complexes and other nearshore features where the tide gauges are located.

If we are solely interested in tidal elevations, then the simple answer is to use data assimilation within the IndWPac model to achieve highly accurate solutions, from the deep ocean all the way to the well-resolved coastal regions. However, in many other applications, such as the forecasting and analysis of coupled surge, tide and wave processes, capturing the large-scale responses to meteorology, and modeling the shallow water physics including the nonlinear interactions of the processes becomes vital. In order to accomplish this, correctly specifying high-resolution bathymetry and topography becomes a controlling factor. Furthermore, physics based improvements to more accurately quantify dissipation within forward barotropic models are possible offshore, through coupling to coarser 3D baroclinic numerical models, and nearshore, through bottom bedform and sediment roughness data. 


\section{Acknowledgements}

We are indebted to Professor Seungwon Suh from Kunsan National University for providing the computational grid and bathymetric data for the South Korean peninsula. We also thank Dr. Shintaro Bunya from Mitsubishi Research Institute, for providing the computational grid and bathymetric data for Tokyo Bay, and Dr. Patrick Timko from Bangor University for providing the SRTM30_PLUS bathymetry with synthetic abyssal hill roughness. This model development work was supported by the Office of Naval Research under grant N00014-15-1-2623 and Factory Mutual Insurance Company (FM Global), Norwood, MA. The development of the absorption-generation sponge layer was supported by the National Science Foundation under grant ACI-1339738.

\section{References}

Apecechea, M.I., Verlaan, M., Zijl, F., Le Coz, C., Kernkamp, H., 2017. Effects of self-attraction and loading at a regional scale: a test case for the Northwest European Shelf. Ocean Dynamics 67, 729-749. doi:10.1007/s10236-017-1053-4.

Arbic, B.K., Richman, J.G., Shriver, J.F., Timko, P.G., Metzger, E.J., Wallcraft, A.J., 2012. Global modeling of internal tides within an eddying ocean general circulation model. Oceanography 25, 20-29. doi:10.5670/oceanog.2012.38.

Arbic, B.K., Wallcraft, A.J., Metzger, E.J., 2010. Concurrent simulation of the eddying general circulation and tides in a global ocean model. Ocean Modelling 32, 175-187. doi:10.1016/j . ocemod.2010.01.007.

Beaman, R.J., 2010. Project 3DGBR: A high-resolution depth model for the Great Barrier Reef and Coral Sea. Technical Report June. Marine and Tropical Sciences Research Facility (MTSRF). Cairns. Australia. URL: http://www .deepreef .org/bathymetry/65-3dgbr-bathy .html.

Beaman, R.J., O’Brien, P.E., 2011. Kerguelen Plateau Bathymetric Grid, November 2010. Technical Report November. Geoscience Australia. Canberra, Australia. URL: https://www.deepreef . org/bathymetry/98-kergdem-bathy.html.

Becker, J.J., Sandwell, D.T., Smith, W.H.F., Braud, J., Binder, B., Depner, J., Fabre, D., Factor, J., Ingalls, S., Kim, S.H., Ladner, R., Marks, K., Nelson, S., Pharaoh, A., Trimmer, R., Von Rosenberg, J., Wallace, G., Weatherall, P., 2009. Global Bathymetry and El- 
evation Data at 30 Arc Seconds Resolution: SRTM30_PLUS. Marine Geodesy 32, 355-371. doi:10.1080/01490410903297766.

Bell, T.H., 1975. Topographically generated internal waves in the open ocean. Journal of Geophysical Research 80, 320-327. doi:10.1029/JC080i003p00320.

Bilskie, M.V., Hagen, S.C., 2013. Topographic accuracy assessment of bare earth lidar-derived unstructured meshes. Advances in Water Resources 52, 165-177. doi:10.1016/j.advwatres. 2012.09 .003$.

Buczkowski, B.J., Reid, J.A., Jenkins, C.J., Reid, J.M., Williams, S.J., Flocks, J.G., 2006. usSEABED: Gulf of Mexico and Caribbean offshore surficial-sediment data release. Technical Report. URL: http://pubs.usgs.gov/ds/2006/146/.

Buijsman, M., Arbic, B., Green, J., Helber, R., Richman, J., Shriver, J., Timko, P., Wallcraft, A., 2015. Optimizing internal wave drag in a forward barotropic model with semidiurnal tides. Ocean Modelling 85,42-55. doi:10.1016/j.ocemod.2014.11.003.

Buijsman, M.C., Klymak, J.M., Legg, S., Alford, M.H., Farmer, D., MacKinnon, J.A., Nash, J.D., Park, J.H., Pickering, A., Simmons, H., 2014. Three-Dimensional Double-Ridge Internal Tide Resonance in Luzon Strait. Journal of Physical Oceanography 44, 850-869. doi:10.1175/ JPO-D-13-024.1.

Bunya, S., Dietrich, J.C., Westerink, J.J., Ebersole, B.A., Smith, J.M., Atkinson, J.H., Jensen, R., Resio, D.T., Luettich, R.A., Dawson, C., Cardone, V.J., Cox, A.T., Powell, M.D., Westerink, H.J., Roberts, H.J., 2010. A High-Resolution Coupled Riverine Flow, Tide, Wind, Wind Wave, and Storm Surge Model for Southern Louisiana and Mississippi. Part I: Model Development and Validation. Monthly Weather Review 138, 345-377. doi:10.1175/2009MWR2906.1.

Cai, S., Long, X., Liu, H., Wang, S., 2006. Tide model evaluation under different conditions. Continental Shelf Research 26,104-112. doi:10.1016/j.csr.2005.09.004.

Caldwell, P.C., Merrifield, M.A., Thompson, P.R., 2015. Sea level measured by tide gauges from global oceans as part of the Joint Archive for Sea Level (JASL) from 1846-01-01 to 2015-07-31. National Oceanographic Data Center, NOAA. doi:10.7289/V5V40S7W.

Charnock, H., 1959. Tidal Friction from Currents near the Seabed. Geophysical Journal International 2, 215-221. doi:10.1111/j.1365-246X.1959.tb05794.x. 
Chassignet, E.P., Hurlburt, H.E., Smedstad, O.M., Halliwell, G.R., Hogan, P.J., Wallcraft, A.J., Baraille, R., Bleck, R., 2007. The HYCOM (HYbrid Coordinate Ocean Model) data assimilative system. Journal of Marine Systems 65, 60-83. doi:10.1016/j.jmarsys.2005.09.016.

Choi, B., Kim, K., Eum, H., 2002. Digital Bathymetric and Topographic Data for Neighboring Seas of Korea. Korean Society of Coastal and Ocean Engineers 14, 41-50 (in Korean with English abstract).

Codiga, D.L., 2011. Unified Tidal Analysis and Prediction Using the UTide Matlab Functions. Technical Report 01. Graduate School of Oceanography, University of Rhode Island. Narragansett, RI. doi:10.13140/RG.2.1.3761.2008.

Cummins, P.F., Thupaki, P., 2018. A note on evaluating model tidal currents against observations. Continental Shelf Research 152, 35-37. doi:10.1016/j.csr.2017.10.007.

Dresback, K.M., Kolar, R.L., Luettich, Jr., R.A., 2005. On the Form of the Momentum Equation and Lateral Stress Closure Law in Shallow Water Modeling, in: Estuarine and Coastal Modeling, American Society of Civil Engineers, Reston, VA. pp. 399-418. doi:10.1061/40876(209) 23.

Dutkiewicz, A., Müller, R.D., O'Callaghan, S., Jónasson, H., 2015. Census of seafloor sediments in the world's ocean. Geology 43, 795-798. doi:10.1130/G36883.1.

Egbert, G.D., Erofeeva, S.Y., 2002. Efficient Inverse Modeling of Barotropic Ocean Tides. Journal of Atmospheric and Oceanic Technology 19, 183-204. doi:10.1175/1520-0426(2002)019<0183: EIMOBO $>2.0 . \mathrm{CO} ; 2$.

Egbert, G.D., Ray, R.D., 2000. Significant dissipation of tidal energy in the deep ocean inferred from satellite altimeter data. Nature 405, 775-778. doi:10.1038/35015531.

Egbert, G.D., Ray, R.D., 2001. Estimates of M2 tidal energy dissipation from TOPEX/Poseidon altimeter data. Journal of Geophysical Research: Oceans 106, 22475-22502. doi:10.1029/ $2000 J C 000699$.

Egbert, G.D., Ray, R.D., Bills, B.G., 2004. Numerical modeling of the global semidiurnal tide in the present day and in the last glacial maximum. Journal of Geophysical Research: Oceans 109. doi:10.1029/2003JC001973. 
Fang, G., Kwok, Y.K., Yu, K., Zhu, Y., 1999. Numerical simulation of principal tidal constituents in the South China Sea, Gulf of Tonkin and Gulf of Thailand. Continental Shelf Research 19, 845-869. doi:10.1016/S0278-4343(99)00002-3.

Fang, G., Wang, Y., Wei, Z., Choi, B.H., Wang, X., Wang, J., 2004. Empirical cotidal charts of the Bohai, Yellow, and East China Seas from 10 years of TOPEX/Poseidon altimetry. Journal of Geophysical Research: Oceans 109, 1-13. doi:10.1029/2004JC002484.

Gao, X., Wei, Z., Lv, X., Wang, Y., Fang, G., 2015. Numerical study of tidal dynamics in the South China Sea with adjoint method. Ocean Modelling 92, 101-114. doi:10.1016/j.ocemod.2015.05. 010.

Garrett, C., Kunze, E., 2007. Internal Tide Generation in the Deep Ocean. Annual Review of Fluid Mechanics 39, 57-87. doi:10.1146/annurev.fluid.39.050905.110227.

Goff, J.A., Arbic, B.K., 2010. Global prediction of abyssal hill roughness statistics for use in ocean models from digital maps of paleo-spreading rate, paleo-ridge orientation, and sediment thickness. Ocean Modelling 32, 36-43. doi:10.1016/j.ocemod.2009.10.001.

Green, J.A., Huber, M., Waltham, D., Buzan, J., Wells, M., 2017. Explicitly modelled deep-time tidal dissipation and its implication for Lunar history. Earth and Planetary Science Letters 461, 46-53. doi:10.1016/j.epsl.2016.12.038.

Green, J.A.M., 2010. Ocean tides and resonance. Ocean Dynamics 60, 1243-1253. doi:10.1007/ s10236-010-0331-1.

Green, J.A.M., Nycander, J., 2013. A Comparison of Tidal Conversion Parameterizations for Tidal Models. Journal of Physical Oceanography 43, 104-119. doi:10.1175/JPO-D-12-023.1.

Green, J.M., David, T.W., 2013. Non-assimilated tidal modeling of the South China Sea. Deep Sea Research Part I: Oceanographic Research Papers 78, 42-48. doi:10.1016/j.dsr.2013.04.006.

Heathershaw, A., Simpson, J., 1978. The sampling variability of the Reynolds stress and its relation to boundary shear stress and drag coefficient measurements. Estuarine and Coastal Marine Science 6, 263-274. doi:10.1016/0302-3524(78)90015-4.

Heathershaw, A.D., 1979. The turbulent structure of the bottom boundary layer in a tidal current. Geophysical Journal International 58, 395-430. doi:10.1111/j.1365-246x.1979.tb01032.x. 
Hendershott, M.C., 1972. The Effects of Solid Earth Deformation on Global Ocean Tides. Geophysical Journal International 29, 389-402. doi:10.1111/j.1365-246X.1972.tb06167.x.

Hope, M.E., Westerink, J.J., Kennedy, A.B., Kerr, P.C., Dietrich, J.C., Dawson, C., Bender, C.J., Smith, J.M., Jensen, R.E., Zijlema, M., Holthuijsen, L.H., Luettich, R.A., Powell, M.D., Cardone, V.J., Cox, A.T., Pourtaheri, H., Roberts, H.J., Atkinson, J.H., Tanaka, S., Westerink, H.J., Westerink, L.G., 2013. Hindcast and validation of Hurricane Ike (2008) waves, forerunner, and storm surge. Journal of Geophysical Research: Oceans 118, 4424-4460. doi:10.1002/jgrc. 20314.

Jayne, S.R., St. Laurent, L.C., 2001. Parameterizing tidal dissipation over rough topography. Geophysical Research Letters 28, 811-814. doi:10.1029/2000GL012044.

Kerr, P.C., Martyr, R.C., Donahue, A.S., Hope, M.E., Westerink, J.J., Luettich, R.A., Kennedy, A.B., Dietrich, J.C., Dawson, C., Westerink, H.J., 2013. U.S. IOOS coastal and ocean modeling testbed: Evaluation of tide, wave, and hurricane surge response sensitivities to mesh resolution and friction in the Gulf of Mexico. Journal of Geophysical Research: Oceans 118, 4633-4661. doi:10.1002/jgrc. 20305.

Krien, Y., Mayet, C., Testut, L., Durand, F., Tazkia, A.R., Islam, A.K.M.S., Gopalakrishna, V.V., Becker, M., Calmant, S., Shum, C.K., Khan, Z.H., Papa, F., Ballu, V., 2016. Improved Bathymetric Dataset and Tidal Model for the Northern Bay of Bengal. Marine Geodesy 39, 422-438. doi:10.1080/01490419.2016.1227405.

Lavelle, J.W., Thacker, W.C., 2008. A pretty good sponge: Dealing with open boundaries in limitedarea ocean models. Ocean Modelling 20, 270-292. doi:10.1016/j. ocemod.2007.10.002.

Le Provost, C., Lyard, F., 1997. Energetics of the M2 barotropic ocean tides: an estimate of bottom friction dissipation from a hydrodynamic model. Progress in Oceanography 40, 37-52. doi:10.1016/S0079-6611(97)00022-0.

Lefevre, F., Provost, C.L., Lyard, F.H., 2000. How can we improve a global ocean tide model at a region scale? A test on the Yellow Sea and the East China Sea. Journal of Geophysical Research: Oceans 105, 8707-8725. doi:10.1029/1999JC900281.

Locarnini, R.A., Mishonov, A.V., Antonov, J.I., Boyer, T.P., Garcia, H.E., Baranova, O.K., Zweng, M.M., Paver, C.R., Reagan, J.R., Johnson, D.R., Hamilton, M., Seidov, D., 2013. World Ocean 
Atlas 2013. Vol. 1: Temperature. Technical Report. URL: https://data.nodc.noaa.gov/woa/ WOA13/DOC/woa13_vol1.pdf.

Lu, X., Zhang, J., 2006. Numerical study on spatially varying bottom friction coefficient of a 2D tidal model with adjoint method. Continental Shelf Research 26, 1905-1923. doi:10.1016/j.csr . 2006.06 .007$.

Lyard, F., Lefevre, F., Letellier, T., Francis, O., 2006. Modelling the global ocean tides: modern insights from FES2004. Ocean Dynamics 56, 394-415. doi:10.1007/s10236-006-0086-x.

Matsumoto, K., Takanezawa, T., Ooe, M., 2000. Ocean Tide Models Developed by Assimilating TOPEX/POSEIDON Altimeter Data into Hydrodynamical Model: A Global Model and a Regional Model around Japan. Journal of Oceanography 56, 567-581. doi:10.1023/A: 1011157212596

Melet, A., Nikurashin, M., Muller, C., Falahat, S., Nycander, J., Timko, P.G., Arbic, B.K., Goff, J.A., 2013. Internal tide generation by abyssal hills using analytical theory. Journal of Geophysical Research: Oceans 118, 6303-6318. doi:10.1002/2013JC009212.

Ngodock, H.E., Souopgui, I., Wallcraft, A.J., Richman, J.G., Shriver, J.F., Arbic, B.K., 2016. On improving the accuracy of the M2 barotropic tides embedded in a high-resolution global ocean circulation model. Ocean Modelling 97, 16-26. doi:10.1016/j.ocemod.2015.10.011.

Nycander, J., 2005. Generation of internal waves in the deep ocean by tides. Journal of Geophysical Research 110, C10028. doi:10.1029/2004JC002487.

Padman, L., Fricker, H.A., Coleman, R., Howard, S., Erofeeva, L., 2002. A new tide model for the Antarctic ice shelves and seas. Annals of Glaciology 34, 247-254. doi:10.3189/ 172756402781817752 .

Persson, P.o., Strang, G., 2004. A Simple Mesh Generator in MATLAB. SIAM Rev. 46. doi:10. $1137 / \mathrm{S} 0036144503429121$.

Platzman, G.W., 1975. Normal Modes of the Atlantic and Indian Oceans. Journal of Physical Oceanography 5, 201-221. doi:10 .1175/1520-0485(1975) 005<0201 : NMOTAA>2 . 0 . CO; 2.

Porter-Smith, R., Harris, P., Andersen, O.B., Coleman, R., Greenslade, D., Jenkins, C.J., 2004. Classification of the Australian continental shelf based on predicted sediment threshold exceedance 
from tidal currents and swell waves. Marine Geology 211, 1-20. doi:10.1016/J . MARGE0.2004. 05.031.

Pringle, W.J., 2017. Major tidal constituents for the Indian Ocean and Western Pacific Basin. Mendeley Data. doi:10.17632/tjyjn56jbf.1.

Pringle, W.J., Wirasaet, D., Westerink, J.J., . Modifications to Internal Tide Conversion Parameterizations and Implementation into Barotropic Ocean Models. MethodsX , submitted.

Ray, R.D., 1998. Ocean self-attraction and loading in numerical tidal models. Marine Geodesy 21, 181-192. doi:10.1080/01490419809388134.

van Rijn, L.C., 2007. Unified View of Sediment Transport by Currents and Waves. I: Initiation of Motion, Bed Roughness, and Bed-Load Transport. Journal of Hydraulic Engineering 133, 649-667. doi:10.1061/(ASCE) 0733-9429(2007) 133:6(649).

Robertson, R., Ffield, A., 2008. Baroclinic tides in the Indonesian seas: Tidal fields and comparisons to observations. Journal of Geophysical Research: Oceans 113, 1-22. doi:10.1029/2007 JC004677.

Sandwell, D.T., Becker, J.J., Olson, C., Jackson, A., 2014. SRTM15_PLUS: Data Fusion of SRTM Land Topography with Measured and Estimated Seafloor topography. URL: ftp://topex.ucsd. edu/pub/srtm15_plus/.

Schlichting, H., 1979. Boundary layer theory. seventh ed., McGraw-Hill.

Shum, C.K., Woodworth, P.L., Andersen, B., Egbert, G.D., Francis, O., King, C., Klosko, S.M., Le Provost, C., Li, X., Molines, J.m., Parke, M.E., Ray, R.D., Schlax, M.G., Tiemey, C.C., Vincent, P., Wunsch, C.I., 1997. Accuracy assessment of recent ocean tide models. Journal of Geophysical Research: Oceans 102, 173-194. doi:10.1029/97JC00445.

Smagorinsky, J., 1963. General Circulation Experiments with the Primitive Equations. I. The Basic Experiment. Monthly Weather Review 91, 99-164. doi:10.1175/1520-0493(1963) 091<0099: GCEWTP>2.3. CO; 2 .

Snyder, R.L., Sidjabat, M., Filloux, J.H., 1979. A Study of Tides, Setup and Bottom Friction in a Shallow Semi-Enclosed Basin. Part II: Tidal Model and Comparison with Data. Journal of Physical Oceanography 9, 170-188. doi:10.1175/1520-0485(1979) 009<0170:ASOTSA>2 . 0 . C0; 2. 
Stammer, D., Ray, R.D., Andersen, O.B., Arbic, B.K., Bosch, W., Carrère, L., Cheng, Y., Chinn, D.S., Dushaw, B.D., Egbert, G.D., Erofeeva, S.Y., Fok, H.S., Green, J.A.M., Griffiths, S., King, M.A., Lapin, V., Lemoine, F.G., Luthcke, S.B., Lyard, F., Morison, J., Müller, M., Padman, L., Richman, J.G., Shriver, J.F., Shum, C.K., Taguchi, E., Yi, Y., 2014. Accuracy assessment of global barotropic ocean tide models. Reviews of Geophysics 52, 243-282. doi:10.1002/2014RG000450.

Suh, S.W., Lee, H.Y., Kim, H.J., 2014. Spatio-temporal variability of tidal asymmetry due to multiple coastal constructions along the west coast of Korea. Estuarine, Coastal and Shelf Science 151, 336-346. doi:10.1016/j.ecss.2014.09.007.

TCarta Marine, 2012. Marine Global Bathymetric Model for (DBM) East Asia.

Technology Riverside Inc., AECOM, 2015. Mesh Development, Tidal Validation, and Hindcast Skill Asessment of an ADCIRC Model for the Hurricane Storm Surge Operational Forecast System on the US Gulf-Atlantic Coast. Technical Report. National Oceanic and Atmospheric Administration/Nation Ocean Service, Coast Survey Development Laboratory, Office of Coast Survey. doi:10.7921/G0MC8X6V.

Timko, P.G., Arbic, B.K., Goff, J.A., Ansong, J.K., Smith, W.H., Melet, A., Wallcraft, A.J., 2017. Impact of synthetic abyssal hill roughness on resolved motions in numerical global ocean tide models. Ocean Modelling 112,1-16. doi:10.1016/j.ocemod.2017.02.005.

Wang, X., Chao, Y., Shum, C.K., Yi, Y., Fok, H.S., 2012. Comparison of two methods to assess ocean tide models. Journal of Atmospheric and Oceanic Technology 29, 1159-1167. doi:10.1175/ JTECH-D-11-00166.1.

Weatherall, P., Marks, K.M., Jakobsson, M., Schmitt, T., Tani, S., Arndt, J.E., Rovere, M., Chayes, D., Ferrini, V., Wigley, R., 2015. A new digital bathymetric model of the world's oceans. Earth and Space Science 2, 331-345. doi:10.1002/2015EA000107.

Wei, Z., Fang, G., Susanto, R.D., Adi, T.R., Fan, B., Setiawan, A., Li, S., Wang, Y., Gao, X., 2016. Tidal elevation, current, and energy flux in the area between the South China Sea and Java Sea. Ocean Science 12, 517-531. doi:10.5194/os-12-517-2016.

Westerink, J.J., Luettich, R.A., Baptists, A.M., Scheffner, N.W., Farrar, P., 1992. Tide and Storm Surge Predictions Using Finite Element Model. Journal of Hydraulic Engineering 118, 1373-1390. doi:10.1061/(ASCE) 0733-9429(1992)118:10(1373). 
Westerink, J.J., Luettich, R.A., Feyen, J.C., Atkinson, J.H., Dawson, C., Roberts, H.J., Powell, M.D., Dunion, J.P., Kubatko, E.J., Pourtaheri, H., 2008. A Basin- to Channel-Scale Unstructured Grid Hurricane Storm Surge Model Applied to Southern Louisiana. Monthly Weather Review 136, 833-864. doi:10.1175/2007MWR1946.1.

Whiteway, T., 2009. Australian Bathymetry and Topography Grid, June 2009. doi:10.4225/25/ 53D99B6581B9A.

Wilmes, S.B., Green, J.A., 2014. The evolution of tides and tidal dissipation over the past 21,000 years. Journal of Geophysical Research: Oceans 119, 4083-4100. doi:10.1002/2013JC009605.

Wilmes, S.B., Green, J.A., Gomez, N., Rippeth, T.P., Lau, H., 2017. Global Tidal Impacts of LargeScale Ice Sheet Collapses. Journal of Geophysical Research: Oceans 122, 8354-8370. doi:10.1002/ 2017 JC013109.

Woodworth, P.L., Hunter, J.R., Marcos, M., Caldwell, P., Menéndez, M., Haigh, I., 2017. Towards a global higher-frequency sea level dataset. Geoscience Data Journal 3, 50-59. doi:10.1002/gdj3. 42.

You, Z.J., 2005. Estimation of bed roughness from mean velocities measured at two levels near the seabed. Continental Shelf Research 25, 1043-1051. doi:10.1016/j.csr.2005.01.001.

Zahel, W., Müller, M., 2005. The computation of the free barotropic oscillations of a global ocean model including friction and loading effects. Ocean Dynamics 55, 137-161. doi:10.1007/ s10236-005-0029-y.

Zaron, E.D., 2017. Topographic and frictional controls on tides in the Sea of Okhotsk. Ocean Modelling 117, 1-11. doi:10.1016/j.ocemod.2017.06.011.

Zaron, E.D., Egbert, G.D., 2006. Estimating Open-Ocean Barotropic Tidal Dissipation: The Hawaiian Ridge. Journal of Physical Oceanography 36, 1019-1035. doi:10.1175/JP02878.1.

Zhang, Y., Kennedy, A.B., Panda, N., Dawson, C., Westerink, J.J., 2014. Generatingabsorbing sponge layers for phase-resolving wave models. Coastal Engineering 84, 1-9. doi:10.1016/j . coastaleng.2013.10.019.

Zu, T., Gan, J., Erofeeva, S.Y., 2008. Numerical study of the tide and tidal dynamics in the South China Sea. Deep Sea Research Part I: Oceanographic Research Papers 55, 137-154. doi:10.1016/ j.dsr.2007.10.007. 

tions for each rely on the current mobility parameter $\psi$ :

$$
\psi=\frac{u_{f}^{2}}{(s-1) g d_{50}}
$$

where $u_{f}$ is the effective mean current speed $(7), s=\rho_{s} / \rho_{0}$ is the relative sediment density $\left(\rho_{s}\right.$ is the sediment density), $g$ is the acceleration due to gravity, and $d_{50}$ is the median sediment grain diameter. The equations for each individual roughness type are then:

$$
\begin{aligned}
k_{s, r} & =f_{s c} d_{50}(85-65 \tanh [0.015(\psi-150)]) \\
k_{s, m} & =\max \left(\min \left(0.02,200 d_{50}\right), 2 e^{-5} f_{f s} h[1-\exp (-0.05 \psi)](550-\psi)\right) \\
k_{s, d} & =\max \left(0,8 e^{-5} f_{f_{s}} h[1-\exp (-0.02 \psi)](600-\psi)\right)
\end{aligned}
$$

where $h$ is the still water depth, $f_{s c}$ is the "factor which expresses the effect of a gradually decreasing ripple roughness for very coarse sediment beds", and $f_{f s}$ is the "factor which expresses the effect of a gradually decreasing mega-ripple roughness for very fine sediment beds" (van Rijn, 2007):

$$
\begin{aligned}
& f_{c s}=\min \left[1,\left(\frac{0.25 d_{\text {grav }}}{d_{50}}\right)^{1.5}\right] \\
& f_{f s}=\min \left[1, \frac{d_{50}}{1.5 d_{\text {sand }}}\right]
\end{aligned}
$$

where $d_{\text {grav }}=2 \times 10^{-3} \mathrm{~m}$, and $d_{\text {sand }}=6.2 \times 10^{-5} \mathrm{~m}$. Here, all sediments are assumed to have $d_{50}>d_{\text {silt }}=3.2 \times 10^{-5} \mathrm{~m}$, in which otherwise a lower limit of $k_{s}=20 d_{\text {silt }}$ is applied. 